\title{
6G Enabled Smart Infrastructure for Sustainable Society: Opportunities, Challenges, and Research Roadmap
}

\author{
Agbotiname Lucky Imoize ${ }^{1,2, *(\mathbb{D})}$, Oluwadara Adedeji ${ }^{3}\left(\mathbb{D}\right.$, Nistha Tandiya $^{4}$ and Sachin Shetty ${ }^{5}$ \\ 1 Department of Electrical Engineering and Information Technology, Institute of Digital Communication, \\ Ruhr University, 44801 Bochum, Germany \\ 2 Department of Electrical and Electronics Engineering, Faculty of Engineering, University of Lagos, \\ Akoka, Lagos 100213, Nigeria \\ 3 Department of Electrical and Electronic Engineering, Faculty of Technology, University of Ibadan, \\ Ibadan 200284, Nigeria; padedeji314@stu.ui.edu.ng \\ 4 Bradley Department of Electrical and Computer Engineering, Virginia Polytechnic Institute and State \\ University, Blacksburg, VA 24061, USA; nistha@vt.edu \\ 5 Virginia Modelling Analysis and Simulation Center, Department of Computational Modelling and Simulation \\ Engineering, Old Dominion University, Norfolk, VA 23529, USA; sshetty@odu.edu \\ * Correspondence: aimoize@unilag.edu.ng or agbotiname.imoize@rub.de
}

check for

updates

Citation: Imoize, A.L.; Adedeji, O.; Tandiya, N.; Shetty, S. 6G Enabled Smart Infrastructure for Sustainable Society: Opportunities, Challenges, and Research Roadmap. Sensors 2021, 21, 1709. https://doi.org/10.3390/ s21051709

Academic Editors: Waqas Khalid, Heejung Yu, Rehmat Ullah and Rashid Ali

Received: 27 January 2021

Accepted: 20 February 2021

Published: 2 March 2021

Publisher's Note: MDPI stays neutral with regard to jurisdictional claims in published maps and institutional affiliations.

Copyright: (c) 2021 by the authors. Licensee MDPI, Basel, Switzerland. This article is an open access article distributed under the terms and conditions of the Creative Commons Attribution (CC BY) license (https:// creativecommons.org/licenses/by/ $4.0 /)$.

\begin{abstract}
The 5G wireless communication network is currently faced with the challenge of limited data speed exacerbated by the proliferation of billions of data-intensive applications. To address this problem, researchers are developing cutting-edge technologies for the envisioned 6G wireless communication standards to satisfy the escalating wireless services demands. Though some of the candidate technologies in the 5G standards will apply to 6G wireless networks, key disruptive technologies that will guarantee the desired quality of physical experience to achieve ubiquitous wireless connectivity are expected in 6G. This article first provides a foundational background on the evolution of different wireless communication standards to have a proper insight into the vision and requirements of $6 \mathrm{G}$. Second, we provide a panoramic view of the enabling technologies proposed to facilitate $6 \mathrm{G}$ and introduce emerging $6 \mathrm{G}$ applications such as multi-sensory-extended reality, digital replica, and more. Next, the technology-driven challenges, social, psychological, health and commercialization issues posed to actualizing 6G, and the probable solutions to tackle these challenges are discussed extensively. Additionally, we present new use cases of the 6G technology in agriculture, education, media and entertainment, logistics and transportation, and tourism. Furthermore, we discuss the multi-faceted communication capabilities of $6 \mathrm{G}$ that will contribute significantly to global sustainability and how 6G will bring about a dramatic change in the business arena. Finally, we highlight the research trends, open research issues, and key take-away lessons for future research exploration in $6 \mathrm{G}$ wireless communication.
\end{abstract}

Keywords: 6G wireless communication; 6G vision; 6G requirements; $6 \mathrm{G}$ enabling technologies; 6G challenges; 6G applications; $6 \mathrm{G}$ use cases; $6 \mathrm{G}$ infrastructure; $6 \mathrm{G}$ sustainability; $6 \mathrm{G}$ business model

\section{Introduction}

The commercialization of 5G commenced in 2019, and further adoption is expected in 2021 and beyond. There have been tangential research interest on future 6G wireless networks [1]. The COVID-19 pandemic forced more businesses online, birthing a "New Normal" with a borderless workplace. Ericsson has forecasted that there will be faster commercialization of $5 \mathrm{G}$ as more people embrace this shift to a borderless workplace. The resulting surge in Internet usage beams light on the need for better connectivity to meet the growing demand for more stringent network requirements. This is required to facilitate emerging technologies such as extended reality [2], haptics [3], connected autonomous systems [4], telemedicine, Industrial Internet of Things (IIoT) [5], which are sensitive to 
latency and require ultra-fast data speed. For example, ultra-low latency and ultra-fast data speed reduce the collision rates and improve the safety of the autonomous vehicle. These applications are necessary to facilitate autonomous and smart life, multisensory virtual experience, intelligent cities, smart agriculture, and more. Unfortunately, the promising 5G networks cannot meet these growing demands [6,7]. Thus, there is an imperative need for the development of 6G communication networks. 6G wireless networks are also proposed to ameliorate social needs, thereby facilitating the actualization of the Sustainable Development Goals (SDGs) [8]. The proposed network requirements of 6G can be summarized as (1) Ultra-fast data rates as high as 1Tbps (2) Ultra-low latency of less than 1ms (3) Increased mobility and coverage (4) Flexible, and efficient connection of trillion level objects [9] (5) Peak spectral efficiency of $60 \mathrm{~b} / \mathrm{s} / \mathrm{Hz}$ (6) Very high system reliability (7) Improved network security.

6G is expected to have data-rates in the order of terabits per second and a latency of less than $1 \mathrm{~ms}$. It is expected to drive the Internet of Everything, with $10^{7}$ connections per $\mathrm{km}^{2}$ [10]. To achieve this, $6 \mathrm{G}$ will leverage on subterahertz and Terahertz spectrum ( $300 \mathrm{GHz}$ to $10 \mathrm{THz})[11,12]$, which provides a higher frequency spectrum as against the millimeter wave spectrum (30-300 GHz) adopted in 5G [13]. Exploring a higher frequency spectrum is necessary because the sub- $6 \mathrm{GHz}$ range is already crowded. Apart from giving room for more spectrum, the Terahertz spectrum gives rise to higher data rates desirable in 6G networks. However, transmitting at a higher frequency spectrum is prone to high path loss, making the distance for transmission limited. This and other challenges with $\mathrm{THz}$ transmissions, such as hardware constraints, are treated in this paper. Additionally, Optical wireless technologies [14] such as Visible Light Communication (VLC) [15] and Free Space Optical communication [16] are discussed extensively.

Additionally, technologies such as Reconfigurable Intelligent Surfaces (RIS) [17-19], cell-free massive MIMO [20], Artificial Intelligence (AI), which are expected to drive the actualization of 6G, are broached. We consider RIS, which will be deployed on doors, windows of buildings to reflect received signal without interference. Furthermore, we explore why the RIS technology is a preferable candidate to the existing relays. The massive MIMO technology is introduced in 5G with a more dense network of access points (APs) [21]. This is further developed in 6G to include a network with no cells (cell-free) [22]. The benefits are tremendous as it improves spectral efficiency in communication networks. However, there are challenges with obtaining channel information and concerns about health risks associated with such a dense network of APs. There is limited literature to address these concerns; thus, the need for this review. We also believe Pervasive AI is critical in actualizing 6G. Artificial Neural Networks [23,24], Deep Neural Networks [25] have been proposed to enable intelligent networks.

Despite the auspicious view of this technology, challenges with complex data and more have been highlighted. These challenges have been delineated in this article. Other enabling technologies such as Quantum Communication [26], Ambient Backscatter Communication Systems (ABCS) [27], Blockchain [28], UAVs [29], and more have also been proposed and treated extensively in this paper. Future generation networks are desired to have high speed and low latency and secured communication. Quantum communication has been proposed to enable security and facilitate faster processing power for future wireless networks [30]. However, there are doubts if research in quantum communication will be ripe enough to facilitate the $6 \mathrm{G}$ communication systems [31]. However, this technology will see more light in the beyond 6G, towards the 7G era. Blockchain is another technology proposed to facilitate security, and we have examined this with the hope that it would provide the desired privacy and integrity in future wireless networks. Blockchain technology has been introduced in 5G [32], and further research on the challenges treated in Section 5 of this paper would facilitate the security of future wireless networks.

Energy efficiency is another interesting topic for future wireless networks. It is desirable to have hardware that is compatible with the energy requirements of 6G. Ambient Backscatter Communication Systems (ABCS), an Energy Harvesting (EH) technique, is 
proposed to enable wireless charging. This gives room for longer battery life, which has been proposed as a requirement for future wireless networks [33]. With the ABCS, devices have an alternative source of power from wireless communication. This is consequently extending the battery life of devices. Simultaneous Wireless and Information Power Transfer (SWIPT) [34], if enabled by 6G, will resolve energy requirements issues at the mobile unit [35]. We believe this will enable haptics [36], the Internet of Bio-Nano Things, and other applications with very restrictive energy requirements.

Seamless and fast ubiquitous communication is also desirable in 6G. UAVs and CubeSats, which form the Internet of Space things [37], will facilitate this. We have considered the benefits of CubeSats compared to the conventional satellites, for example, their low cost is desirable [38]. Challenges with UAVs such as network handover management and how advanced technologies such as AI interface can solve these challenges are treated in detail in this paper.

This paper provides researchers with a guide to what $6 \mathrm{G}$ will be. It proposes a panoramic vision of $6 \mathrm{G}$, the enabling technologies, and the associated challenges. This makes the paper to be robust, compensating for the individual lapses in the existing literature. Additionally, we provide an extensive analysis of the social, psychological, health, and commercialization challenges associated with 6G, which are missing in earlier reports to the authors' best knowledge. The article also introduces new use cases of 6G in education, media and entertainment, tourism and transport, and logistics, which have not been given adequate treatment in the existing literature. Finally, we discuss the multi-faceted communication capabilities of $6 \mathrm{G}$ that will contribute immensely to global sustainability. We discussed how 6G would bring about drastic changes in the business domain to orchestrate economic stability.

Figure 1 presents the layout of the paper. In summary, the key discussions in the paper are as follows:

1. The vision of $6 \mathrm{G}$ wireless networks, considering the essential requirements and comparing them with the existing generations of wireless communication networks.

2. A comprehensive review of the $6 \mathrm{G}$ enabling technologies such as Pervasive AI, Reconfigurable Intelligent Surfaces, Ambient Backscatter Communication, and more.

3. The technical challenges associated with the enabling technologies and the nontechnical challenges such as social, psychological, commercialization, and health concerns towards the actualization of $6 \mathrm{G}$ wireless communication.

4. New applications and use cases in agriculture, education, media and entertainment, tourism, transport, and logistics to be enabled by 6G.

5. Harnessing the potentials of $6 \mathrm{G}$ to meet the UN sustainability goals and business model tailored towards attaining global economic stability.

6. The recent trends and future research directions for $6 \mathrm{G}$ wireless communication. We identified some open research issues and summarized the proposed research focus.

7. Finally, the lessons learned from the survey are delineated, and the conclusion to the paper is presented.

The rest of this paper is organized as follows: Section 2 presents the related works of literature. Section 3 presents the evolution of wireless networks, from $1 \mathrm{G}$ to $6 \mathrm{G}$. The technologies facilitating each generation are introduced, and a comparative analysis of 5G, beyond $5 \mathrm{G}(\mathrm{B} 5 \mathrm{G})$ and $6 \mathrm{G}$, is presented. The proposed $6 \mathrm{G}$ vision is delineated in Section 4. The paper goes further to treat the $6 \mathrm{G}$ enabling technologies and the associated challenges in Section 5. Applications of 6G such as Holographic communication, Multisensory (XR), Tactile Internet, and more are presented in Section 6. New 6G use cases in agriculture, education, media and entertainment, logistics and transportation, and tourism are introduced in Section Section 7. In addition to the challenges of the enabling technologies, this paper further delineates the challenges associated with commercialization, social, health, and psychological issues in Section Section 8. 6G sustainability and business model is presented in Section 9. Future research areas and trends are broached, and the lessons learned are summarized in Section 10. Finally, the conclusion to the paper is given in Section 11. 


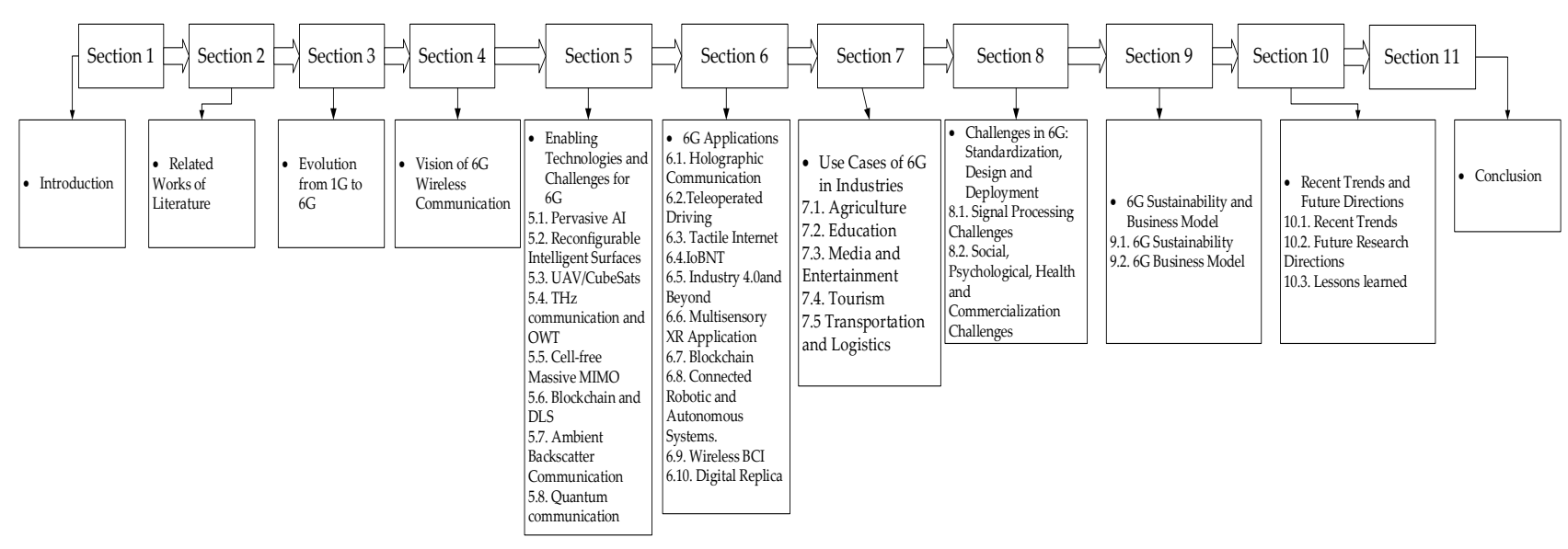

Figure 1. This is a figure showing the layout of the paper.

\section{Related Works and Contributions}

There are a few related works of literature that proposed the vision, requirements, enabling technologies, and design of 6G wireless networks [33,39-42]. In particular, David et al. [33] opined that $6 \mathrm{G}$ would enable wireless charging and high data rates. The authors also identified the need for socio-ethics in the 6G design. Nayak and Patgiri [39] proposed 6G to change the perceptual experience in lifestyle, business, and society. The study also presents some technology-driven challenges in 6G wireless networks and the probable solutions. In [40], the authors examined critical features such as security, secrecy, and privacy to make 6G truly human-centric. Tariq et al. [41] present an extension to the existing vision of $5 \mathrm{G}$ and show speculatively how the $5 \mathrm{G}$ vision and technologies can be enhanced to drive the anticipated 6G. Yang et al. [42] proposed integrating machine learning and big data to facilitate intelligent transmission. The application of Big data and AI has also been considered in the scholarly works of literature $[24,43,44]$. Other enabling technologies such as Intelligent Reflecting Surfaces [17], Blockchain [28], Terahertz communication [11], and more, proposed for 6G communication, have also been surveyed. The vision and requirements proposed by different researchers are discussed extensively in Section 4 of this paper. Additionally, the future projections of wireless communication presented in existing reports are highlighted.

This paper extensively considers existing research, clearly outlining the enabling technologies and the associated challenges, applications, and new applications such as the IoBNT and Digital Replica, which are not given adequate treatment in many related papers. Use cases in agriculture, education, media and entertainment, and more are discussed extensively. Apart from the technical challenges associated with the enabling technologies, this paper examines the social, psychological, and health concerns that could pose a challenge to $6 \mathrm{G}$ adoption. This paper also explores the recent research breakthroughs in $5 \mathrm{G}$ and the limitations of $5 \mathrm{G}$, which make $6 \mathrm{G}$ a highly prospective candidate. A comparative review of some of the proposed enabling technologies, open research issues and lessons learned, and proposed future research directions are also discussed extensively.

In summary, Table 1 examines the limitations of some of the existing surveys and our contributions in this paper to fill the knowledge gap. We hope this paper gives the reader a panoramic view of what $6 \mathrm{G}$ will be, clearly outlining the possible challenges associated with the 6G-enabling technologies, applications, use cases, and more. Finally, this paper provides a future outlook of what needs to be done to facilitate this desirable generation of wireless communication towards achieving the United Nations Sustainable Development Goals. 
Table 1. Limitations of some related surveys and our contributions.

\begin{tabular}{l} 
Ref. Focus and Coverage \\
\hline \\
Considers the vision, applications, \\
[45] research activities, challenges, and
\end{tabular}
potential solutions.

Limitations

- Applications were limited to five.

- Challenges with each enabling technology were omitted.

\section{This Paper's Contributions}

- More applications such as teleoperated driving, IoBNT, Digital replica, and more are treated in this paper.

- Provides a holistic review of the challenges of each technology.

- Additionally, it analyses enabling technologies not treated, such as RIS, CubeSats, ABCS, and more.

- Examines the most recent research trends and highlights future directions and lessons learned.
Vision and potential techniques. The study presents some

[9] technology-driven challenges such as power supply, security, hardware design, and probable solutions.
- The space-air-ground integrated network was proposed, but the supporting technologies of $\mathrm{UAV} / \mathrm{CubeSats}$ were not explained.

- Applications not clearly outlined.
- An extensive analysis of UAV/Cubesats and how these will facilitate $6 \mathrm{G}$ requirements are presented.

6G applications are clearly outlined, and a comparative analysis of why the existing $5 \mathrm{G}$ is limited is shown.

- Enabling technologies such as Cell-Free massive MIMO, ABCS, quantum communication not presented in the paper were delineated in this paper.
[33] The authors examine the vision, requirements, and Services.
- The enabling technologies are not outlined.

- Future research directions not presented.
- Vision, Requirements, Applications, and Enabling Technologies are discussed robustly.

- Open Research Issues and Future Research Directions outlined.
This work presents an extension to the existing vision of $5 \mathrm{G}$ and shows

[41] speculatively how the $5 G$ vision and technologies can be enhanced to drive the anticipated $6 \mathrm{G}$.
- Although use cases were discussed, the driving applications were omitted. Open Research Issues and Future Research Directions not clearly outlined.
- Driving trends and applications extensively discussed. Challenge with each enabling technology clearly outlined.

- Open Research Issues and Future Research Directions are clearly outlined.
$6 \mathrm{G}$ vision, key features, potential applications, enabling technologies. Emphasizes critical features such as

[40] security, secrecy, and privacy to make framework, key technologies, and challenges are outlined to support the $6 \mathrm{G}$ vision.
- Challenges with enabling technologies are not clearly outlined.

- Applications such as IoBNT, digital replica not considered.
- Enabling Technologies such as Blockchain, ABCS discussed.

- Challenges with enabling technologies are clearly outlined.

- Applications such as IoBNT, digital replica, and wireless BCI are discussed.

- Research activities updated to include the most recent research activities.
The work presents topics in human-machine interface, multi-sensory data fusion, ubiquitous

[46] computing, and precision sensing. The authors added key disruptive technologies that include new architecture, new security, and a new spectrum.
- Enabling Technologies limited to six and did not include technologies such as blockchain, ABCS.

- Applications not clearly outlined.
- Enabling Technologies and challenges are discussed extensively.

- Additionally, the existing and probable solutions to some of these challenges are highlighted

- 6G Applications are clearly outlined.
The authors present a vision on $6 \mathrm{G}$, considering the applications, service

[47] classes, essential requirements, and trends. The enabling technologies and open research problems were highlighted.

\section{- Enabling Technologies} discussed, but the challenges were not clearly outlined.

- Additionally, non-technical challenges such as commercialization and psychological challenges are not discussed.
- Arobust discussion on Blockchain as an emerging technology is reported.

- Technical challenges associated with the enabling technologies and non-technical challenges such as commercialization are discussed. 
Table 1. Cont

\begin{tabular}{|c|c|c|c|c|c|}
\hline \multirow{2}{*}{$\begin{array}{l}\text { Ref. } \\
{[48]}\end{array}$} & \multirow{2}{*}{$\begin{array}{l}\text { Focus and Coverage } \\
\text { This survey focuses on } 6 \mathrm{G} \\
\text { applications, requirements, challenges, } \\
\text { and critical areas of research focus. } \\
\text { The survey also covers key } \\
\text { technologies such as THz, blockchain, } \\
\text { AI, and optical wireless } \\
\text { communication (OWC). }\end{array}$} & \multicolumn{2}{|c|}{ Limitations } & \multicolumn{2}{|c|}{ This Paper's Contributions } \\
\hline & & घ & $\begin{array}{l}\text { The challenges with the } \\
\text { enabling technologies proposed } \\
\text { are not discussed. } \\
\text { Use cases not discussed. }\end{array}$ & $\begin{array}{l}\square \\
\square\end{array}$ & $\begin{array}{l}\text { Discusses the challenges with enabling } \\
\text { technologies. } \\
\text { Presents use cases in education, media, } \\
\text { entertainment, and more. } \\
\text { Examines the proposed applications, the } \\
\text { requirements, and why existing } 5 \mathrm{G} \text { cannot meet } \\
\text { the requirements. }\end{array}$ \\
\hline$[49]$ & $\begin{array}{l}\text { Presents the enabling technologies, } \\
\text { including the holographic radio } \\
\text { characteristics and targeted } \\
\text { application scenarios. Additionally, } \\
\text { considers non-technical challenges } \\
\text { such as industry barrier and } \\
\text { consumer habits. }\end{array}$ & $\square$ & $\begin{array}{l}\text { Applications not } \\
\text { clearly outlined. } \\
\text { Open research issues and future } \\
\text { research directions not } \\
\text { discussed. }\end{array}$ & & $\begin{array}{l}\text { More enabling technologies are discussed. } \\
\text { Technical and non-technical challenges } \\
\text { are presented. } \\
6 \mathrm{G} \text { applications are clearly outlined. } \\
\text { Open research issues, future research directions, } \\
\text { and lessons learned are outlined. }\end{array}$ \\
\hline
\end{tabular}

\section{The Evolution from $1 \mathrm{G}$ to $6 \mathrm{G}$}

The analog wireless cellular network, which formed the first generation of wireless communication, was in use in the 1980s. This facilitated voice calls between mobile users. The Advanced Mobile Phone System (AMPS), International Mobile Telecommunications Standard (IMTS), and Point to Call formed the basis for the 1G. Additionally, some European countries adopted the Nordic Mobile Radio System (NMR). This resulted in compatibility challenges. The first-generation network was monopolized and was not affordable for many. 2G brought about high-quality, secure mobile voice and basic data services such as fax and text messaging. GSM was at the core of the $2 \mathrm{G}$. It was regarded as the "Groupe Speciale Mobile" - a group of technical personnel set up by the Postal and Telecommunication Administration (CEPT) Conference to develop digital mobile communication technology [50]. This was developed as the wireless counterpart of the land-lined Integrated Services Digital Network (ISDN) system. The acronym was later changed to refer to "Global Systems for Mobile Communication." The GSM standard was deployed in 1991, using the $900 \mathrm{MHz}$ band [51].

The GSM architecture comprises the Mobile Station, Network and Switching Subsystem, and the Base Station Subsystem (BSS), also known as the radio network. Additionally, included is an intelligent network subsystem that enables intelligent functionality such as prepaid services and short message services (SMS). GSM utilized Frequency Division Multiple Access (FDMA) and Time Division Multiple Access (TDMA) for simultaneous communication between the subscriber and the base station [52]. The former allowed communication using multiple frequencies, while the latter enabled communication through multiplexing by time slots. General Packet Radio Service (GPRS) was developed to facilitate features such as always-on, higher capacity, internet-based content, packet-based data services, enabling services such as color internet service, email on the move, and visual communications, multimedia messages, and location-based services [53].

In the early twenty-first century, 3G was developed as an upgrade to the features in $2 \mathrm{G}$. It permitted faster data rates in the range of $300 \mathrm{kbps}-30 \mathrm{Mbps}$ and services such as video conferencing, remote supervision systems, and enabled information services. Technologies such as Wideband Code Division Multiple Access (WCDMA), Universal Mobile Telephone Service (UMTS) were key to achieving the 3G. The 3rd Generation Partnership Programme (3GPP) was formed in 1998 to oversee UMTS implementation and other enabling technology for 3G. 3GPP2 was also formed in the United States to develop global specifications for $3 \mathrm{G}$ systems. Critical concepts for evolution toward beyond $3 \mathrm{G}$ networks are presented in [54].

Long-Term Evolution (LTE) was deployed in 2009. With the proliferation of smartphones and tablets, online gaming, and other services, $4 \mathrm{G}$ has been a significant success, enabling these services with its data speed of $100 \mathrm{Mps}-1000 \mathrm{Mbps}$. Although the first 
release of LTE was in 2005 by 3GPP in release 6 , the full development was only achieved in release 8 in 2008. Further details on the technical solutions for the $3 \mathrm{G}$ long-term evolution are reported in [55]. The LTE is often regarded as the 4G; however, the LTE-Advanced features such as increased peak data rate, spectral efficiency, simultaneous active subscribers, and improved cell-edge performance make it the true $4 \mathrm{G}$. Key performance indicators for 4G LTE are given by [56,57], and radial basis function neural network pathloss prediction model in LTE network was reported in [58]. A higher data rate was achieved and lower latency in $20 \mathrm{~ms}-100 \mathrm{~ms}$, which was lower than that obtained in 3G. 4G facilitated video streaming, online gaming, and more. The need for a higher data rate and lower latency gave room for interests in $5 \mathrm{G}$.

5G commercialization started in 2019, and it opens up new use cases in the Internet of Things (IoT), immersive gaming, virtual reality, and more. 6G is expected to have a higher data rate in the range $100 \mathrm{Gbps}-1 \mathrm{Tbps}$ and latency lower than $1 \mathrm{~ms}$. This opens up applications in holographic communication, tactile internet, extended reality, and more. Table 2 summarizes the technology, data rates, and supporting applications from 1G to 6G. The change in latency from $1 \mathrm{G}$ to $6 \mathrm{G}$ is also shown. Furthermore, a comparative analysis of 5G, Beyond 5G (B5G), and 6G is presented in Table 3.

Table 2. Comparing the different generations of wireless communication from $1 \mathrm{G}$ to $6 \mathrm{G}$.

\begin{tabular}{|c|c|c|c|c|c|c|}
\hline Features & 1G & $2 \mathrm{G}$ & $3 G$ & $4 \mathrm{G}$ & $5 \mathrm{G}$ & $6 \mathrm{G}$ \\
\hline Technology & $\begin{array}{l}\text { AMPS [59], IMTS, } \\
\text { PTT }\end{array}$ & $\begin{array}{l}\text { GSM [60], GPRS, } \\
\text { CDMA [61], EGDE }\end{array}$ & $\begin{array}{l}\text { WCDMA [62], } \\
\text { UMTS, TD-SDMA, } \\
\text { CDMA2000 [63], } \\
\text { WiMAX [64] }\end{array}$ & $\begin{array}{l}\text { LTE [65], MIMO } \\
\text { [66] }\end{array}$ & $\begin{array}{l}\text { Massive MIMO, } \\
\text { network } \\
\text { densification, } \\
\text { millimeter- wave } \\
\text { transmission }\end{array}$ & $\begin{array}{l}\text { RIS [67], Cell-free } \\
\text { Massive MIMO [68], } \\
\text { Terahertz spectrum } \\
\text { [69], AI [24] }\end{array}$ \\
\hline Data-rate range & $>3 \mathrm{kbps}$ & 10 kbps-200 kps & 300 kbps-30 Mbps & $100 \mathrm{Mps}-1000 \mathrm{Mbps}$ & 1-30 Gbps & 100 Gbps-1 Tbs \\
\hline Latency & $>1000 \mathrm{~ms}$ & $300 \mathrm{~ms}-1000 \mathrm{~ms}$ & $100 \mathrm{~ms}-500 \mathrm{~ms}$ & $20 \mathrm{~ms}-100 \mathrm{~ms}$ & $1 \mathrm{~ms}-10 \mathrm{~ms}$ & $<1 \mathrm{~ms}$ \\
\hline $\begin{array}{l}\text { Multiple Access/ } \\
\text { Multiplexing } \\
\text { schemes }\end{array}$ & FDMA [70] & TDMA, CDMA & CDMA [71] & OFDMA [72] & $\begin{array}{l}\text { OFDM, GFDM [73] } \\
\text { FBMC [74], } \\
\text { Adaptive } \\
\text { Time-Frequency. } \\
\text { Multiplexing [75] }\end{array}$ & $\begin{array}{l}\text { OMA [76], NOMA } \\
\text { [76], OAM [77], } \\
\text { Spatial } \\
\text { Multiplexing [78] }\end{array}$ \\
\hline Applications & Calls, Fax & $\begin{array}{l}\text { Encrypted and data } \\
\text { services }\end{array}$ & $\begin{array}{l}\text { Faster Data, Video } \\
\text { calling, remote } \\
\text { supervision systems }\end{array}$ & $\begin{array}{l}\text { HD Television } \\
\text { content, Online } \\
\text { Gaming }\end{array}$ & $\begin{array}{l}\text { Internet of Things } \\
\text { [5], Virtual reality, } \\
\text { Immersive gaming }\end{array}$ & $\begin{array}{l}\text { Autonomous } \\
\text { systems, tactile } \\
\text { devices, Internet of } \\
\text { Everything, BCI, } \\
\text { Telemedicine }\end{array}$ \\
\hline
\end{tabular}

This table compares the different generations of wireless communication from $1 \mathrm{G}$ to $6 \mathrm{G}$ with respect to the supporting technologies, data features, and enabling applications. It shows that with higher data rates and lower latency, more sophisticated applications are enabled.

Table 3. A comparative analysis of $5 \mathrm{G}, \mathrm{B} 5 \mathrm{G}$, and $6 \mathrm{G}$.

\begin{tabular}{|c|c|c|c|}
\hline Description & $5 G$ & Beyond 5G & $6 \mathrm{G}$ \\
\hline Frequency bands & $\begin{array}{l}\text { - } \quad \text { Sub-6GHz } \\
\text { - } \quad \text { mmWave for fixed access }\end{array}$ & $\begin{array}{ll}\text { - } & \text { Sub-6GHz } \\
\text { - } & \text { mmWave for fixed access }\end{array}$ & $\begin{array}{ll}\text { - } & \text { Sub-6GHz } \\
\text { - } & \text { mmWave for mobile access } \\
\text { - } & \text { Exploration of higher frequency } \\
& \text { and THz bands (above } 300 \mathrm{GHz} \text { ) } \\
\text { - } \quad \text { Non-RF (optical, VLC) }\end{array}$ \\
\hline Rates requirements & $20 \mathrm{~Gb} / \mathrm{s}$ & $100 \mathrm{~Gb} / \mathrm{s}$ & $1 \mathrm{~Tb} / \mathrm{s}$ \\
\hline $\begin{array}{l}\text { Radio only delay } \\
\text { requirements }\end{array}$ & $100 \mathrm{~ns}$ & $100 \mathrm{~ns}$ & $10 \mathrm{~ns}$ \\
\hline $\begin{array}{l}\text { End-to-End delay(latency) } \\
\text { requirements }\end{array}$ & $5 \mathrm{~ms}$ & $1 \mathrm{~ms}$ & $<1 \mathrm{~ms}$ \\
\hline Processing delay & $100 \mathrm{~ns}$ & $50 \mathrm{~ns}$ & $10 \mathrm{~ns}$ \\
\hline
\end{tabular}


Table 3. Cont.

\begin{tabular}{|c|c|c|c|}
\hline Description & $5 G$ & Beyond 5G & $6 G$ \\
\hline Device types & $\begin{array}{ll}\text { - } & \text { Sensors } \\
\text { - } & \text { Smartphones } \\
\text { - } & \text { Drones }\end{array}$ & $\begin{array}{ll}\text { - } & \text { Sensors } \\
\text { - } & \text { Smartphones } \\
\text { - } & \text { Drones } \\
\text { - } & \text { XR equipment }\end{array}$ & $\begin{array}{ll}\text { - } & \text { Sensors and DLT } \\
\text { - } & \text { CRAS } \\
\text { - } & \text { XR and BCI } \\
& \text { Smart implants }\end{array}$ \\
\hline Architecture & $\begin{array}{l}\text { Dense sub-6 GHz small } \\
\text { base stations with umbrella } \\
\text { macro stations. } \\
\text { mmWave small cells of } \\
\text { about } 100 \mathrm{~m} \text { (about } \\
\text { fixed access). }\end{array}$ & $\begin{array}{l}\text { Denser sub-6 GHz small } \\
\text { cells with umbrella macro } \\
\text { base stations. } \\
<100 \text { m tiny and dense } \\
\text { mmWave cells. }\end{array}$ & $\begin{array}{l}\text { - Cell-free smart surfaces at high } \\
\text { frequency supported by mmWave } \\
\text { tiny cells for mobile and free } \\
\text { access. } \\
\text { - Temporary hotspots are served by } \\
\text { drone-carrier base stations or } \\
\text { tethered balloons. } \\
\text { - } \quad \text { Trials of tiny THz cells. }\end{array}$ \\
\hline Services & $\begin{array}{ll}\text { - } & \text { eMBB } \\
\text { - } & \text { URLLC } \\
\text { mMTC }\end{array}$ & $\begin{array}{ll}\text { - } & \text { Reliable eMBB } \\
\text { - } & \text { URLLC } \\
\text { - } & \text { mMTC } \\
\text { - } & \text { Hybrid (URLLC + eMBB) }\end{array}$ & $\begin{array}{ll}\text { - } & \text { HCS } \\
\text { - } & \text { MPS } \\
\text { - } & \text { MBRLLC } \\
\text { mURLLC }\end{array}$ \\
\hline
\end{tabular}

This table zooms in on the comparison of 5G, Beyond 5G, and 6G, presenting a specific latency, brief description of the architecture, and services such as MBRLLC, mURLLC that have been proposed. The device types are also shown to include BCI and smart implants in 6G.

\section{Vision of 6G Wireless Communication}

There have been different descriptions of what the $6 \mathrm{G}$ network should be by researchers [40,45,79-81]. Furthermore, the authors in [82] defined it as a technology that will make human society a "Ubiquitous Intelligent Mobile Society." In [41], the authors envisioned $6 \mathrm{G}$ to facilitate super smart cities with pervasive autonomous systems. It is expected that $6 \mathrm{G}$ will be supported by existing $5 \mathrm{G}$ infrastructure such as Software-Defined Networking [83], Network Function Virtualization (NFV) [84], and Network Slicing (NS) [85] together with new infrastructure. In order to give a future assessment of how well 6G has accomplished the required cases, this paper examines various visions and requirements projected by different researchers [42-44]. It presents a blend of what $6 \mathrm{G}$ will be. Just as we envisage, some researchers also believe there will be a pervasive application of AI to make $6 \mathrm{G}$ a reality $[20,70]$. There is also research on optical wireless communication to enable indoor and outdoor communication at high-data rates [86]. Simultaneous Wireless and Information Power Transfer (SWIPT) [35], which is an Energy Harvesting (EH) technique, has been proposed to improve the battery life of UEs [40,41].

6G is expected to support smart cities, the Internet of Everything (IoE) [39], tactile devices [9], and more. The requirements are high reliability [7], the high data rate in the order of $1 \mathrm{~Tb} / \mathrm{s}$, ultra-low latency of less than 1ms, high energy and spectral efficiency [87], security and privacy [88], and ubiquitous connectivity that connects everyone, including people in rural areas $[89,90]$. The Ultra-Reliable Low Latency Communication (URLLC) required in $6 \mathrm{G}$ networks is also under more stringent conditions than that obtainable in 5G, with delay jitters, context awareness, and UAV/Satellite compatibility being considered. Sustainability is also desirable in future wireless networks, and there is a need for Green Networking architecture that will be environmentally friendly [91].

Table 4 presents the vision and requirements projected by different researchers. This gives a sneak peek at the ongoing discussion on 6G networks. The focus and future projections are also highlighted. Services and Key Performance Indicators [92,93] are given, as shown in Table 5. Additionally, applications such as immersive extended reality, BrainComputer Interface (BCI), Connected Robotic and Autonomous System (CRAS), and more, proposed to be supported by 6G, are presented in Table 6 . Figure 2 shows a brief overview that compares the Key Performance Indicators in 5G and those expected in 6G. 


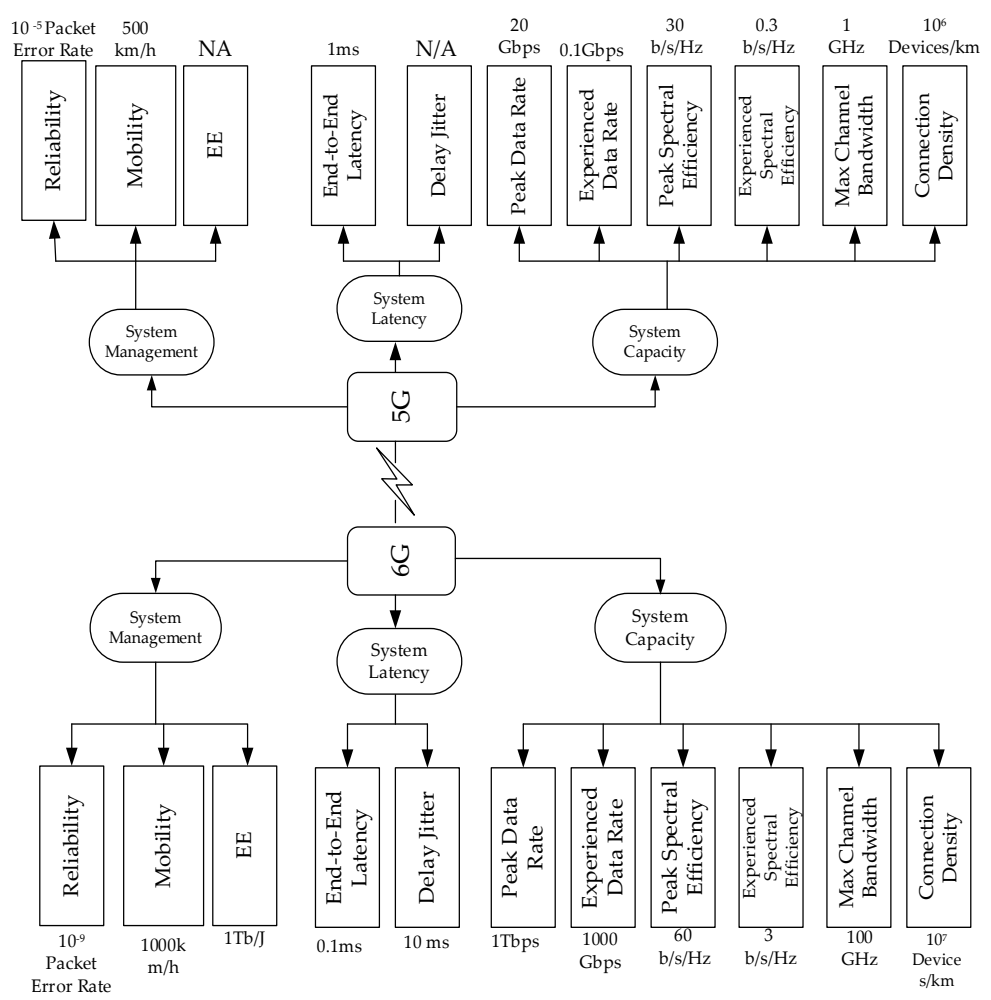

Figure 2. Comparative Analysis of 5G and 6G Key Performance Indicators.

Furthermore, driving trends towards $6 \mathrm{G}$ are introduced in Table 6, and a pictorial guide of the driving trends towards $6 \mathrm{G}$ is shown in Figure 3. Since the flag-off of the 6G research project in Finland in May 2018 [94], many countries have been interested in 6G research. $6 \mathrm{G}$ research, though still in its fledgling state, has recorded positive results towards the achievement of this vision. Table 7 gives the initiatives in selected countries or research centers that carry out leading research in $6 \mathrm{G}$ and its progress.

Table 4. A summary of the vision and requirements of $6 \mathrm{G}$ wireless networks.

\begin{tabular}{|c|c|c|c|c|}
\hline Ref. & Vision & Requirements & Focus & Future Projections \\
\hline [47] & $\begin{array}{l}\text { To support future IoE smart } \\
\text { cities. It also provides a fully } \\
\text { immersive experience of XR } \\
\text { and Convergence of } \\
\text { Communications, Computing, } \\
\text { Control, Localization, and } \\
\text { Sensing(3CLS). }\end{array}$ & $\begin{array}{l}\text { A blend of URLLC and eMBB } \\
\text { with perceptual factors from } \\
\text { the user. Introduces a new } \\
\text { concept QoPE. Multi-purpose } \\
\text { 3CLS and Energy Services. }\end{array}$ & $\begin{array}{l}\text { Human-centric services based } \\
\text { on QoPE, Energy Services, and } \\
\text { Mobile Broadband Reliable } \\
\text { Low Latency } \\
\text { Communications. }\end{array}$ & $\begin{array}{l}\text { Quantum computing and } \\
\text { Communications. }\end{array}$ \\
\hline [40] & $\begin{array}{l}\text { Enhanced conventional mobile } \\
\text { communication, accurate } \\
\text { indoor positioning, support } \\
\text { new communication devices } \\
\text { such as wearable devices, } \\
\text { integrated and implantable } \\
\text { sensors, quality network on } \\
\text { aircraft, worldwide } \\
\text { connectivity. }\end{array}$ & $\begin{array}{l}\text { eMBB-Plus, } \\
\text { SURLLC (URLLC+mMTC), } \\
\text { massive Vehicle-to-Everything } \\
\text { to support Robotic } \\
\text { communication. }\end{array}$ & $\begin{array}{l}\text { Security, Privacy, Energy } \\
\text { Efficiency, Intelligent } \\
\text { Networks, affordability and } \\
\text { Customization, Trade-offs } \\
\text { between key features and } \\
\text { potential solutions. }\end{array}$ & $\begin{array}{l}\text { The dependency on basic } \\
\text { sciences, social and need for } \\
\text { research on psychological } \\
\text { factors could hamper } \\
\text { commercialization. }\end{array}$ \\
\hline [9] & $\begin{array}{l}\text { Data-driven society enabled } \\
\text { by almost instantaneous } \\
\text { unlimited wireless } \\
\text { connectivity. Supports fine } \\
\text { telemedicine, intelligence } \\
\text { disaster prediction, and } \\
\text { surreal VR. }\end{array}$ & $\begin{array}{l}\text { Undetectable or non-existent } \\
\text { latency, Multi-band ultra-fast } \\
\text { speed transmission, flexible } \\
\text { integrated network, } \\
\text { multi-mode multi-joint } \\
\text { transmission, and Intelligent } \\
\text { transmission. }\end{array}$ & $\begin{array}{l}\text { Potential techniques for } 6 \mathrm{G} \\
\text { networks and challenges } \\
\text { associated with } 6 \mathrm{G} \\
\text { communication. }\end{array}$ & $\begin{array}{l}\text { Power supply, Network, and } \\
\text { Hardware Design Issues. }\end{array}$ \\
\hline
\end{tabular}


Table 4. Cont.

\begin{tabular}{|c|c|c|c|c|}
\hline Ref. & Vision & Requirements & Focus & Future Projections \\
\hline$[41]$ & $\begin{array}{l}\text { Supports super smart cities, } \\
\text { IoT, driverless cars, and } \\
\text { pervasive empowerment by } \\
\text { AI. Radar technologies will be } \\
\text { integrated with mobile } \\
\text { communication. Additionally, } \\
\text { a possibility for wireless } \\
\text { power transfer, RF energy } \\
\text { harvesting, optical wireless } \\
\text { communication and LiFi. }\end{array}$ & $\begin{array}{l}\text { Increase in data rate from } 1 \\
\text { Gbps in } 5 G \text { to at least } 10 \text { Gbps } \\
\text { per user, URLLC, better } \\
\text { spectral and energy efficiency } \\
\text { than 5G. }\end{array}$ & $\begin{array}{l}\text { Use Cases, Challenges, and } \\
\text { Key Enabling Technologies. }\end{array}$ & $\begin{array}{l}\text { The shift from the electronic } \\
\text { era in } 5 \mathrm{G} \text { to the optical and } \\
\text { photonics era. }\end{array}$ \\
\hline
\end{tabular}

An ICT infrastructure enables end-users to perceive and be surrounded by a "huge artificial brain" offering virtually zero latency, unlimited storage, and immense condition capabilities. Vision for battery-free communication.
Exceedingly high reliability (1-10-9), extremely low latency (0.1-1 ms), and delay jitter. They are targeting communication efficiency on the order of $1 \mathrm{pJ} / \mathrm{b}$
Enablers of the $6 \mathrm{G}$, distributed security mechanisms,

Pervasive AI, and holistic management of

Communication,

Computation, Caching and Control (C4) resources.
Use of Blockchain, Pervasive application of AI, subterahertz, Visible Light Communication, and Optical Beamforming.
The convergence of network densification, high throughput, high reliability, low power consumption, and capability for handling massive volumes of data and very high data rate Supports smart wearables, implants, autonomous vehicles, computing reality devices, sensing, 3D Mapping.

Supports Mobile augmented reality, VR, Holographic

[95] teleconferencing, tactile internet of things, industrial IoT, intelligent driving.

Seamless, ubiquitous

connection, Teleoperation, cooperative and autonomous driving.

massive broadband

energy, and spectral efficiency.
eMBB-Plus, Big

communication, secure

ultra-reliable low latency

communication, 3D integrated

communication, holographic,

tactile, and human-bond

communication. connectivity per device.

Ultra-long range

communication with a latency

of less than $1 \mathrm{~ms}$, low backhaul

and access network

congestion, AI, satellite

integration, enhanced security with blockchain.

Mobile broadband bandwidth

and low latency (mBBLL),

bandwidth machine type

(mBBMT), massive low latency

machine type (mLLMT),

6G-Lite, security, Intelligence,

Evolution, 6G Enabling

Technologies, Challenges.

ision, Requirements,

Applications, Challenges, and

Research Directions.
FSO communication, $\mathrm{THz}$ communication, Spectrum and Interference management, Autonomous Wireless systems, resource management.
Blockchain, Quantum computing, multidisciplinary affiliations with the physical and social sciences, intelligent 6G.

FSO communication, $\mathrm{THz}$ communication, Spectrum and Interference management, Autonomous Wireless systems, resource management.
A large-dimensional and autonomous network architecture that integrates space, air, ground, and underwater.

To provide a full sensory

[81] volume of data, extremely high throughput, and very low latency. It also supports super-high definition and extremely high-definition (EHD) videos, Internet of NanoThings, and Internet of Bodies.
A peak data rate of at least 1 $\mathrm{Tb} / \mathrm{s}$, a user experience data rate of $1 \mathrm{~Gb} / \mathrm{s}$, and over-the-air latency of 10-100 $\mu$ s and high mobility of Vision, requirements, at least $1000 \mathrm{~km} / \mathrm{h}$, ten times architecture, and key the connectivity of $5 \mathrm{G}$ and energy efficiency of 10-100 times and spectrum efficiency of 5-10 times those of $5 \mathrm{G}$.
Identified the following promising techniques: $\mathrm{THz}$ communications, SM-MIMO, LIS and HBF, OAM multiplexing, laser communications and VLC, quantum communications and computing, blockchain-based spectrum sharing, and Molecular communications and the Internet of NanoThings. 
Table 4. Cont.

\begin{tabular}{|c|c|c|c|c|}
\hline Ref. & Vision & Requirements & Focus & Future Projections \\
\hline [80] & $\begin{array}{l}\text { Intelligent Connectivity with } \\
\text { pervasive AI, Deep } \\
\text { connectivity(tactile internet, } \\
\text { deep data mining, telepathy), } \\
\text { Holographic } \\
\text { connectivity(holographic } \\
\text { communication, high fidelity, } \\
\text { AR/VR), Ubiquitous } \\
\text { connectivity(Space-Air- } \\
\text { Ground-Sea network } \\
\text { integration). }\end{array}$ & $\begin{array}{l}\text { Massive connectivity, } \\
\text { reliability, real-time and } \\
\text { throughput requirements, } \\
\text { reduced spectral efficiency, } \\
\text { pervasive sensors. }\end{array}$ & $\begin{array}{l}\text { Vision, requirement, } \\
\text { challenges(technical and } \\
\text { non-technical), and potential } \\
\text { key technologies. }\end{array}$ & $\begin{array}{l}\text { Future trends were not } \\
\text { explicitly stated, but the paper } \\
\text { discussed the key technologies } \\
\text { required for } 6 \mathrm{G} \text {. }\end{array}$ \\
\hline [33] & $\begin{array}{l}\text { Wireless charging, Optical } \\
\text { free-space communication, } \\
\text { outdoor wireless } \\
\text { communication. }\end{array}$ & $\begin{array}{l}\text { Ultra-long battery lifetime, } \\
\text { lesser focus on high bit rates. }\end{array}$ & $\begin{array}{l}\text { Battery life, Regulations, and } \\
\text { rules for frequency } \\
\text { assignment, ethics } \\
\text { surrounding the adoption of } \\
6 \mathrm{G} \text {. }\end{array}$ & $\begin{array}{l}\text { Inclusion of human sensory } \\
\text { information and emotion in } \\
\text { future applications; also, } \\
\text { sociotechnical designs to } \\
\text { assess legal, psychological, } \\
\text { and economic requirements. }\end{array}$ \\
\hline
\end{tabular}

This table gives a sneak peek into the discussion on the $6 \mathrm{G}$ vision and requirements. The table also serves as a guide to the focus and future projections by researchers. Technologies such as pervasive AI, blockchain are proposed by various researchers. Additionally, applications such as wireless charging and wearables are proposed. This overview is important as it helps keep track of what research thinks 6G would be, compare and contrast as the research progresses.

Table 5. Services, Key Performance Indicators (KPIs), and Applications of 6G.

\begin{tabular}{|c|c|c|c|c|}
\hline Service & $\mathbf{K P}$ & & & ications \\
\hline HCS & a. & $\begin{array}{l}\text { QoPE is capturing raw wireless metrics as } \\
\text { well as human and physical factors. }\end{array}$ & & $\begin{array}{l}\text { Emphatic communication. } \\
\text { BCI. } \\
\text { Affective communication. } \\
\text { Haptics. }\end{array}$ \\
\hline MPS & $\begin{array}{l}\text { a. } \\
\text { b. } \\
\text { c. } \\
\text { d. } \\
\text { e. } \\
\text { f. }\end{array}$ & $\begin{array}{l}\text { Energy. } \\
\text { Computing latency. } \\
\text { Latency and reliability communication } \\
\text { Control stability. } \\
\text { Localization accuracy. } \\
\text { Sensing and mapping accuracy. }\end{array}$ & $\begin{array}{l}\text { a. } \\
\text { b. } \\
\text { c. } \\
\text { d. }\end{array}$ & $\begin{array}{l}\text { Environmental mapping and imaging. } \\
\text { Telemedicine. } \\
\text { Connected Robotics and Autonomous System (CRAS). } \\
\text { Some special cases of extended reality (XR) services. }\end{array}$ \\
\hline MBRLLC & $\begin{array}{l}\text { a. } \\
\text { b. } \\
\text { c. }\end{array}$ & $\begin{array}{l}\text { Energy efficiency. } \\
\text { Stringent rate-reliability latency } \\
\text { requirements. } \\
\text { Rate-reliability latency in mobile } \\
\text { environments. }\end{array}$ & $\begin{array}{l}\text { a. } \\
\text { b. } \\
\text { c. } \\
\text { d. }\end{array}$ & $\begin{array}{l}\text { Legacy eMBB and URLLC. } \\
\text { XR/VR/ AR. } \\
\text { Autonomous vehicular systems. } \\
\text { Autonomous drones. }\end{array}$ \\
\hline mURLLC & $\begin{array}{l}\text { a. } \\
\text { b. } \\
\text { c. } \\
\text { d. }\end{array}$ & $\begin{array}{l}\text { Scalable URLLC. } \\
\text { Massive reliability. } \\
\text { Ultra-high reliability. } \\
\text { Massive connectivity. }\end{array}$ & $\begin{array}{l}\text { a. } \\
\text { b. } \\
\text { c. } \\
\text { d. } \\
\text { e. }\end{array}$ & $\begin{array}{l}\text { Blockchain and DLT. } \\
\text { Autonomous robotics. } \\
\text { Massive sensing. } \\
\text { Classical Internet of things. } \\
\text { User tracking. }\end{array}$ \\
\hline
\end{tabular}

This table shows in detail the 6G services introduced in Table 3. Key Performance Indicators (KPIs) and enabling applications are also highlighted. 
Table 6. A summary of the driving trends towards 6G wireless networks.

Driving Trends
The convergence of Communications, Computing, Control,
Localization, and Sensing (3CLS).

The convergence of Communications
Localization, and Sensing (3CLS).

The emergence of Smart Reflective Surfaces and Environments.

Massive Availability of Small Data.

More bits, More spectrum, and More Reliability.

From Self-Organizing Networks to Self-Sustaining Networks.

Ubiquitous connectivity that encompasses air, ground, and undersea.

The emergence of Haptics and the End of Smartphone era.

\section{Description}

Provides computing, control, localization, and sensing in addition to Wireless Communication that previous generations provided. Supports applications such as XR, CRAS, DLS.

Driven by smart reflective surfaces that serve as walls, roads, doors, and entire buildings, help maintain a line of sight and obtain a quality signal with minimal loss.

The shift from centralized big data to massive distributed small data.

Exploring higher frequency spectrum $(\mathrm{THz})$, which is proposed to facilitate the actualization of $1 \mathrm{~Tb} / \mathrm{s}$.

$\mathrm{AI}$ is proposed to facilitate intelligent wireless networks that are self-sustaining.

6G is envisioned to integrate space-air-ground-sea mode to facilitate wireless communication in flying vehicles, $\mathrm{XR}, \mathrm{BCI}$, and more.

The pervasive use of wearables and implants, supported by BCI and XR.

This table highlights driving trends towards 6G. For example, the convergence of Communications, Computing, Control, Localization and Sensing (3CLS) or Communication, Computation, Caching and Control (C4) is a crucial driving trend towards 6G. Additionally, the emerging Smart Reflective Surfaces are expected to facilitate 6G. Other trends such as the emergence of haptics are also highlighted.

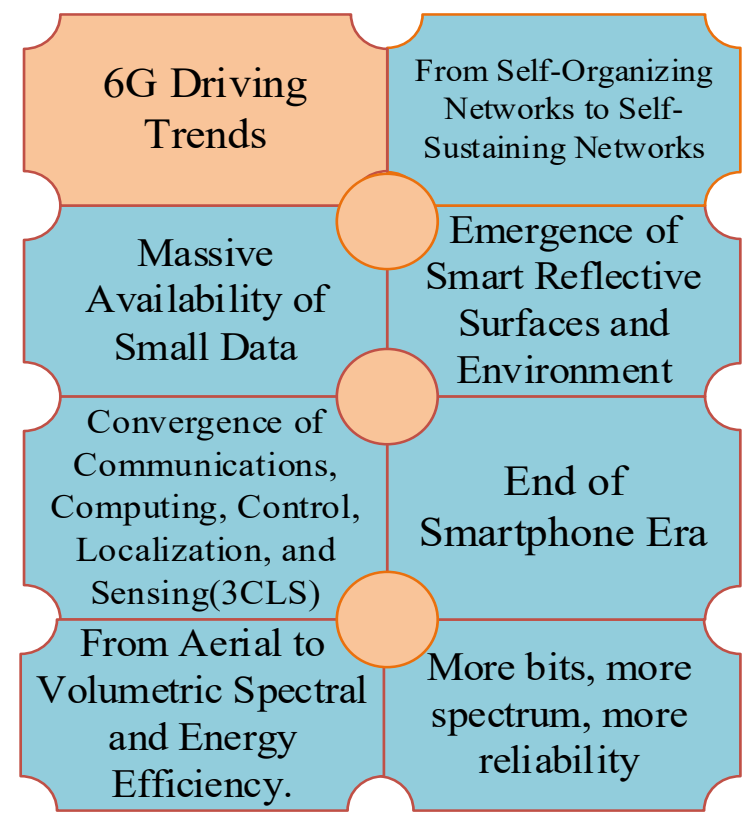

Figure 3. 6G Driving Trends. 
Table 7. 6G research in selected countries and regions.

\begin{tabular}{lll}
\hline Country & Year & Research Initiatives \\
\hline
\end{tabular}

The consortium comprises academia, research centers, industrial partners, business units, and others. This is coordinated by the Centre for Wireless Communication, University of

Finland 2018 Oulu, Finland.

The 6Genesis project is focused on research that embraces electronics and materials, wireless communication, computer science, and engineering. First 6G Wireless Summit was held in Levi, Lapland, Finland, in March 2019.

The Federal Communications Commission opened the spectrumbetween $95 \mathrm{GHz}$ and $3 \mathrm{THz}$ to create a new category ofExperimental licenses.

United States

2019

BWA Lab working on Ultra-MIMO based Intelligent Network

ComSenTer researching wireless communication in the $\mathrm{THz}$ region. Research ongoing by NYU Wireless, VIVO communication Research Institute.

Ministry of Science and Technology in 2019 announced the establishment of two groups for $6 \mathrm{G}$ research: One group will consist of relevant government departments, and the other team will be made up of 37 universities, research institutes, and enterprises, which will lay out the technical side of $6 \mathrm{G}$ and offer advice.

China

2019

ZTE has a group on advanced technologies, researching networks beyond 5G. Huawei also commenced research at their research facility in Ottawa, Canada. They also have a research facility in Segrate, Italy, where research on microwave communication, frequency spectrum, and transmission speed is carried out.

The Netherland $2019 \quad$ The Eindhoven University of Technology developed new antenna technology.

Networking Research beyond 5G, an EU-Japan project, is investigating the possibility of THz spectrum from $100 \mathrm{GHz}$ to $450 \mathrm{GHz}$.

EU 2019

Terranova project, a research group by the EU, is working toward a reliable 6G connection with 400 Gigabit per second transmission capability in the terahertz spectrum.

6th International Telecommunication Union Workshop on networks in 2030 held in Lisbon, Portugal in January 2020.

LG partnership with the Korea Advanced Institute of Science and Technology to conduct 6G

South Korea

2019 research. Samsung also kicked off 6G research in 2019.

SK Telecom announced a collaboration with Nokia and Ericsson on 6G research in 2019.

\begin{tabular}{lll}
\hline Russia & 2019 & $\begin{array}{l}\text { The Polytechnic Institute of Physics, Nanotechnology, and Telecommunications are } \\
\text { researching 6G. }\end{array}$ \\
\hline Germany & 2019 & TU Berlin introduces an Einstein Fellowship to study 5G and 6G. \\
\hline
\end{tabular}

A committee of professionals from the private sector and university researchers to investigate

Japan 2020
the challenges of 6G. Sony, NTT Docomo, and Intel partner to carry out 6G research.

Osaka University and Nanyang Technological University Singapore partner to develop a chip that allows an $11 \mathrm{Gbps}$ data rate.

\begin{tabular}{lll}
\hline Germany & 2020 & $\begin{array}{l}\text { The German government set aside } 50 \text { billion Euros to develop future wireless technologies, } \\
\text { including 6G, quantum computing. }\end{array}$ \\
\hline United Kingdom & 2020 & The University of Surrey launched 6GIC in November 2020. \\
\hline China & 2020 & In November 2020, China launched the first 6G test satellite into orbit. \\
\hline
\end{tabular}

This table shows the initiatives by different countries, from the flag-off in Finland in 2018 and the recently launched satellites by China in 2020. Different research initiatives by different countries are also highlighted, and some novel innovations are also stated.

\section{Enabling Technologies and Challenges for $6 \mathrm{G}$}

In this section, we present a robust discussion of the enabling technologies of the $6 \mathrm{G}$ communication system. We envision that Artificial Intelligence, which was introduced in $5 \mathrm{G}$, will be further explored and central in achieving an intelligent $6 \mathrm{G}$ network. Reconfigurable Intelligent Surfaces will be deployed on doors, windows, buildings, and these reflect signals and help in places where maintaining Line of Sight (LoS) is tricky. The advantages 
of this over conventional relay systems are discussed. Cell-free Massive MIMO, TeraHertz, and Optical Wireless Technology, and more are also treated in this section. Quantum communication has been proposed, although research is in its inchoate state. This will improve the computing efficiency and security of future wireless networks. Unmanned Aerial Vehicles (UAV) and Cubesats are proposed to facilitate space communication. Some literature presents this as the Internet of Space Things [31,37]. This is important as it expands coverage and facilitates ubiquitous connectivity. The desirable wireless charging can be enabled by Ambient Backscatter Communication System (ABCS), explored in this section. We also compare and contrast Ambient Backscatter Communication System with the traditional Backscatter Communication System. Figure 4 gives a pictorial guide to the enabling technologies treated in this section. The challenges associated with the enabling technologies are also treated in this section. Furthermore, the challenges related to social, psychological, and commercialization issues are discussed in Section 8 of this paper.

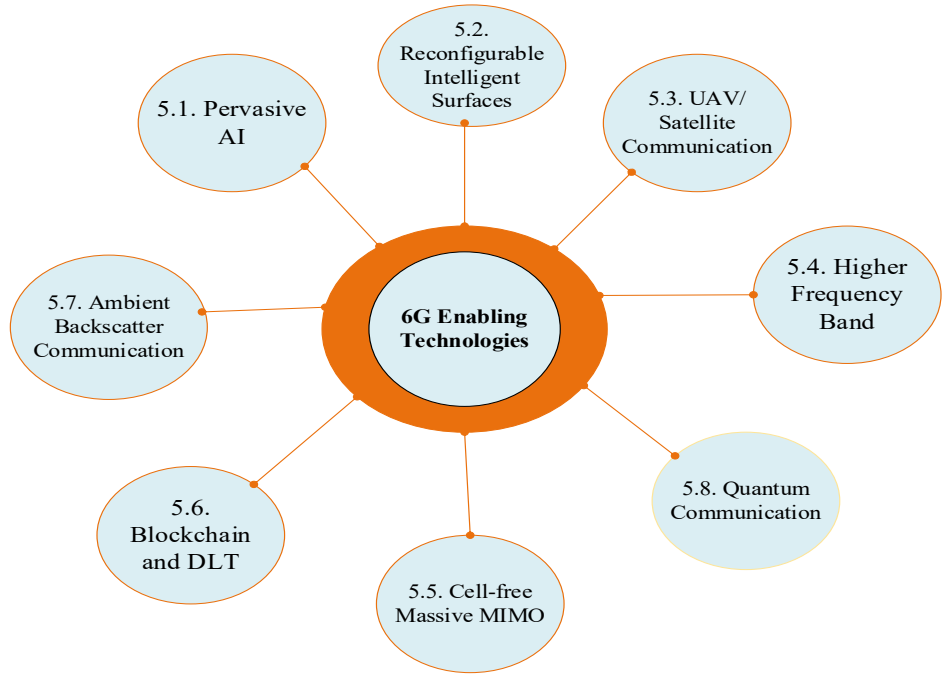

Figure 4. 6G Enabling Technologies.

\subsection{Pervasive Artificial Intelligence}

Over the past decade, the progress in the field of artificial intelligence (AI) has accelerated due to the introduction of deep learning (DL) and ease in its implementation [96,97]. These advancements, coupled with AI's data processing and decision-making capability, have made it a popular tool in various fields such as wireless communication. As discussed in Section 4 of this paper, one of the key visions of $6 \mathrm{G}$ is to support the connectivity of billions of heterogeneous devices to the network. This requirement makes it indispensable to replace traditional mathematical models and algorithms with complex, data-driven machine learning techniques $[31,47,48]$. In the absence of abundant training data, the techniques in the domain of Transfer learning [98] and generative models [99] can be put to use.

Furthermore, the traditional theories cannot optimally adapt to real-time fluctuations in operating conditions [100], non-linearities, and imperfections of practical systems for which DL and Reinforcement Learning algorithms are better suited [101]. As a result of this, $\mathrm{AI}$ is considered one of the key enabling technologies to cater to the open problems of the $6 \mathrm{G}$ communication system. In this subsection, we summarize the literature pertaining to the application of AI for various open problems of $6 \mathrm{G}$, indicating its pervasiveness

Machine Learning has been applied in 5G, and [102] classify some of these applications under unsupervised, supervised, and reinforcement learning. AI's potential to improve network handover, reduce network energy consumption, predict, detect and enable self-healing network anomalies, and optimize network planning involving basestation has been discussed in [8], all of which make AI favorable for a reduction in capital 
and operations costs. Chen et al. [23] give an elaborate list of critical applications of AI in wireless communication and how they can be applied to other enabling technologies such as UAVs [103], VR [104], Caching and Computing [105], and IoT [106]. This presents AI as a technology that interfaces with other technologies and facilitates 6G [107]. This is important as it helps achieve user-centric wireless services presented earlier in Table 4. Yang et al. [42] presented an $\mathrm{AI}$-enabled architecture for $6 \mathrm{G}$ networks divided into an intelligent sensing layer, data mining and analytics layer, intelligent control layer, and smart application layer. This shows AI pervasive prospect in every stage of the OSI model [24]. A holistic application of DL is proposed in end-to-end optimal design of the Physical Layer system [108,109], and optimization of energy management strategy for infrastructure and devices $[42,110]$. There is a plentitude of work in literature that targets narrower problem areas. We provide a bird's eye view of these approaches in Table 8, where we have categorized them according to their relevance in the OSI model. This table reiterates the pervasiveness of AI in future 6G communication networks.

Advanced machine learning techniques can be harnessed to manage big data and algorithm-driven applications. Toward this end, Zhang et al. [97] survey how to bridge the gap between deep learning and networking. Several deep learning techniques with potential applications to networking are delineated. An exhaustive review of the current challenges and open issues in mobile and wireless networking focusing on deep learning is presented. In [111], DL is proposed as a prospective strategy to design practical mobile traffic classifiers (TC), leveraging automatically extracted features, coping with encrypted traffic, and reflecting their complex traffic trajectories. Here, different DL techniques from (standard) TC are broached. Although the mobile context declined, the latter outcome can appeal to the broader umbrella of encrypted TC tasks. Finally, the performance of these DL classifiers is critically investigated based on exhaustive experimentation.

Table 8. Application of AI in different layers of $6 \mathrm{G}$ communication networking protocol stack.

\begin{tabular}{|c|c|c|c|}
\hline Layer & Application & Advantage of Using AI & Reference \\
\hline \multirow{7}{*}{ Physical Layer } & Coverage and Capacity Optimization & $\begin{array}{l}\text { Dynamic sleep control of Base stations without } \\
\text { assuming any specific model or the } \\
\text { environment. } \\
\text { Dynamic Fractional Frequency Reuse } \\
\text { Strategies. }\end{array}$ & {$[112]$} \\
\hline & Adaptive Coding and Modulation & $\begin{array}{l}\text { Higher spectrum efficiency or better tradeoff } \\
\text { between data rate and reliability to suit real-time } \\
\text { channel conditions using fewer model-based } \\
\text { approximations. }\end{array}$ & {$[112]$} \\
\hline & Symbol Detection & $\begin{array}{l}\text { Detect symbols in a dynamic, multiuser environment } \\
\text { by skipping intermediate estimation tasks. }\end{array}$ & {$[112]$} \\
\hline & Channel Prediction and Estimation & Improve flexibility, scalability, and generality. & {$[112-115]$} \\
\hline & Channel Coding & & {$[116,117]$} \\
\hline & Synchronization, Localization & & {$[118-120]$} \\
\hline & Beamforming & & {$[121,122]$} \\
\hline Data Link Layer & Dynamic Spectrum Sharing & $\begin{array}{l}\text { Make use of the dynamic environment to tune } \\
\text { transmission parameters to improve channel } \\
\text { throughput and user sum rate. }\end{array}$ & {$[112]$} \\
\hline \multirow{3}{*}{ Network Layer } & Traffic and Mobility Prediction & Improve Prediction Accuracy. & {$[112]$} \\
\hline & Mobility and Handover Management & - & {$[123]$} \\
\hline & Intelligent Network Management & - & [124]. \\
\hline \multirow{2}{*}{ Application Layer } & Intelligent Caching and Content Prediction & - $\quad$ Reduce Latency. & {$[125]$} \\
\hline & Mobile Edge Computing & - $\quad$ Slicing, Caching, Mobility, offloading. & {$[126,127]$} \\
\hline
\end{tabular}


Table 8. Cont.

\begin{tabular}{|c|c|c|c|}
\hline Layer & Application & Advantage of Using AI & Reference \\
\hline \multirow{4}{*}{ Cross-I } & $\begin{array}{l}\text { Distributed Resource Allocation in } \\
\text { Cognitive Radio Networks }\end{array}$ & - & [112] \\
\hline & Interference Alignment and Caching & $\begin{array}{l}\text { Improve network sum-rate and } \\
\text { energy-efficiency. }\end{array}$ & [128] \\
\hline & Mobile Social Network Optimization & $\begin{array}{l}\text { - Improve reliability, optimal resource sharing, } \\
\text { reduce latency. }\end{array}$ & [128] \\
\hline & End-to-end Radio Design & - Optimize communication system. & {$[101,108,129]$} \\
\hline
\end{tabular}

Challenges Associated with AI

Many challenges have been identified with the application of AI in wireless networks. Getting training data is cumbersome, and there are practically no training data to work with as we have in other fields such as natural language processing and computer vision. These data require computational and processing resources, which leads to communication costs [130]. The several features of the data, with changing values, also presents another challenge as working with higher dimensionality [131] is cumbersome. The authors in [132] presented ten challenges associated with Machine Learning applications in 6G. The challenges identified are end-to-end qualified service provision, cross-layer cooperation, dynamic online learning with proactive exploration, scalability, efficient dataset generation, computation overhead deployment, feasibility verification, standardization, learning efficiency, and deployment in distributed and centralized systems. The authors in [44] also identified challenges: Training issues, lack of explainability, interoperability and bounding performance, and uncertainty in generability.

Deep-learning-based solutions require high computational complexity, which might not fit in current mobile phones [109]. Barring the complexity, Artificial Neural Network (ANN) based RL algorithm must be meticulously designed to reduce computational resources required on these devices [23]. Quantum communication [26] offers a promising approach to circumventing the challenge of limited computational resources and energy efficiency [26]. Applying Artificial Neural Networks in IoT also comes with the trade-off challenge between accuracy and computational/energy requirements [23]. Thus, identifying the right use cases for ML/DL applications is more of a priority than tweaking neural networks and network procedures [133].

\subsection{Reconfigurable Intelligent Surfaces}

Reconfigurable Intelligent Surfaces (RIS) [107] are envisaged as a key enabling technology in 6G, just like massive MIMO in 5G [17]. They have been proved to improve the performance of networks [134] and with virtually no interference [135]. They are envisioned to facilitate energy efficiency because they are relatively passive and only require a limited number of active antennas at the BS to achieve massive MIMO gains [95]. The advantage of RIS is not just them having passive elements that improve energy efficiency. They also have a low-cost compared to other alternatives. They have name variants such as large, intelligent surfaces [136,137], reconfigurable intelligent surfaces [18,138], and software-controlled metasurfaces [139]. Figure 5 shows an RIS-assisted communication system with the RIS reflecting signal, thus enabling communication from the BS to the mobile unit. 


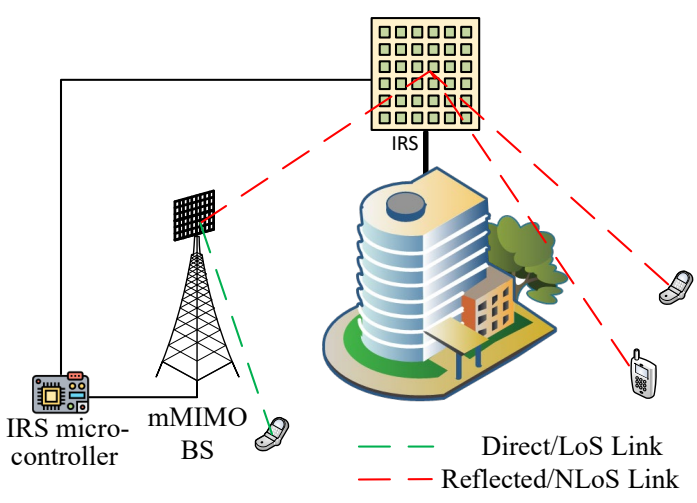

Figure 5. This diagram shows a Reconfigurable Intelligent Surface (RIS)-assisted communication system.

The metasurfaces are implemented with conventional reflect arrays [140,141], liquid crystal arrays [142], or software-defined metamaterials [139,143]. Table 9 juxtaposes the types of metasurfaces, classifying them based on structure, energy consumption, and more. The authors in [138] posited that RIS improves energy efficiency as they do not require power amplifiers, which contrasts with other relay systems. Consequently, the RIS ameliorates the problem of interference in an ultra-dense network since the RIS is passive [67]. Being passive also makes it easy to be deployed, and they can be deployed on buildings and structures. It also can be configured to provide security at the physical layer $[67,144,145]$. The RIS also supports low-power device-to-device (D2D) communication, which helps to actualize Simultaneous Wireless Information and Power Transfer (SWIPT) $[67,146]$. We compare the features of RIS with existing relay systems in Table 10.

Table 9. Types of metasurfaces being used for the design of $6 \mathrm{G}$ wireless networks.

\begin{tabular}{ll}
\hline Reconfigurable Intelligent Surfaces & \\
\hline \multirow{2}{*}{ Structure } & Patch-array based \\
\cline { 2 - 2 } Tuning mechanisms & Metamaterial based \\
\cline { 2 - 2 } & Active \\
\cline { 2 - 2 } Power source & Passive-lossy \\
\hline \multirow{2}{*}{ Pavive-lossless } \\
\cline { 2 - 2 } Energy consumption & Reflecting/ Refracting RIS \\
\cline { 2 - 2 } & Electrical Excitation \\
\cline { 2 - 2 } & Thermal Excitation \\
\hline This table classifies metasurfaces based on structure, tuning mechanisms, power source, and energy consumption.
\end{tabular}

The spectral and energy efficiency can also be enhanced by jointly optimizing the active transmit beamforming at the AP and the passive reflects beamforming at the RIS. Therefore, RIS improves spectral efficiency [138]. Operating passively, RIS help reduce the implementation cost of future wireless communication $[87,135]$. In addition to passive beamforming, which provides communication between the user and BS, RIS use in information transfer through sensors has also been proposed [137,147]. According to the authors in [138], other advantages of RIS are: they are more energy-efficient and environmental friendly compared to conventional relay systems and compatible with standards and hardware of earlier wireless generations. RIS is also being considered to be deployed to secure wireless networks [148-150]. 
Table 10. Contrasting RIS with similar existing technologies for 6G.

\begin{tabular}{lllll}
\hline Features & RIS & $\begin{array}{l}\text { Active, Intelligent } \\
\text { Surface-Based Massive } \\
\text { MIMO }\end{array}$ & $\begin{array}{l}\text { Backscatter } \\
\text { Communication }\end{array}$ & $\begin{array}{l}\text { Amplify and Forward } \\
\text { Relay }\end{array}$ \\
\hline Hardware architecture & Passive elements & Active elements & Active elements & Active elements \\
\hline Power consumption & Low & High & High & High \\
\hline $\begin{array}{l}\text { Environment propagation } \\
\text { control }\end{array}$ & $\begin{array}{l}\text { Adjusts the phase shift } \\
\text { through smart controllers. }\end{array}$ & $\begin{array}{l}\text { Reflects received signal } \\
\text { from external sources such } \\
\text { as TV. }\end{array}$ & $\begin{array}{l}\text { The backscatter signals are } \\
\text { weak and with a } \\
\text { low signal-to-noise ratio. }\end{array}$ & $\begin{array}{l}\text { Amplifies received signal } \\
\text { and receiver noise. }\end{array}$ \\
\hline $\begin{array}{l}\text { Noise effect } \\
\text { received signal. }\end{array}$ & $\begin{array}{l}\text { The use of artificial noise } \\
\text { is helpful to the } \\
\text { system [151]. }\end{array}$ & Low & Low \\
\hline Leployment
\end{tabular}

Challenges with Reconfigurable Intelligent Surfaces

Although the RIS looks promising to facilitate communication beyond 5G, some challenges have been posed. In [152], the limitation in the phase range of unit cells making up the aperture was identified. Achieving a full-phase range may require complex cell topology, which would increase hardware complexity. Increasing hardware complexity defeats the aim of energy efficiency proposed in 6G networks. Another challenge identified is the quantization of the phase range of the unit cells. The flexibility of RIS is also desired so it can adjust to the dynamic characteristic of the reflected wavefront.

Dynamic modulation of RIS using low-power semiconductor elements such as PIN diode was proposed to address dynamic reconfigurability problems [152,153]. This was implemented in [67], and a variable resistor load was also proposed to control the reflection amplitude. However, controlling the reflection amplitude and phase shift is costly in practice because it is better to implement discrete amplitude/phase-shift levels that require a small amount of electromechanical systems, i.e., microelectromechanical systems (MEMS) [135] have made reconfiguring easy, through controlling phase shifters in real-time.

Another challenge associated with the RIS is estimating the channel information [135,154], correctly. Most of the existing works have been based on the conjecture that RIS has perfect channel state information. This has not been proved to be true and highly unlikely in practice because the RIS does not have radio resources for channel estimation [155], although equipping the RIS with a low-power RF chain for channel estimation capability has been proposed [67]. However, this compromises the reduced complexity and energy-saving features desired in 6G networks. Ironically, RIS can be deployed to allow energy transfer [156]. The high-dimensional channels are estimated in severe under-sampling constraints [152], making accurate estimation of Channel Information challenging. Consequently, it is difficult to actualize the RIS phase control due to imperfect channel estimation and hardware complexity [87].

Models have been proposed to resolve the challenge of channel estimation, one of which is the Ray-tracing-based methods [157], which were proposed to estimate the channel information by the authors in [18]. However, they are costly and require stringent site information [67]. In [152], the knowledge of signal covariance matrix through extensive research in random matrix theory and high-dimensional statistics was proposed. This corroborates the dependence on basic sciences as suggested in [40]. The authors in [158] proposed a three-stage mechanism for channel estimation: sparse matrix factorization, ambiguity elimination, and matrix completion, respectively. The methods used were based on mathematical tools of random spatial processes and stochastic geometry. The theoretical framework used was validated with Monte Carlo Simulation. A minimum mean squared error (MMSE) based channel estimation protocol between the BS and RIS to serially estimate each RIS link was proposed in [155]. Machine learning, Deep learning, 
and Federated learning models have also been proposed to help resolve this challenge at a lower computational cost [159-161].

A deep reinforcement learning model was proposed in [162] to predict the RIS reflection matrices with minimal training overhead. A joint compressive sensing and deep learning solution were also proposed in [159]. This designs the LIS reflection matrix with negligible training overhead. The idea presented in the paper, however auspicious, was proved in theory but not assessed with practical data. Further research is needed in researching this with practical implementation. Although this is a daunting task as Machine learning methods are not error-free, getting training data sufficient for deep learning models is quite cumbersome [163]. Nevertheless, this is a viable research area to explore. It is imperative to model the channel with real practical data to assess its accuracy and compare it with existing channel estimation models that have been deployed.

\subsection{UAVs/ Satellite Communication}

Unmanned Aerial Vehicles (UAVs), also known as a swarm of self-governing drones [164], are aircrafts without a human pilot onboard the flying network (thus the name "unmanned") [165]. It is supported by a control system and a human who controls it remotely [166]. They are usually deployed in military applications [167]. Other applications in traffic monitoring [168,169], fire detection [167,170], maritime services, filmmaking, journalism [171], smart farming, remote surveillance, business and industry, and more have been seen over the years. We believe UAVs are key in actualizing future wireless networks, and this has been corroborated by various researchers [172,173].

The Internet of Space Things, comprising of CubeSats and UAVs, is also proposed in [31] to enable key technology for 6G and beyond. CubeSats, which are also known as U-class spacecraft, are miniaturized several spacecraft with sizes which are multiples of $\mathrm{U}$, up to $6 \mathrm{U}$, and $\mathrm{U}$ being $10 \times 10 \times 10 \mathrm{~cm}$ cubic units. They have a lower unit cost [31] as they weigh less [38] and, in most cases, share a rocket with a larger satellite [38]. CubeSats are currently deployed in earth sensing [174,175], positioning [176], IoT [177], machineto-machine communication [37]. Other applications to science and commerce are treated in [178]. Figure 6 shows how UAV and CubeSats can enable ubiquitous connectivity.

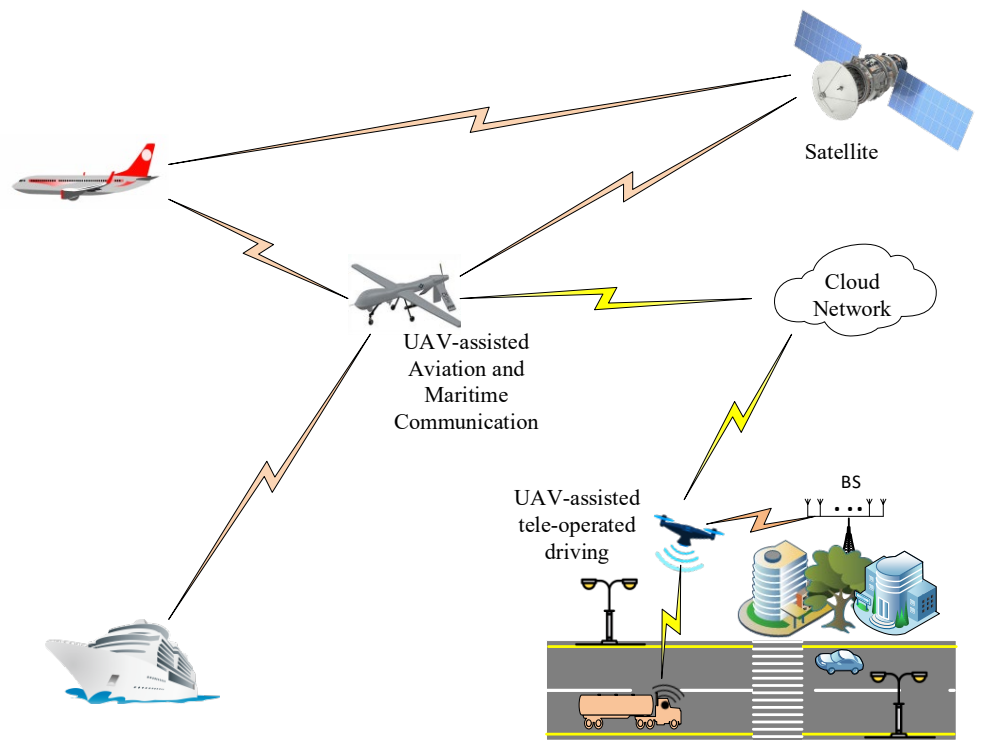

Figure 6. UAV/CubeSat facilitated ubiquitous connectivity.

\subsubsection{Applications of Unmanned Aerial Vehicles}

Several application scenarios for Millimeterwave-empowered Unmanned aerial vehicle (mmWave-UAV) such as access point, communication terminal, and backbone link are investigated in [179]. The work demonstrates the coupling relationship between mmWave 
beamforming and UAV positioning for optimal mmWave-UAV communication. Furthermore, the key enabling techniques for UAV communications, joint $\mathrm{Tx} / \mathrm{Rx}$ beam alignment, beam tracking, multi-beam forming, full-duplex relaying, and the potential challenges are discussed extensively. Remote Controlled Unmanned Aerial Vehicles (RC-UAVs) are envisioned to aid heterogeneous wireless communication [180]. Cooperative game theory was deployed to select the best UAV during the handover process and optimize handover among UAVs by reducing; handover latency, end-to-end delay, and signalling overheads. Further, Software Defined Network with Media Independent Handover UAV (SDN-MIHUAV) architecture was employed as forwarding switches to achieve seamless mobility.

The flying networks can be deployed to provide internet services to disaster-struck areas. It will facilitate the ubiquitous connectivity being desired in 6G networks. It is one of the major enabling technologies for achieving ultra-low latency communication [24]. UAVs also have a more robust line of sight than fixed BS and degree of freedom controlled by mobility. This is an ongoing development in harnessing the enormous potentials of UAVs for wireless communication. UAVs can withstand geographical and environmental limitations on wireless communications such as ships on the ocean. Facebook is partnering with Airbus to make drones that beam the internet from high altitudes. This helps to provide wireless connectivity in rural areas. A similar trend is Google deploying Loon in some rural communities. However, this uses balloons and not UAVs. UAVs are different from Satellite communication as they operate at a much lower altitude. The swarm of self-governing drones also possesses flexibility and can be used to collect, deliver, and transmit telematics. They also help with mobility and handover management in wireless networks [42,165].

\subsubsection{CubeSat Communication}

Satellite communication will be key in actualizing $6 \mathrm{G}$ networks, and miniaturized or small satellites are being developed. Small satellites have a relatively low design and deployment cost. They also have lower implementation complexity. These satellites are deployed in Low Earth Orbit (LEOs), which allows them to have a low latency communication. LEO satellites are proposed in [82] as the most prospective satellite communication. For example, SpaceX, Facebook, OneWeb, and recently, Amazon are the key players who have existing LEO satellite projects for internet-beaming [181].

There are different satellites based on their weights; pico-satellites, also known as CubeSats, have emerged as the most popular [182]. However, most of the CubeSats research focused on remote-sensing applications and not much consideration on communication applications. The authors proposed the Internet of Space things in [37], and CubeSats will be a powerful technology to facilitate this. Additionally, it is worthy to note that some literature has expanded space communication to include high altitude and Geostationary Orbit Satellite (GEO) $[183,184]$. Table 11 compares UAV and CubeSat communication, comparing the altitude, control, dimensionality, and power control.

Table 11. A comparison of UAVs and CubeSats.

\begin{tabular}{cc}
\hline UAV Communication & CubeSat Communication \\
\hline Operates at low altitude, usually no more than a few kilometers. & Operates at high altitude. \\
\hline $\begin{array}{c}\text { Flexible and more comfortable to control and configure to suit } \\
\text { the environment. }\end{array}$ & Not as flexible. \\
\hline Capable of moving in 3-dimensional movements. & Limited to 2-dimensional movements. \\
\hline Higher power consumption but can be improved. & Low Power Consumption, utilizing solar power generation. \\
\hline
\end{tabular}

Compares the features of UAVs and CubeSats. UAVs fly at a lower altitude when compared to CubeSats. UAVs can move in 3D and act as relay nodes that incorporate terrestrial and non-terrestrial communication. 


\subsubsection{Challenges with UAV/Satellite Communication}

The authors in [185] identified some challenges with UAV-enabled Wireless systems, such as the topology of the network changing with the nodes and the links altering. The routing protocol requires a complex implementation; maintaining user sessions with the intermittent transfer from an out-of-service UAV to an active UAV and energy conservation in UAVs also pose challenges. UAVs have limited communication resources, nodes are not fixed, and the channel can be impaired. Therefore, the challenges with UAVs can be categorized as challenges with resource management [186], resource allocation, routing, and energy constraints. Applications of AI-controlled UAVs have been suggested to solve these issues [24], and deep reinforcement learning is proposed to enhance handover amongst several UAVs [42].

Building the UAVs to work in different environments by enhancing the capability of the networking protocol helps to address the issue of intermittent network changes and channel impairment [185]. Optimizing interactions between nodes, such that a node can go to sleep when they are redundant, reduces power consumption and, subsequently, the energy requirement of the UAVs. Overlaying UAV-to-UAV (U2U) connection and cellular ground user uplink (GUE-UL) communication was suggested by [29] as a better alternative in urban areas for simultaneously maximizing GUE-UL performance and guaranteeing a minimum U2U coverage rate of $100 \mathrm{kps}$ to the majority of UAV pairs.

One of the significant challenges with CubeSats and other miniature satellites is the lack of a standardized channel model [187]. Some models have been presented, such as RF and optical links, but the channel presents signal attenuation because of molecular absorption and scattering losses by gas molecules and aerosols in the atmosphere. Additionally, background noise and the stars, beam divergence loss due to beam diffraction close to the receiver, atmospheric turbulence, and pointing loss attributable to satellite vibration [182]. As noted by the authors in [37], other challenges with CubeSats are long delays, signaling issues, and topological variations. There are also challenges with integration with next-generation networks, data scheduling on account of the limited transceiver. A deep learning approach was proposed in [96] to resolve resource allocation challenges in CubeSats.

\subsection{Terahertz Communication and Optical Wireless Technology}

$\mathrm{RF}$ frequency band below $6 \mathrm{GHz}$ has been exhausted, and there are research interests in higher spectrum. Spectral efficiency can be increased by increasing bandwidth while applying massive MIMO. This is achievable at higher frequency bands (millimeter-wave, Terahertz, and Free Space Optics). The authors in [188] proposed the opportunity for terabit-per-second data rates, high energy efficiency, and miniaturized transceiver size. Transmitting at higher bandwidth also makes an application such as Holographic communication, which requires very high data rate, permissible. Akyildiz et al. [69] identified some $\mathrm{THz}$ communication applications obtainable at the macroscale, microscale, and nanoscale. There has been development in a chip-wireless network on chip (WNoC)-for $\mathrm{THz}$ band transmission [189]. However, characterization of the channel has been a challenge that casts doubt on the practicability.

Rappaport et al. [12] also identified wireless cognition, hyper-active position location, sensing, and imaging as some of the applications obtainable when transmitting above the $100 \mathrm{GHz}$ range. Optical Wireless Technologies such as light fidelity, visible light communication, optical camera communication, and Free-Space Optical (FSO) communication have been used since the $4 \mathrm{G}$. They provide a high data rate, low latency, and security [48]. VLC is a good cost-effective means of alleviating the challenge of spectrum shortage in the sub $6 \mathrm{GHz}$ band. It provides a higher frequency spectrum and dual utility for light bulbs: illumination and communication [190]. It makes communication achievable wherever light bulbs are being used, thereby facilitating the ubiquitous connectivity expected in 6G networks [191]. 
Furthermore, they also facilitate underwater communication [192]. VLC possesses high bandwidth, and it is immune to interference from other electromagnetic sources [15]. VLC also provides system security [193], and it is expected to break the terabit-per second barrier [6]. FSO allows broadband communication through the transmission of modulated light signals through free space [194]. This provides a cost-effective alternative communication for a low-income population [195]. It can be deployed in terrestrial and inter-satellite communication [16]. Table 12 compares $\mathrm{THz}$ and other spectrum bands such as mmWave, VLC, and FSO.

Table 12. Comparison of mmWave, THz, VLC and FSO.

\begin{tabular}{|c|c|c|c|c|}
\hline $\begin{array}{l}\text { Network } \\
\text { Characteristics }\end{array}$ & mmWave & THz & VLC & FSO \\
\hline Frequency range & $30-300 \mathrm{GHz}$ & $0.3-10 \mathrm{THz}$ & $400-800 \mathrm{THz}$ & $187-400 \mathrm{THz}$ \\
\hline Wireless Generation & $5 G$ & B5G & 4G, 5G, B5G & $4 \mathrm{G}, 5 \mathrm{G}, \mathrm{B} 5 \mathrm{G}$ \\
\hline Data rate & $1-20 \mathrm{Gbps}$ & 100 Gbps-1 Tbps & 4-15 Gbps [196] & 13 Tbps \\
\hline Hardware architecture & $\begin{array}{l}\text { Large scale antenna } \\
\text { array at the BS [197] }\end{array}$ & $\begin{array}{l}\text { Photonics and } \\
\text { Electronic based } \\
\text { hardware [31] }\end{array}$ & $\begin{array}{l}\text { LEDs and Laser Diodes } \\
\text { (LD) in Visible } \\
\text { light range }\end{array}$ & $\begin{array}{l}\text { Point-to-point lasers in } \\
\text { the infrared range }\end{array}$ \\
\hline Transmission distance & $5 \mathrm{~km}$ & $10-100 \mathrm{~m}$ & $15 \mathrm{~cm}-197 \mathrm{~cm}$ [196] & $4 \mathrm{~km}$ \\
\hline Applications & $\begin{array}{l}\text { Telecommunication, } \\
\text { radio astronomy, } \\
\text { remote sensing, } \\
\text { automotive radars }\end{array}$ & $\begin{array}{l}\text { Wireless cognition, } \\
\text { hyper-active position } \\
\text { location, sensing, } \\
\text { and imaging }\end{array}$ & $\begin{array}{l}\text { Indoor and Outdoor } \\
\text { communication }\end{array}$ & $\begin{array}{l}\text { Outdoor } \\
\text { communication, } \\
\text { Storage Area Network, } \\
\text { Military access [195] }\end{array}$ \\
\hline
\end{tabular}

This table compares THz transmission with other higher frequency transmissions such as mmWave, and emerging OWT such as VLC and FSO. The hardware architecture, applications, and more are also considered.

\section{Challenges with Terahertz Communication and OWT}

$\mathrm{THz}$ communication has inherent short propagation capability. It becomes difficult to detect weak signals as sensitivity decreases at the THz range [198]. At higher frequencies, bond cables suffer signal degradation. As presented by the authors in [8], communication in the $\mathrm{THz}$ range is susceptible to severe path-loss and atmospheric absorption, hardware compatibility, waveform, channels, and protocols. The authors in [152] also presented three challenges with transmitting at a higher frequency band: packaging and interconnect techniques that provide reliable interconnection between interior and exterior environment, transceiver design that meets the compact physical size power efficiency, and issue with standardization and measurements [199]. They suggested cutting-edge technology in micro-machining, low-temperature co-fired ceramic (LTCC) [200], and additive manufacturing techniques in improving packaging challenges. Spatially over-sampled antennas and phased array architectures can be leveraged to improve the transceiver design, and electrooptic sampling can solve the issue of measurements. Spatially over-sampled antenna, new phased-array antenna, and compact computational approaches also are promising in actualizing accurate beam steering with less exponential power [12].

Yifei et al. [49] also identified the following challenges with $\mathrm{THz}$ communication: severe path-loss, weak diffraction effect at short wavelength, excessive attenuation from the resonance of molecules in the air, and weak diffraction that result in sensitivity to blocking and shadows, superfast channel fluctuation. Zhai et al. [201] proposed THzphism, a frequency-based beam spreading technique that utilizes several true-time delay (TTD) devices in a phased array antenna. This helps to improve angular coverage while maintaining the distance covered by the $\mathrm{THz}$ system. This encourages the adoption of phased-arraybased beamforming in reducing severe pathloss. Precoding techniques such as analog beamforming, hybrid precoding, and delay-phase precoding were also proposed by the authors in [202] as providential in reducing the severe-path loss challenge experienced in $\mathrm{THz}$ transmission. 
Akyildiz et al. [69] considered the challenges associated with THz band device technologies and $\mathrm{THz}$ band communication networks. They also identified security as another challenge of THz band systems. Petrov et al. [188] identified the following challenges associated with $\mathrm{THz}$ transmission: design of supporting $\mathrm{THz}$ electronics, $\mathrm{THz}$ channel modeling [187], coverage planning, effective medium access control, and support for nodes mobility. Ideally, a photonic solution would be a viable option for transmission in $\mathrm{THz}[49,203]$, but it has a larger component size [45]. Plasmon-based THz link components have also been promising in facilitating $\mathrm{THz}$ communication as they have miniaturized sizes and operate at ultra-high data rates [45].

Hybridization of micro-LED matrices and CMOS driver arrays on a single chip will also be required to solve the challenges of huge matrices [6]. As the Doppler effect is more severe in the $\mathrm{THz}$ range and channel status is always changing, spatial consistency is proposed to give realistic and updated CIRs [12]. The authors in [6] also presented the need for the complex device by parallelizing several chips and introducing a dedicated optical imaging system leading to optical beamforming, which will significantly increase cellular throughput. A CMOS-based modulation circuit was proposed in [41] to get an improved performance gain.

VLC is posed with the challenge of interference with ambient light sources, and it is proposed that increase in VLC devices will result in interference between VLC devices [15]. Signal jamming [204] and data snooping are also some of the security challenges with VLC that need to be resolved [193]. Handover management, configuration algorithm for both illumination and configuration, and compatibility with existing spectrums are challenges identified with VLC [190]. LED transmissions provide a short-range susceptible to absorption, shadowing, and beam dispersion [191]. VLC and FSO require line of sight for communication. Non-light sight communication attributable to obstruction on the beam path makes communication difficult. There is also doubt on the safety of lasers [194]. Just as VLC, FSO is susceptible to absorption, scattering, scintillation, atmospheric turbulence, and other hostile environmental conditions [195,205]. Geometric loss, background noise, and misalignment error are other challenges of FSO identified in [86].

\subsection{Cell-Free Massive MIMO}

The combination of Time Division Duplex (TDD), massive MIMO operation [206], densely distributed network [207], and user-centric network [208] refers to the ubiquitous cell-free massive MIMO [22]. Cell-free Massive MIMO, which is the generally adopted terminology, combines the distributed MIMO and Massive MIMO [68] concepts such that there are no boundaries and cells in the network. This allows users to move seamlessly from one network to another. It cancels out interference problems and reduces the frequent handover experienced in current networks, thereby improving user experience. Figure 7 shows a pictorial layout of the Cell-free Massive MIMO communication system.

Cell-free Massive MIMO has significantly outperformed existing small-cell systems throughput and more resistant to shadow fading correlation [68]. Massive MIMO was proposed by Alamu et al. [209] to improve Energy Efficiency and Spectral Efficiency. Utilizing spatial multiplexing in Massive MIMO allows multiple users to share spectrum resources efficiently. Cell-free Massive MIMO presents high spectral efficiency, system scalability, and almost-optimal linear processing [22]. It can also meet the requirements of ubiquitous, ultra-reliable low latency communication desired in $6 \mathrm{G}$ networks. The potentials of larger intelligent surfaces (LIS) in Massive MIMO operations have been identified in [20] and also in LEO satellite communications using full frequency reuse (FFR) [210]. 


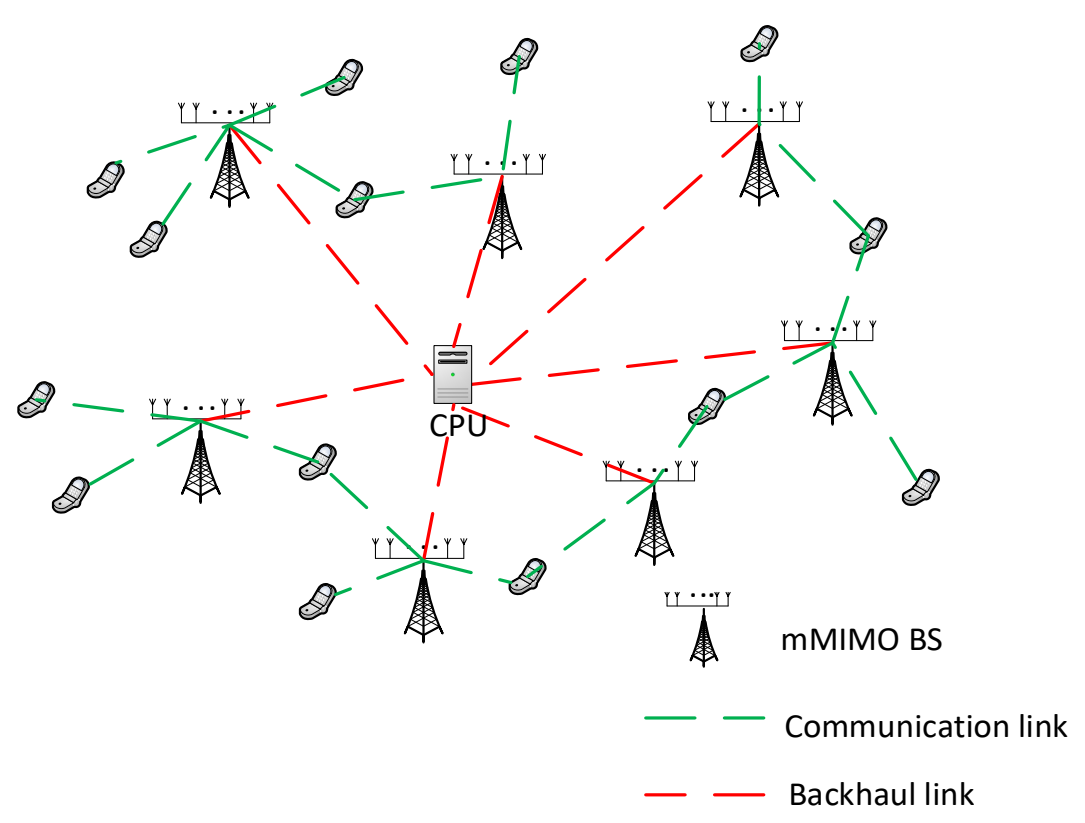

Figure 7. An illustration of Cell-free Massive MIMO.

Challenges with Cell-Free Massive MIMO

One major challenge with cell-free massive MIMO is obtaining accurate Channel State Information (CSI) [22,133]. There are also challenges with practical deployment. There is cost/complexity of the deployment, limited backhaul capacity [211], network synchronization, and a cost-effective radio stripe system presented in [22]. Issues such as practical control, distributed signal processing, resource allocation, channel modeling [187], and estimation were raised [22]. There have been efforts to circumvent this challenge of channel estimation. The authors in [133] proposed Machine Learning (ML) as a primary tool for channel estimation and channel charting through unsupervised learning as a promising future direction. However, concerns about active eavesdropping have been raised [212], which casts doubt on the security of these systems.

To improve security, Hoang et al. [212] suggested maximization problems to maximize the achievable secrecy rate subject to the quality of service constraints. There may be a trade-off problem between secrecy rate and energy consumption in future cell-free massive MIMO networks. Matthaiou et al. [152] identified the following challenges with the cell-free Massive MIMO: practical user-centric approaches, scalable power control, and the need for advanced distributed signal processing (SP). These are areas that need research focus.

\subsection{Blockchain and Distributed Ledger Systems}

Many papers addressing the vision and requirements have proposed blockchain adoption in 6G wireless networks $[47,81]$. Blockchain is proposed to provide network decentralization $[6,40]$, spectrum sharing $[9,81,95]$, and security $[41,45,48]$. The authors in [47] presented blockchain as one of the applications of 6G. Blockchain is a form of distributed ledger [48] that serves as a database with several nodes replicating and saving an identical copy of the ledger. It is a perfect complement to the massive IoT with improved interoperability, security, privacy, reliability, and scalability [32,213]. This makes it a good enabling technology to improve the integrity and security of future wireless networks.

Blockchain is also being considered for the fledgling 5G communication network. Blockchain was proposed to give 5G IoT integrity, accelerated data change, lower cost, security, immutability [32]. Integration of machine learning with blockchain in 5G and beyond has also been proposed [28]. Blockchain provides real-time data delivery, resilience, and low latency to the network [214]. The integration of edge computing with blockchain is also a desirable research field. This provides reliable access and control of the network, 
storage computation over a large number of distributed edge nodes, and improved network security, data integrity, and computation validity of the system [215]. Jocovic et al. [216] proposed integrating Interplanetary File System (IPFS) and blockchain to provide enormously high security, transparency, credibility, and immutability of stored data. The application of Blockchain in UAVs is also being considered [28].

\section{Challenges with Blockchain Technology}

Although blockchain technology is proposed to give security and privacy to future wireless networks, the system on its own is not resistant to cyber-attacks. Security and privacy have been identified as concerns in blockchain technology [217]. Xie et al. [217] also identified a limited throughput, energy efficiency, lack of incentive and punishment mechanism and regulation as some of the challenges associated with blockchain application in smart cities, enabled by wireless communication. Scalability has also been identified as a challenge in blockchain deployment [28,215].

Yang et al. [215] also identified research challenges with integrated blockchain and edge computing systems such as scalability enhancement, security and privacy, selforganization, function integration, and resource management. The integrity provided by the immutability of the blockchain comes at the expense of higher computational capability and delay performance. This can be resolved by applying the edge cloud [79]. Big Data can also be adapted to perform pattern recognition on ledger transactions to give more security. AI can also be leveraged to design a new generation blockchain that supports automatic generation of smart contacts, enhanced security under malicious attacks, and highly flexible operations [215].

\subsection{Ambient Backscatter Communication}

Ambient backscatter (AB) was proposed by [6] to enable tiny devices to operate without a battery, such that they are powered by redirecting ambient RF signals without requiring active RF transmission. Ambient backscatter communication is a form of backscatter communication that can harvest energy from devices in its "ambient" environment such as Wi-Fi, TV, and RF signal to modulate information [218]. When this passive backscatter system is integrated with an active transmission system, it forms the symbiotic radio (SR) [219]. This addresses the energy efficiency problems in low-power consumption devices such as sensor networks. This helps to reduce the cost of devices with low-power components and reduced infrastructure [31]. There is also no need to allocate a different frequency spectrum for ambient backscattering communication systems (ABCS), thereby improving spectrum resource utilization [27]. When perfected, ambient backscatter communication will enhance the battery life of mobile devices [218].

Ambient Backscatter Communication $(\mathrm{ABC})$ sensors were deployed to solve the problem posed by the fusion of local decisions over multiple-access fading channels in WSN, considering the IoT vertical [220]. ABC sensors are deployed to detect the presence or absence of a given phenomenon and transmit their decisions to a multiple-antenna fusion center reader (FCR). In this case, a part of an incident RF ambient signal is reflected. This facilitates the development of decision fusion rules in the full and statistical channel state information (CSI) scenarios to enhance their implementation and lower computational complexity. To increase the data rate of passive transceiver-to-transceiver communications for ambient backscatter (AB), Qian et al. [221] employed M-PSK for backscattering and derived the optimal multi-level energy detector and the closed-form symbol error rate (SER). A 4PSK-AB hardware prototype that gives a data rate of $20 \mathrm{~kb} / \mathrm{s}$ was developed to integrate the 4PSK-modulated transmitter, multilevel detector, and energy harvester. Recently, the issue of symbol detection in ABCS with the multi-antenna reader was addressed [222]. Leveraging the ON-OFF keying modulation, the optimal detector, which can avoid the error floor phenomenon, was devised. Additionally, multiple antennas are employed at the reader to improve the bit error rate (BER) $[223,224]$ and extend the 
tag-reader communication range. Table 13 compares ambient backscatter communication with traditional backscatter communication.

Table 13. Differences between traditional backscatter and ambient backscatter communication systems.

\begin{tabular}{cc}
\hline Ambient Backscatter Communication & Traditional Backscatter Communication \\
\hline Utilizes ambient RF & Requires special-purpose power infrastructure, e.g., RFID reader \\
\hline Provides device-to-device(D2D) communication & Does not provide D2D communication \\
\hline Energy-efficient as ambient energy is utilized & Not as energy-efficient \\
\hline
\end{tabular}

This Table compares and contrasts ambient backscatter communication with traditional backscatter communication. This is with respect to the mode of operation, energy efficiency, and more.

\section{Challenges with Ambient Backscatter Communication}

There is a limited coverage area for operation as backscatter transmitters need to be placed near their RF source [27]. This means that one has to be close to the backscatter transmitter to utilize the system. This limits mobility while retaining communication. In [27], the authors also identified reduced transmission performance on account of interference between transmit and receive antenna thanks to proximity and the dynamics of ambient signals, data transmission scheduling for backscatter devices as challenges. ABCS are also susceptible to security threats [27].

Liu et al. [225] identified at least three challenges associated with ambient backscatter communication, namely: the challenge of extracting backscatter information owing to weak signals, the need for less-complex digital signal processing techniques, and hardware architecture need for a centralized controller to control communication. Challenges associated with EE and SE and compatibility with other wireless communication systems have also been identified [31].

\subsection{Quantum Communication}

One question posed by the authors in [133] is what happens when massive MIMO is combined with quantum communication or molecular communication? There have been growing research interests in quantum communications and how they can be adopted to B5G networks. Quantum computing gives high data rates and security [41]. Quantum communication [226] was proposed as enabling architecture in 6G as it has the potential of accelerating the speed of information processing leading to a more optimal solution in 6G communication [95]. Quantum communication may also provide a shield from cyberattacks through sophisticated quantum computing and quantum communication [30].

Future quantum internet is proposed to be likely based on long-distance quantum optical communication suitably interfaced with solid-state nodes for quantum information processing [227]. There are also interests in quantum-based satellite communication [228] and quantum machine learning and deep learning for 6G [229]. Quantum computing can significantly accelerate and enhance AI algorithms that require big data and massive training [81]. The concept of quantum optical communication opens up innovation in telecommunication and ICT, and quantum optics is a providential paradigm for the transmission and control of optical signals to have a better degree of freedom [26]. The authors in [26] delineated the infusion of quantum and $\mathrm{THz}$ communication in the actualization of 6G.

\section{Challenges with Quantum Communication}

While channels of classical computing are well treated within the framework of classical information theory, the quantum channel is not entirely understood [229]. Constraints identified in quantum internet by authors in [230] are quantum measurement, entanglement, non-cloning, and teleporting. Getting supporting infrastructure for quantum communication with quantum switches and routers becomes difficult as a result of the non-cloning theorem [229]. Cacciapuoti et al. [230] also identified decoherence and fidelity, entanglement distribution, and deployment challenges as some of the challenges associ- 
ated with quantum communication. Blockchain has been suggested to enable security and privacy in quantum communication [28,217].

Table 14 compares these enabling technologies and how they facilitate the requirements desirable in $6 \mathrm{G}$.

Table 14. Assessment of the enabling technologies and the desired requirements in 6G.

\begin{tabular}{|c|c|c|c|c|c|c|c|c|}
\hline $\begin{array}{l}\text { Enabling } \\
\text { Technology }\end{array}$ & $\begin{array}{l}\text { High Data } \\
\text { Rate }\end{array}$ & $\begin{array}{l}\text { Security, } \\
\text { Privacy, } \\
\text { Integrity }\end{array}$ & $\begin{array}{l}\text { Ultra- } \\
\text { Reliable Low } \\
\text { Latency }\end{array}$ & $\begin{array}{c}\text { Spectrum } \\
\text { Allocation } \\
\text { and Efficiency }\end{array}$ & Scalability & $\begin{array}{l}\text { Energy } \\
\text { Efficiency }\end{array}$ & $\begin{array}{l}\text { User-Centric } \\
\text { Services }\end{array}$ & $\begin{array}{l}\text { Ubiquitous } \\
\text { Connectivity }\end{array}$ \\
\hline Pervasive AI & $\checkmark$ & $\checkmark$ & & $\checkmark$ & $x$ & $\checkmark$ & $\checkmark$ & $\checkmark$ \\
\hline IRS & $\checkmark$ & $\checkmark$ & & & & $\checkmark$ & $\checkmark$ & $\checkmark$ \\
\hline UAV/CubeSat & & & $\checkmark$ & $x$ & & & & $\boldsymbol{\nu}$ \\
\hline Blockchain & & $\checkmark$ & $\checkmark$ & $\checkmark$ & $x$ & & & \\
\hline TeraHertz/OWT & $\checkmark$ & $\checkmark$ & $\checkmark$ & & & & & $\checkmark$ \\
\hline $\begin{array}{c}\text { Cell-Free } \\
\text { Massive MIMO }\end{array}$ & $\checkmark$ & & $\checkmark$ & $\boldsymbol{v}$ & $\checkmark$ & $\boldsymbol{\nu}$ & $\boldsymbol{v}$ & $\boldsymbol{\nu}$ \\
\hline $\begin{array}{c}\text { Quantum } \\
\text { Communication }\end{array}$ & $\checkmark$ & $\checkmark$ & & & & & & \\
\hline $\begin{array}{c}\text { Ambient } \\
\text { Backscatter } \\
\text { Communication }\end{array}$ & $\checkmark$ & & & & & $\checkmark$ & & \\
\hline
\end{tabular}

$\boldsymbol{V}$-Support; $\boldsymbol{x}$-Do not support Blank- Link not established. This table maps the enabling technologies treated to selected requirements such as energy efficiency, high data rate, and more. Additionally, requirements that some enabling technologies do not favor or serve more as challenges are noted. The blank spaces are requirements that have no direct link with the mapped enabling technology, e.g., ambient backscatter is more directly related to energy efficiency, and the link has not been established with latency and other fields that are conspicuously blank.

\section{6G Applications}

Every generation of wireless networks has facilitated new applications, and 6G is not an exception. The need for higher data rates, lower latency, high reliability, and more have given rise to the development and deployment of new wireless generation networks. In this section, we examine the applications to be facilitated by 6G. Although these or similar applications have been proposed to be enabled by 5G, 5G cannot meet the requirements to facilitate these applications seamlessly at the current development stage. Some limitations in 5G, such as scarce bandwidth and high-energy consumption, have been identified [231]. Although 5G tests have shown prospects with the actualization of a data rate of $8 \mathrm{Gbps}$ [232] and $1 \mathrm{Gbps}$ at $6.5 \mathrm{~km}$ distance [233], these are still below the peak data of $20 \mathrm{Gbps}$ proposed in the literature. Therefore, existing 5G networks cannot meet high-speed intensive applications such as holographic communication, which require 1 Tbps for seamless communication [39]. Other limitations identified with 5G wireless networks are high interference due to massive interconnection, insufficient computing capacity, and lack of ubiquitous connectivity. Hence there is a need for 6G communication, which promises better features than $5 \mathrm{G}$.

Some of the applications to be facilitated and fully enabled by 6G are holographic communication, teleoperated driving, tactile internet, Industry 4.0, and more. New applications that were not considered in the 5G context, such as IoBNT and Digital replica, are also introduced in this paper. Table 15 gives a summarized description of these applications. Furthermore, we outline the challenges in achieving some of these applications. Additionally, desirable features of these applications are considered. These applications, the 5G limitations, and how 6G wireless networks will enable them are highlighted in this section. In this literature, it has been established that the existing features of 5G are not efficient enough to enable the requirements of these technologies. We consider each application in this section, pointing out some of the requirements that make $6 \mathrm{G}$ an ideal candidate for these applications. 
Table 15. Brief description of 6G applications.

\section{Applications}

Holographic Communication

Tactile Internet

Industry 4.0 and beyond

Teleoperated Driving

Internet Bio-Nano Things

Multisensory XR Applications

Blockchain and Distributed Ledger Technologies

Connected Robotics and Autonomous Systems (CRAS)

Wireless Brain-Computer Interface (BCI)

Digital Replica
Brief Descriptions

This enables human communication through holographs-3D images in thin air. To improve the experience of remote communication as we embrace a borderless workplace. Latency and high bandwidths are some of the challenges associated with Holographic Communication. 6G will solve these challenges.

Enables human-to-machine interactions and machine-to-machine interactions.

Comprises cyber-physical systems, IoT, and cloud computing.

Additionally, AI and ultra-fast wireless networks will drive the 4th industrial revolution. This enables smart cities, factories which are some of the vision for $6 \mathrm{G}$.

Allows cars to be controlled remotely. These cars are also referred to as semi-autonomous vehicles. Semi-autonomous cars require a fast and ubiquitous wireless network with ultra-low latency.

An interconnection of biological nano-sized objects(nanomachines). Takes application largely in healthcare. $6 \mathrm{G}$ is proposed to provide the perceptual requirements and ultra-low latency required by IoBNT.

AR/MR/VR that incorporates perceptual experience. Supported by URLLC and eMBB and perceptual factors to be supported by 6G. An excellent candidate to provide a better gaming experience.

Blockchain is postulated to provide security for $6 \mathrm{G}$ networks. They also require low latency, reliable connectivity, and scalability, which $6 \mathrm{G}$ networks will provide.

CRAS is required to improve industrialization through the use of robots and autonomous systems for industrial operations. They require a high rate and reliability and low latency.

$\mathrm{BCI}$ enables the communication between the brain and electronic devices. This requires ultra-low latency, high reliability, and high data rate.

These are also called digital twins, and they create a digital copy to replace people, places, systems, objects. This requires a very high data rate, which $6 \mathrm{G}$ will enable.

This table acts as a guide for the applications considered in this section. The brief descriptions are highlighted to give the reader a background knowledge of the applications, which would be expatiated as the section progresses.

\subsection{Holographic Communication}

Holography utilizes a laser beam to produce images. This concept has been used in color motion holography [234], metasurface holography [235], 3D holographic display [236], and holographic type communication (HTC) $[237,238]$. New 5G enabled disruptive technology is used in persuasion for real-time holograms [239]. An exciting feature of 5G technology is hologram generation and delivery [240]. Timing synchronization setting for transmission jitter of less than a microsecond is required in multi-stream holographic applications. More reliable remote surgery needs latency of less than $1 \mathrm{~ms}$, which is extremely difficult to achieve in the current $5 \mathrm{G}$ systems [6,241]. Although some promising results have been discovered in $5 \mathrm{G}$ research, $1 \mathrm{Gbps}$ was achieved over a $6.5 \mathrm{~km}$ distance, giving a world record [233]. This has been experimented with in the $26 \mathrm{GHz}$ range. However, this is still way below the requirements needed to enable full holographic support in the order of 1Tbps [39]. Therefore, the major challenge with holographic communication is high data-rate and low latency [10]. To achieve seamless holographic communication, extremely high data transmission, hundreds of times more than what is obtainable in 5G systems, is required [8].

With $6 \mathrm{G}$ wireless networks proposed to have a data rate in the order of 1Tbps and ultra-low or non-existing latency, holographic communication will cease to be just a utopian 
technology limited to movies. As we go higher in the frequency spectrum, and with technologies such as VLC and more, higher data rates would be achieved. A truly ubiquitous environment empowered by real-time holograms could make smart devices appear like horse carriages. Peak data rates would reach Tbit/s in the 2030s, which will require massive bandwidths availability. The huge data rate would enable $16 \mathrm{~K}$ video resolution in 360 degrees with a refresh rate of $240 \mathrm{~Hz}$ required for holographic displays [242]. 6G is expected to meet these requirements to support the massive transmission of real-time data over the air. Furthermore, 6G-empowered XR technologies and holograms supported by advanced AI techniques would help clear the time and space barriers to advance remote surgery [240].

Microsoft developed Holo Lens, and this has stirred more research interests in this field. Projects such as Holoportation, Ada, and many more, cutting across engineering, commerce, games, etc. Spatial, a virtual communication application that uses Microsoft Holo Lens 2. This allows workers in different locations to communicate using avatars or holographic shapes of themselves. An effective holographic video conferencing enhances the borderless workplace experience where people can work from home. The holographic display has also been primarily embraced in recent times. The holographic display market is projected to reach USD 3576 million by 2020 from USD 567 million in 2013 [243], USD 7.6 billion in 2023, and projected to nearly USD 1 trillion in 2030.

\subsection{Teleoperated Driving}

$6 \mathrm{G}$ is proposed to increase the functionality of Autonomous Driving. There is interest in teleoperated driving (or semi-autonomous vehicles) where a human controls the vehicle remotely. Teleoperated driving has been used in deep-sea and space exploration. Companies such as Ericsson and Huawei have tested teleoperation on 5G networks [244]. Teleoperated driving will require ultra-low latency that communicates signals and instructions between the driver and the vehicle, especially in the face of danger where an immediate response is needed. This, if achieved optimally, will enhance car-rental services of the future. A high level of security, privacy, and network integrity is also desired. Although research is towards fully autonomous vehicles, teleoperation is desired when autonomous mode fails or a complicated scenario requires human intervention. Autonomous vehicles are being considered under the scope of the emerging 5G [245]. However, the 5G at its current development state cannot meet the actual requirements of a fully developed $5 \mathrm{G}$ wireless network. Thus, the need for $6 \mathrm{G}$ wireless network development.

\subsection{Tactile Internet}

Tactile internet enables haptic interaction with machines, giving rise to visual feedback and robotic control. This facilitates efficient human-to-machine interaction, machine-tomachine interaction, with key examples found in industry, robotics and telepresence, virtual reality, augmented reality, healthcare, road traffic, education and culture, and smart grid [246]. This technology is useful where human presence is needed to carry out a task [39]. A valuable application of tactile internet is in telesurgery, allowing surgeons to perform surgery remotely [247]. The major challenge with tactile internet is having a seamless network and a delay that humans do not perceive. To achieve this, low latency of $1 \mathrm{~ms}$ is required- this is the primary requirement for tactile internet. This was projected to be achievable in 5G. However, tests have shown existing $5 \mathrm{G}$ networks to have a latency of 10-16 ms. Therefore, it is expected that $6 \mathrm{G}$ wireless networks, which are proposed to have a latency of less than $1 \mathrm{~ms}$, will enable tactile internet and haptic communication. Additionally, precision with very high accuracy is desirable [164] and will be facilitated by 6G. Another desirable feature of tactile internet is security; blockchain, a proposed enabling technology for 6G, has been proposed to allow for a trusted, secured, and reliable tactile internet architecture [217]. 


\subsection{Internet of Bio-Nano Things (IoBNT)}

Research advances in nanotechnology and communication engineering have engendered embedded computing devices based on graphene and metamaterials. Although artificial materials (i.e., synthesized materials, electronic circuits, etc.) have been developed, a more biological application is preferred using biological cells and interfacing the bio-chemical interaction with the electrical domain. This is to lower the risk of exposure to toxicity associated with artificial devices. These devices can perform intra-body sensing, actuation, processing, and networking with a small size and implanted. They have a low data-storage capacity and low transmission range [39]. The Internet of Bio-Nano Things is proposed to be applied in health care, military, and security fields [248]. The authors in [31] identified IoBNT to aid early diagnosis of diseases, especially in the face of the COVID-19 pandemic. However, doubts that this technology might not be ripe enough for 6G have been identified [31].

Nevertheless, it will play a crucial role in future wireless networks. To enable this, challenges associated with IoBNT need to be resolved. Embedding with molecular communication (MC) is proposed to improve the range of transmission [248]. However, challenges exist in the design and development of nanodevices and coordination of molecular communication in nanodevices [249]. Additionally, there are challenges with the security and bioethics of this technology [248]. Furthermore, challenges with modeling the peculiar non-linear biological environment exists.

\subsection{Industry 4.0 and Beyond}

The fourth industrial revolution, also tagged Industry 4.0, is expected to enhance the computerization obtained in the third industrial revolution. Although 5G initiated Industry 4.0, 6G is expected to facilitate its full actualization. A combination of cyber-physical activities, IoT and IIoT, cloud computing, and AI will make Industry 4.0 achievable [250]. Some technologies that will transform Industry 4.0 are Big Data and Analytics, Autonomous Robots, IIoT, Cybersecurity, AR, Cloud, and more. High-precision manufacturing is vital to the actualization of Industry 4.0 [6], as it minimizes human intervention with no tradeoff to accuracy. This requires high reliability and extremely low latency; mMTTC and URLLC, which will be improved in 6G, makes the actualization of this possible. Industry X.0 was introduced in [31] as a succession to Industry 4.0, and 6G sets a foundation upon which this would be built. The role of big data [251] and biology [252] in industry 5.0 has been investigated. Industry 5.0 is proposed to be user-centric and personalized service-oriented [39].

\subsection{Multisensory XR Applications}

Extended reality (XR) is a term that combines VR, AR, and MR (mixed reality) [253]. It takes application in medicine, education, entertainment, and other fields of life. Research is progressing towards the actualization of full Immersive XR. A new concept of Quality of Physical Experience (QoPE) that merges human factors from the user with classical QoS and QoE was presented by the authors [47]. This facilitates the multisensory feature desired for a more user-centric experience. The main challenge, which was also pointed out in [8], is inadequate hardware capability and insufficient wireless capacity. Table 16 compares the AR, VR, and MR, which make up XR. 
Table 16. Comparing AR, VR, and MR.

\begin{tabular}{cccc}
\hline Parameter & AR & VR & MR \\
\hline Experience & $\begin{array}{c}\text { Overlays virtual object in the } \\
\text { user's environment }\end{array}$ & $\begin{array}{c}\text { Immerses user in a fully } \\
\text { artificial environment }\end{array}$ & Combines AR and VR \\
\hline Required Bandwidth & Multiples of Gbps & Multiples of Gbps [254] & Multiples of Gbps \\
\hline Required Latency & $<15 \mathrm{~ms}$ & $<15 \mathrm{~ms}$ [254] & $<15 \mathrm{~ms}$ \\
\hline Examples & Snapchat lenses, Pokemon Go & $\begin{array}{c}\text { Google Cardboard, HTC Vive, } \\
\text { Oculus Rift }\end{array}$ & Microsoft HoloLens \\
\hline
\end{tabular}

\subsection{Blockchain/Distributed Ledger Services (DLS)}

Blockchain has been identified earlier as one of the enabling technologies for the actualization of 6G. $6 \mathrm{G}$ also provides an enhanced blend of massive machine type communication (mMTC) and URLLC [255]. The reliable connectivity and ultra-low latency ensure the efficient running of DLS, thereby making the relationship symbiotic [47]. Blockchain in $5 \mathrm{G}$ and beyond has been explored in [256] to enable emerging mobile services.

\subsection{Connected Robotics and Autonomous Systems (CRAS)}

The CRAS concept was proposed as an application of 6G in [47,48]. CRAS is being developed, and systems such as autonomous cars, drone-delivery systems are gaining traction. This is applied in manufacturing and industrialization processes. CRAS requires high reliability, ultra-low latency, and high data rate that existing 5G networks cannot provide at this stage of development. $6 \mathrm{G}$ networks are expected to meet these needs.

\subsection{Wireless Brain-Computer Interaction (BCI)}

Wireless Brain-Computer Interaction (BCI) devices help support, enhance and generally improve human functions [257]. This is mostly used in health care to aid people with severe motor disabilities [258]. This requires ultra-low latency and perceptual services that $6 \mathrm{G}$ is expected to provide. This is especially very important in non-visual $\mathrm{BCI}$ for the visually impaired, which requires immediate reactions. Existing $\mathrm{BCI}$ systems are also not reliable enough to be deployed in accuracy-critical applications; the high-reliability 6G provides ameliorates this. Wireless $\mathrm{BCI}$ is more comfortable to use than the wired $\mathrm{BCI}$ thanks to the flexibility of use- users can move while using them [259]. They also have simpler connections. However, vibration and interferences from moving around are challenges that have to be overcome in wireless BCI [260].

\subsection{Digital Replica}

Digital replica, also referred to as digital twin [261] and physical twin [262], give a virtual duplicate of people, objects, places using sensors, AI, and communication technologies [8]. This has been adapted to mimic systems. It has been proposed to enable virtualization of a cyber-physical system, where safety and security analysis can be carried out without disrupting the live feed [261]. It supports an adaptive wireless protocol and provides hardware support to drop packets [263]. Users will be able to interact with digital replica through holographic display and VR devices. This paper proposes applying digital replica in tourism to have a remote experience of their desired tourist destinations. Other desirable applications are surgery and education; surgeons will create digital replicas of organs and perform surgery simulations. This is also good for teaching young surgeons. Digital twin systems have also been proposed to enhance business performance [264]. AI has been proposed to form a self-sustaining system with the digital replica [8]. Quantum optic communication has also been proposed as a key enabling technology for the actualization of the digital replica [26]. Digital replica is one of the new applications not in the context of 5G, proposed to be enabled by 6G; further research is required in this field.

The applications mentioned above, the $5 \mathrm{G}$ limitations, and how $6 \mathrm{G}$ wireless networks will enable them are highlighted in Table 17. 
Table 17. Comparative analysis of the proposed applications in 5G and 6G.

\begin{tabular}{|c|c|c|c|}
\hline Applications & 5G Proposal & 5G Limitation & 6G Facilitation \\
\hline $\begin{array}{l}\text { Holographic } \\
\text { Communication }\end{array}$ & $\begin{array}{l}\text { To provide high bandwidth, low } \\
\text { latency, security, and low energy } \\
\text { footprint [265]. }\end{array}$ & $\begin{array}{l}\text { The maximum data rate from tests } \\
\text { is } 8 \text { Gbps [232], and } 1 \text { Gbps at a } \\
\text { distance of } 6.5 \mathrm{~km} \text { [233], which is } \\
\text { below } 1 \text { Tbps proposed for } \\
\text { seamless communication [39]. }\end{array}$ & $\begin{array}{l}\text { Higher data rate through THz/OWT } \\
\text { and other enabling technologies } \\
\text { highlighted in Table } 14 \text {. } \\
\text { - Superfine time synchronization and } \\
\text { ultra-low latency [266]. } \\
\text { ABCS to improve energy efficiency } \\
\text { and to have a low energy footprint } \\
\text { on the environment. }\end{array}$ \\
\hline Tactile Internet & $\begin{array}{l}\text { A latency of } 1 \mathrm{~ms} \text { and an } \\
\text { ultra-reliable network are } \\
\text { proposed to enable tactile } \\
\text { internet [21]. }\end{array}$ & $\begin{array}{l}\text { Results from } 5 \mathrm{G} \text { tests show a } \\
\text { latency of } 10-16 \mathrm{~ms} \text {, which is } \\
\text { insufficient to support tactile } \\
\text { internet fully. }\end{array}$ & $\begin{array}{l}\text { Technologies such as UAV [267], } \\
\text { blockchain [214], OWT [48], cell-free } \\
\text { massive MIMO [22] to facilitate } \\
\text { ultra-reliability and ultra-low latency. }\end{array}$ \\
\hline $\begin{array}{l}\text { Industry } 4.0 \\
\text { and beyond }\end{array}$ & $\begin{array}{l}\text { - High reliability, ultra-low } \\
\text { latency, security, and } \\
\text { privacy [268]. } \\
\text { Mobility, energy efficiency is } \\
\text { also desirable [269]. }\end{array}$ & $\begin{array}{l}\text { - Lack ubiquitous } \\
\text { connectivity. } \\
\text { New modes of } \\
\text { cyberattacks [270]. }\end{array}$ & $\begin{array}{l}\text { To enable ultra-reliability and } \\
\text { ultra-low latency. } \\
\text { Blockchain and quantum } \\
\text { communication to improve security } \\
\text { and privacy. } \\
\text { - ABCS to improve energy efficiency. }\end{array}$ \\
\hline Teleoperated Driving & $\begin{array}{l}\text { - Massive simultaneous } \\
\text { connection and ubiquitous } \\
\text { connectivity to enable } \\
\text { autonomous and } \\
\text { semi-autonomous } \\
\text { vehicles [271]. } \\
\text { Handover management and } \\
\text { good signal strength [272]. }\end{array}$ & $\begin{array}{l}\text { - Lack of ubiquitous } \\
\text { connectivity. } \\
\text { Limited data rate with } \\
\text { increasing distance. }\end{array}$ & $\begin{array}{l}\text { The integration of } \\
\text { Space-Ground-Air-Water } \\
\text { communication expands the } \\
\text { frontiers of communication and } \\
\text { provides ubiquitous connectivity. } \\
\text { AI to improve handover } \\
\text { management [42]. }\end{array}$ \\
\hline $\begin{array}{l}\text { Internet of Bio-Nano } \\
\text { Things (IoBNT) }\end{array}$ & $\begin{array}{l}\text { Not extensively proposed } \\
\text { in the context of } 5 \mathrm{G} \text {. }\end{array}$ & $\begin{array}{l}\text { Not extensively proposed in the } \\
\text { context of } 5 \mathrm{G}\end{array}$ & $\begin{array}{l}\text { Some works of literature have proposed } \\
\text { IoBNT for beyond } 6 \mathrm{G} \text { (e.g., [31]), and we } \\
\text { believe high reliability is desirable for } \\
\text { these applications. }\end{array}$ \\
\hline $\begin{array}{l}\text { Multisensory } \\
\text { XR }\end{array}$ & $\begin{array}{l}\text { Low latency, high bandwidth, low } \\
\text { power, security [268]. }\end{array}$ & $\begin{array}{l}\text { Although existing } 5 \mathrm{G} \text { networks } \\
\text { can meet the minimum required } \\
\text { latency of } 15 \mathrm{~ms}[254] \text { for AR/VR, } \\
\text { to support a fully immersive } \\
\text { multisensory XR, a lower latency } \\
\text { (i.e., less than } 10 \mathrm{~ms} \text { ) is desirable. }\end{array}$ & $\begin{array}{l}\text { New enabling technologies proposed to } \\
\text { facilitate ultra-low latency ( }<1 \mathrm{~ms}) \text {, higher } \\
\text { bandwidth, ultra-reliable, and secured } \\
\text { wireless network. These are highlighted in } \\
\text { Table } 14 \text {. }\end{array}$ \\
\hline
\end{tabular}

\section{Blockchain} and DLS
High data rate (1-20 Gbps), low latency in the order of $1-10 \mathrm{~ms}$, and blockchain provide improved security [216].
The highest data rate achieved is 8 Gbps and latency is still within the range of $10-16 \mathrm{~ms}$.
- $\quad$ High data rate by $\mathrm{THz}$ transmission and Optical Wireless Technology (OWT).

- $\quad$ Additionally, AI, cell-free massive MIMO, and even then not fully developed quantum communication would make this a reality.
Tests have shown variable data, which is not consistent. The authors in [273] proposed a "safety-relevant" network requirement of $<12 \mathrm{~ms}$ latency and $<6 \mathrm{~ms}$ jitter. The current latency range of $5 \mathrm{G}$ goes above $12 \mathrm{~ms}$.
To provide high reliability and ultra-low latency. The enabling technologies to facilitate this have been discussed earlier under tactile internet. 
Table 17. Cont.

\begin{tabular}{|c|c|c|c|}
\hline Applications & 5G Proposal & 5G Limitation & 6G Facilitation \\
\hline Wireless BCI & Not extensively proposed & $\begin{array}{l}\text { Do not have Quality of Physical } \\
\text { Experience (QoPE) to support the } \\
\text { emerging stringent } \\
\text { requirements [257]. }\end{array}$ & $\begin{array}{ll}\text { - } & \text { To enable QoPE [47]. } \\
\text { Wireless approaching } \\
\text { nano-communication and AI } \\
\text { developing rapidly to enable edge } \\
\text { intelligence [257]. } \\
\text { Consequently, Brain Controlled } \\
\text { Vehicles (BCV), emotion-driven } \\
\text { devices, will become a reality. } \\
\text { - High reliability for the network. }\end{array}$ \\
\hline Digital Replica & $\begin{array}{l}\text { It is not extensively proposed in } \\
\text { the context of } 5 \mathrm{G} \text {. }\end{array}$ & $\begin{array}{l}\text { It is not extensively proposed in } \\
\text { the context of } 5 \mathrm{G} \text {. }\end{array}$ & $\begin{array}{l}\text { Better network features, leveraging on the } \\
\text { data requirements which will also support } \\
\text { holographic communication and } \\
\text { immersive XR. }\end{array}$ \\
\hline
\end{tabular}

\section{6G Use Cases in Industries}

It was shown in the preceding Section 6 the different applications such as holographic communication, tactile internet, multisensory $\mathrm{XR}$ applications, connected robotic and autonomous systems, and more. These applications open up new spheres that contribute to the actualization of new cases. Several use cases have been presented by researchers in the past, such as in manufacturing and health [10]. This paper broaches discussions on some use cases in Agriculture, Education, Media and Entertainment, Tourism, Transport and Logistics which have no significant focus. With $6 \mathrm{G}$ promising very high data rates, ultra-low latency, high reliability, and more, these use cases will become a reality. In this section, we delineate the proposed use cases.

\subsection{Use Cases in Agriculture}

It has been projected that, by the year 2050, current agricultural production must increase by $60-70 \%$ [274] to cater to the needs of the entire population; to achieve this, the pervasive use of high precision wireless technology will play a huge role [274]. Some use cases are autonomous vehicles, AR for training purposes, sensors for tracking variables on the farm, and data. Another application of precision agriculture, as suggested by [275], is automated irrigation control. Precision agriculture, also known as smart farming, will facilitate these by utilizing wireless sensor networks to monitor the farm variables and make intelligent controls. The stages of precision agriculture identified in [274] are: (i) data collection, (ii) diagnosis, (iii) data analysis, (iv) precision field operation and evaluation. This presents an opportunity to carry out farm operations more efficiently. The infusion of $\mathrm{AI}$ in precision energy has been proposed to improve efficiency on farms.

The application of IoT in the agricultural supply chain was also presented in [276]. Some other use cases of precision agriculture have been developed over the years $[277,278]$. A challenge identified with precision agriculture using wireless technology is the topology, making wireless signals susceptible to attenuation. This challenge can be eliminated with the use of IRS proposed in 6G networks. This allows deployment in non-line-of-sight environments, and it is more efficient than using relays. There are also challenges with routing protocols and energy-efficient devices. The authors in [274] reviewed several protocols and identified Zigbee and LoRa wireless protocols as ideal for precision agriculture owing to their low energy requirements. Privacy and security are also challenges identified with precision agriculture [279]. The high data rate and reliability and ultra-low latency by 6G networks will allow the optimized actualization of a fully automated farm system, which results in a more efficient process, and more output. $6 \mathrm{G}$ is also propitious in providing a more secure network through blockchain and other security enabling technologies treated in this paper. 


\subsection{Use Cases in Education}

As a result of the COVID-19 pandemic, many schools have been forced to adopt an online training mode. There has also been growth in enrollment in Massive Open Online Courses (MOOC) in recent years, with an estimated global enrollment of 110 million in 2019. According to a survey to understand the perspective of teachers in a sample population of AR, it was shown that learning online can be enhanced by utilizing AR in training [280]. The survey also showed that AR had not been widely adopted in educational institutions, and most have had contact with it outside educational institutions. This presents a dearth in knowledge acquisition through AR.

The use of holographs and XR will help to give students a better experience while learning. A good example is the training of surgeons, in which XR presents a good platform for training. We propose the application of $6 \mathrm{G}$ in providing remote access to surgeons in the theatre room. This widens the reach of consultants in teaching hospitals to reach more students remotely and provide professional support to students and doctors during surgery. Additionally, the UAV provides mobile ambulance access to the network, thereby allowing communication during emergencies. To actualize this, the Doppler effect from moving the UAV and ambulance will need to be tackled. This use case will benefit from the concept of high mobility hotspot introduced in [250]. 6G networks have been shown to facilitate multi-sensory $\mathrm{XR}$, and holographic communication will also optimize this experience. There is the challenge of a part of the population not being able to access online courses as a consequence of the unavailability of the internet. The ubiquitous feature of $6 \mathrm{G}$ will also ameliorate this challenge.

\subsection{Use Cases in Media and Entertainment}

$5 \mathrm{G}$ is expected to double annual media revenues in the next ten years to $\$ 420$ billion in 2028 [281], and gaming was posited to be at the forefront of 5G innovation. Cloud-based gaming, Over-the-Top TV, AR, and VR open up new media applications. The challenge with $\mathrm{AR}$ and VR applications is that they require very low latency to make delays imperceptible by human users. The ultra-low latency of $6 \mathrm{G}$ would circumvent these delays. This paper proposes tactile internet, $\mathrm{XR}$ video games, cloud gaming, holographic advertising as some of the trends in $6 \mathrm{G}$ that will facilitate growth in media and entertainment. This not only opens up new cases in media and entertainment, but it also provides succor to those with medical needs [282]. The perceptual experience of haptics and implants will give a new sensation different and better than the one currently obtainable. BCI will also provide the visually impaired opportunity to experience fully immersive gaming. VR has been utilized to support the mental health of health care professionals during the COVID-19 pandemic. Advertising will have a wider reach through the $6 \mathrm{G}$ ubiquitous connectivity feature. There is, however, a challenge of producing energy-efficient devices that will support these applications.

\subsection{Use Cases in Tourism}

Many hotels have widely adopted hotel automation based on IoT. AR use cases are also providential in improving challenges associated with accommodation, transportation, and catering solutions. A recommender system was proposed in [283] to aid tourists' decision-making, and the authors identified a need for high bandwidth wireless network infrastructure for the system to work optimally. Smart tourism also presents innovative solutions such as self-guided tours, tourist traffic control, remote monitoring, resource management [284]. This is achievable through the infusion of IoT, cloud computing, and AI [285]. The authors in [286] presented IoT in personalized hotel rooms, voicebased interaction, inventory management, location-based information, and body sensors. Tourism was one of the hardest-hit industries because of the COVID-19 pandemic [287], and virtual reality was one of the solutions identified to help the industry lessen the effects of the pandemic [288]. 
Some tourism companies have already adopted this in virtual tours, booking interfaces, and other travel experiences. Tourism, education, marketing are other areas where VR and AR can be adopted [289]. Digital replica, one of the driving trends in 6G, provides tourism with a more interactive experience [290]. For smart tourism to be widely adopted, the trust of the public is desirable. An IoT-based solution that is secured was proposed in [291], and the security features $6 \mathrm{G}$ will bring reinforces this and make the user experience much better. This paper proposes that there will be a virtual remote experience of tourist centers through fully immersive XR and holographic communication. This will be facilitated by future wireless networks B5G.

\subsection{Uses Cases in Transportation and Logistics}

Smart Logistics is one of the driving trends towards the actualization of Smart Cities, and several applications have been identified [292]. It is propitious to providing a better logistic architecture for business [293]. IoT is one of the backbones of smart logistics [292,294]. Wireless sensor networks also provide an opportunity to carry out feasibility analysis in logistics [295], inventory management against spoilage in perishable foods warehousing [296]. RIS will be widely used in the warehouse to optimize communication between IoT devices. This makes full automation and communication seamless. There is also an opportunity to reduce fatigue and accidents in the warehouse by using fully autonomous forklifts. Enhanced communication and repair through VR and AR is another viable opportunity to be facilitated by $5 \mathrm{G}$, which reduces downtime in the warehouse. Remote tracking will also be more comfortable with UAVs and CubeSats. This makes the utopian idea of a fully connected world become a reality. Thankfully, this is happening in our time!

\section{Challenges in 6G: Standardization, Design, and Deployment}

Despite the benefits 6G promises, some challenges could hamper the actualization of these networks. This paper examines the challenges of enabling technologies for the 6G networks in detail and proposes creative solutions to circumvent these challenges. It also clarifies the psychological and health issues associated with network densification and indoor wireless communication that $6 \mathrm{G}$ will be built. This paper categorizes the challenges based on the enabling technologies stated in Section 5. It also proposes potential solutions for these challenges. Table 18 presents challenges identified by researchers and proposed solutions, which have not been earlier captured in the challenges with the enabling technologies.

Table 18. 6G standardization, design, and deployment challenges and proposed solutions.

\begin{tabular}{|c|c|c|}
\hline Ref. & Challenges & Proposed Solutions \\
\hline [82] & $\begin{array}{l}\text { a. The problem of global coverage. } \\
\text { b. Limited system capacity. } \\
\text { c. Challenge of deploying computing and } \\
\text { d. Hapabilities. } \\
\text { e. } \quad \text { Challenges associated with actualizing } \\
\\
\text { 3D architecture. }\end{array}$ & $\begin{array}{l}\text { a. Adoption of mobile satellite communication. } \\
\text { b. } \\
\text { c. } \\
\text { Collaboctrum optimization. } \\
\text { d. Ind edge. } \\
\text { e. }\end{array}$ \\
\hline [41] & $\begin{array}{ll}\text { a. } & \text { Fixed access network capabilities lagging. } \\
\text { b. } & \text { Interference owing to network densification. } \\
\text { c. } & \text { Hardware constraints. }\end{array}$ & $\begin{array}{l}\text { a. Free Space Optical Communication and quantum } \\
\text { communication. } \\
\text { b. New mathematical tools for analysis and optimization. } \\
\text { c. Need for new materials that are compatible with } 6 \mathrm{G} \\
\text { communication. }\end{array}$ \\
\hline
\end{tabular}


Table 18. Cont.

\begin{tabular}{|c|c|c|}
\hline Ref. & Challenges & Proposed Solutions \\
\hline [9] & $\begin{array}{l}\text { a. Limited lifespan of smartphones. } \\
\text { b. Security Issue. } \\
\text { c. The issue with miniaturizing HF transmitters } \\
\text { and receivers. }\end{array}$ & $\begin{array}{l}\text { a. New mobile device architecture that allows wireless } \\
\text { power transfer and wireless energy harvesting. Low } \\
\text { hardware complexity was also proposed. } \\
\text { b. Advancement of PHY security techniques introduced } \\
\text { in 5G. } \\
\text { c. Optoelectronic Integration. }\end{array}$ \\
\hline
\end{tabular}

a. Integrating different architecture into a

[48] b. Compatibility of devices using 5G technology with Nil $6 \mathrm{G}$ services such as $\mathrm{XR}, 1 \mathrm{~Tb}$ data rate.
a. Achieving accurate beamforming in high mobility cases.
b. Latency results from retraining DL models on
[95] account of the fick
c. Non-compatibility of hardware and software non-generality.
d. Security.
a. DL-based hardware and software solutions. Outdoor positioning with centimeter-level accuracy was also proposed.
b. Prioritizing executing tasks by hierarchy, cross-layer optimization, and end-to-end DL schemes.
c. Digitalization, Visualization, and DL. Additionally, advanced positioning Technology.
d. Joint physical layer and cybersecurity with quantum methods.

a. The trade-off between High Intelligence and Privacy.

[45] b. Complex computation for getting the balance between Security and Spectral Efficiency.

c. Balancing SE and EE.
a. An intermediary between end-user data and AI.
b. Encryption algorithm, PHY layer security with spectral loss, and AI.
c. Energy harvesting, IRS solutions.

[108] a. Limited capacity and latency issues.

Nil.

\subsection{Signal Processing Challenges}

Some signal processing challenges that currently stand in the way of the full actualization of $6 \mathrm{G}$ have been identified in the paper. The challenges are delineated in this section, considering challenges and probable solutions identified by researchers. The challenges can be classified into Channel Estimation, Hardware complexity, and Precoding. Channel Estimation challenges associated with RIS systems have been treated in this paper, and the issue of hardware complexity has been raised severally. The paper focuses on precoding in this section.

\section{Terahertz Precoding}

Precoding is a useful technique in solving the path-loss issue in THz communication [202] without increasing the transmit power. Pencil beams, which are supported by very large-scale array antennas, help to actualize this. Precoding is channel adaptive, and it processes transmitted signals based on the available channel information at the transmitter [202,297]. However, there are challenges with precoding. The authors [31] have identified high power consumption as a challenge. Other challenges posited are the beam split effect and path-loss as a result of the increasing distance. Hardware impairments such as the non-linearity of power amplifiers limit THz precoding performance [12].

\subsection{Social, Psychological, Health, and Commercialization Challenges}

Social factors can make or mar the adoption of technology, and 6G wireless communication is no exception. As humans, our psychology and environment guide many of our 
actions. There was a hot debate that accompanied 5G implementation. It was believed in some quarters that the high-frequency spectrum is insidious to health. Some conspiracy theorists went as far as linking the $5 \mathrm{G}$ network to the proliferation of the COVID-19 pandemic. In this section, we critically examine the social, psychological, and health concerns. Furthermore, we examine some impending challenges that may sprout up during 6G commercialization, and suggestions were made to tackle these challenges. Figure 8 gives a pictorial view of some of these impending issues.

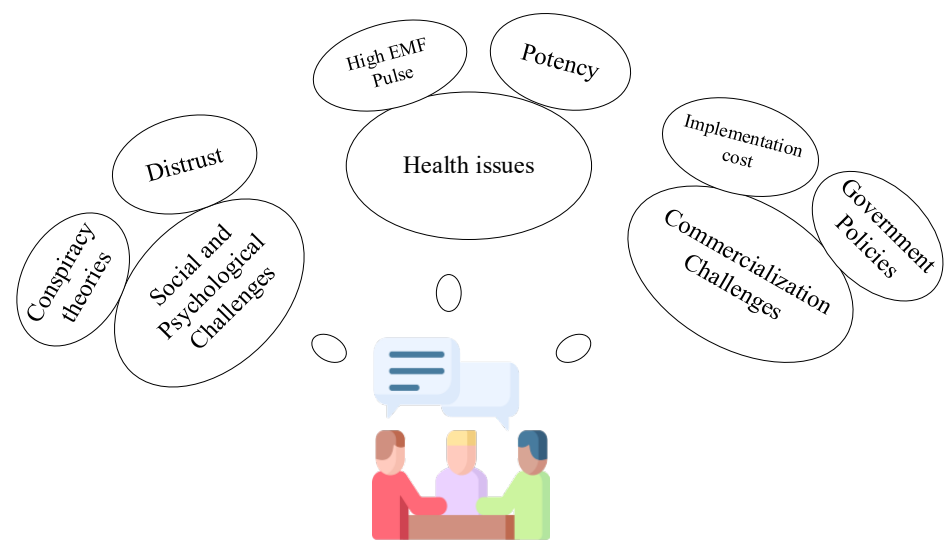

Figure 8. Non-wireless technology-related challenges for 6G.

\subsubsection{Social, Psychological, and Health Challenges}

Considering the cost of implementing future wireless networks, it is important to convince governments and agencies that it is expedient to implement it. Despite the benefits technologies driven by $6 \mathrm{G}$ networks present, there have been concerns on the health risks of $5 \mathrm{G}$ and $6 \mathrm{G}$, especially considering network densification and transmitting at a higher frequency spectrum $[12,48]$. Although transmitting at mmWave, Terahertz, and Visible light are at a higher frequency as against what is currently obtainable, they belong to the non-ionizing range. Although there have been concerns on the dangers of 5G [298] and scientists, have bemoaned and petitioned the WHO about the hazards of 5G, not just with the potency. Still, with the pulse, the world would be exposed to [299], the effects of Electromagnetic Fields (EMF) have been studied [300], and no adverse health effects have been established.

The International Commission on Non-Ionizing Radiation Protection (ICNIRP) has recently updated their exposure guideline to abide by mobile operators and telecommunication companies. The new guideline covers higher frequency bands envisaged in 5G networks and beyond [301]. It is crucial to ensure that these guidelines are adhered to. More research is conducted to ascertain the effects of higher frequency on humans and other organisms in the ecosystem and how to assuage the effects. When these issues are addressed, the social and psychological challenges expected in 5G and beyond will be reduced considerably and subsequently expunged.

\subsubsection{Commercialization Challenges}

6G commercialization challenges were keenly discussed at the 6Genesis Flagship Program (6GFP) launched in Finland in May 2018. The 6GFP consortium comprises academia, research centers, institutes, industrial and business partners, and coordinated by the University of Oulu in Finland. The program is the first to focus on 6G research globally [302]. The Director of the 6G flagship, Matti Latva-aho, noted that 6G would be deployed around 2030 to meet the expectations not provided by 5G, alongside the new ones fusing AI-inspired applications in every field of society with ubiquitous wireless connectivity. The estimated cost of the 6G flagship will be around EUR 250 million over eight years. 
There has been limited literature on the potential commercialization challenges of 6G. Although the deployment of 6G is expected to commence in 2030 [26], it is prudent to foresee the challenges associated with commercialization to prevent or circumvent these challenges. $6 \mathrm{G}$ networks are proposed to facilitate ubiquitous connectivity, even in rural communities. Rural areas have the challenge of lack of revenue per square mile to accommodate the enormous cost of $6 \mathrm{G}$ deployment. One question posed at the first $6 \mathrm{G}$ summit by Tarik Taleb is if autonomous companies would be willing to pay for the cost of connectivity to have access to this technology. Will smart factories need operators for their networks? Will the training costs to adapt to the new networks be worth the money? These are some of the questions that need to be answered from a business perspective. 5G deployment is posed with the challenge of cost, which is envisaged in $6 \mathrm{G}$ deployment.

The use of UAVs and advanced radio techniques, exploitation of solar-powered energyefficient devices, reusability of network components and functions, and deployment of commodity hardware were identified as some of the pillars to actualize connectivity in rural areas [89]. However, this was based on the premise that internet connectivity will be a primary need that the government or government-based entities may provide, but not private entities. This presents an uncertainty on who will bear the cost of deployment. Interference of government policies was witnessed in the 5G deployment. It is not yet clear enough if $6 \mathrm{G}$ networks will be fully supported by the infrastructure of pre-existing generations, especially 5G, or there will be a total overhaul of infrastructure. Nevertheless, it is essential to note that the existing tower infrastructure is unsustainable, and the complete actualization of $5 \mathrm{G}$ and subsequently $6 \mathrm{G}$ will present a more sustainable business model.

Although the mmWave was presented as the enabling spectrum for 5G, early deployment of $5 \mathrm{G}$ has been on the sub-6GHz spectrum. Early $6 \mathrm{G}$ deployment may not be deployed on $\mathrm{THz}$ immediately at the point of deployment. The early adoption of sub-6GHz in 6G was suggested in [250]. It is, therefore, pertinent to maximize the sub-6GHz spectrum. The adoption of a wireless generation is driven by the services provided and not just the enabling technologies. Although some use cases of $6 \mathrm{G}$ have been proposed in this paper, the onus is on the users to adopt these services. If users are reluctant to adopt these use cases, though highly unlikely, it presents a dent in the expected fast adoption of 6G. In all, there is a need for investment in 6G research and its subsequent deployment.

\section{6G Sustainability and Business Model}

In this section, we discuss 6G sustainability and business model. First, we present a brief discussion in Section 9.1 on the multi-faceted communication capabilities of 6G that will contribute significantly to global sustainability and offering massive support for various services to promote healthy and economic stability. Next, we describe how 6G will bring about a dramatic change in the business arena in Section 9.2.

\subsection{G Sustainability}

The 5G networks have drastically resolved several social issues inherent in 4G wireless networks. For example, environmental protection and education have received remarkable improvements in the $5 \mathrm{G}$ era. However, the problems of connectivity and urbanization remain. No doubt, 6G will usher in a great sigh of relief. User-experienced-based hyperdata connectivity will be ubiquitous and regional barriers will be broken to achieve a truly borderless society $[47,302]$. The multi-faceted communication capabilities of $6 \mathrm{G}$ will contribute immensely to global sustainability and offer massive support for various services at the application layer [303]. This will, in turn, accelerates smart farming, access to financial services, and facilitates online healthcare delivery. In terms of energy conservation, 6G will aid electronic circuit miniaturization and empower extra large-scale integration of components to reduce carbon footprint. However, achieving the Sustainable Development Goals (SDGs); data security and inclusiveness, will come at a price. All parties involved; government agencies, hospitals, and society, must meet strict privacy rules to promote 
the integrity of the system. 6G will provide digital infrastructure to address the needs of humans and society.

6G will also enable context-aware environment sensing and indoor localization to aid online monitoring and support the massive uplifting of the SDGs ecosystem. A summary of the set of KPIs for all 17 SDGs, including probable use cases, is presented in [303]. To provide viable solutions to the vast sustainability problems, the $6 \mathrm{G}$ research community needs to closely examine the open ecosystem-based value configuration and decentralized poly-nodal power configuration [304,305]. 6G will be the foci point between nanotechnology, biotechnology, cognitive science, and ICT. Ultimately, this will increase societal requirements; resilience, sustainability, transparency, and inclusivity, leading to a complex societal mix [306,307]. Additionally, 6G will provide an atmosphere of productivity and rapid economic growth in rural and urban geographies towards achieving the UN sustainability goals, especially goals 9 (Industry, Innovation, and Infrastructure), 11 (Sustainable Cities and Communities), amongst others.

\subsection{G Business Model}

Given the recent global financial crisis, there is no denying the fact that the existing corporate business models had a significant impact on the sustainability of the global economy and society [308-310]. This is a wake-up call for all companies to regulate their operations geared towards achieving the UN SDGs [303]. The business scenarios for 6G in the next ten years are envisioned as highly prosperous [302]. Blockchain-empowered decentralized resource configuration techniques have been proposed to support several verticals and business platforms in the prospective 6G wireless network [303]. The probable market trends and uncertainties are elaborated and three scenarios identified by Ziegler and Yrjola [311]. These include user experience, sustainability, and business. Scalability and sustainability are proposed to be critical drivers for future 6G business models [312,313].

$6 \mathrm{G}$ will bring about a dramatic change in the business arena. The future of business will be characterized by a seamless and automated collection of market data from humans and the dynamic business environment. 6G will provide a user-friendly platform for intelligent analysis of big data for high-end products and specialized services. These products and services would be designed to be highly sustainable and well-tailored to address the peculiar needs of the consumers in rural and urban geographies. Additionally, 6G will aid crowdsourcing and enhance cutting-edge distribution platforms to support sharing sustainable business models to accelerate the equitable distribution of resources. Recently, the choices for developing the first-class sustainable 6G business future for all the participants in the future 6G business were recapitulated by [307]. These useful choices for creating the favorite sustainable $6 \mathrm{G}$ business futures have been designed using the quintuple helix model shown in Figure 9. Sustainable 6G business is key to knowledge creation to drive human empowerment, technology acquisition and transfer, economic stability, entrepreneurship and innovation, natural environment conservation, ecological reconstruction, and democratization of government institutions. 


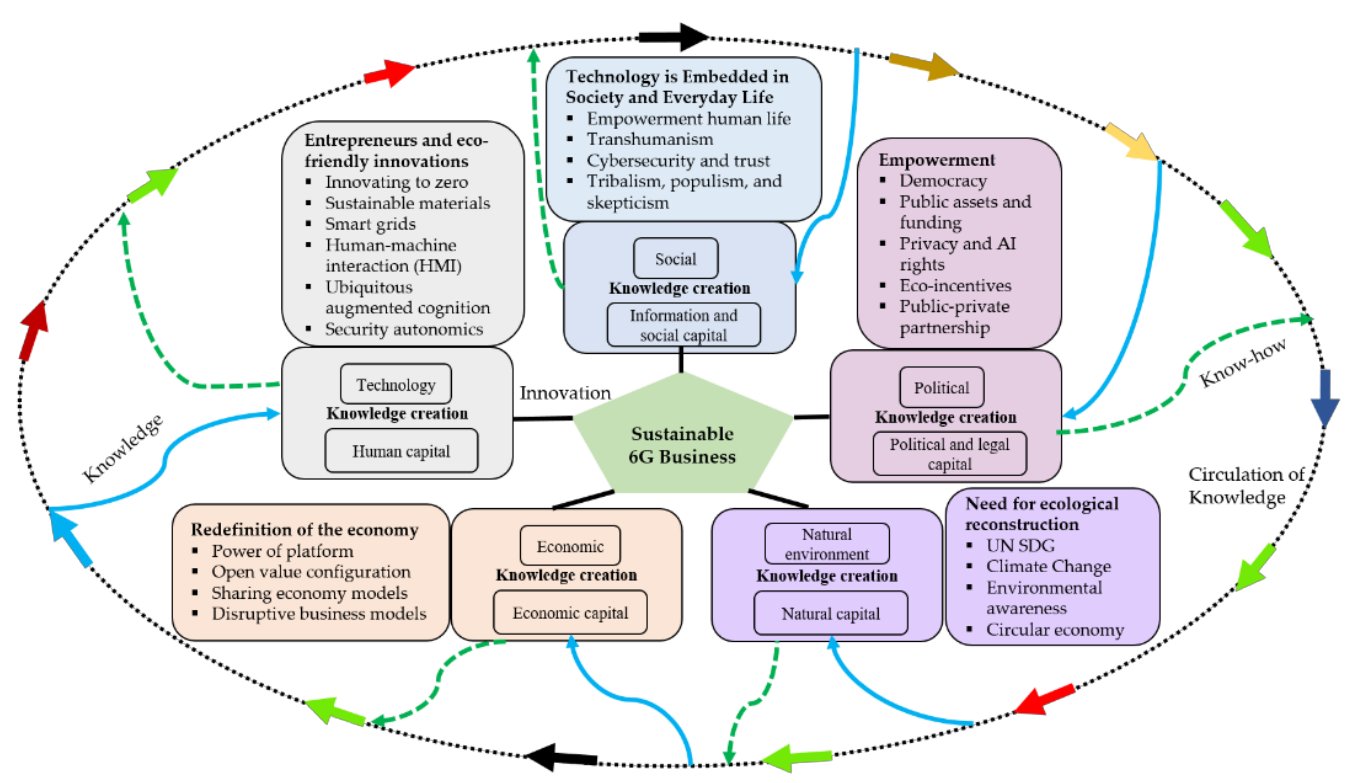

Figure 9. Useful choices for developing the preferred sustainable 6G business futures.

\section{Recent Trends, Future Research Directions, and Lessons Learned}

This section considers some recent trends in 6G applications, such as Holographic communication, space communication, and more. We have also identified areas where further research is needed. We have considered some research propositions by several researchers hoping this will stimulate research and facilitate the progress, development, and rapid implementation of $6 \mathrm{G}$ wireless communication. We conclude the paper with a summary of key take-away lessons for further research and development in 6G wireless communication.

\subsection{Recent Trends}

China launched the first 6G satellite to space in November 2020. The satellite uses high-frequency terahertz waves for data transmission. Although the launch is just a trial, and it is not sure if it will be in the final 6G standard, this has ushered in the 3D architecture of terrestrial, space, and underwater communication, kick-starting transmission on space. There is an ongoing development of 6D Holographic optical field technology. This will be enabled by the exigent specifications of higher data rate and low latency to be facilitated by 6G. This technology presents a new and desirable user experience in media and entertainment. Security has been identified as a challenge in the adoption of the Internet of Bio-Nano Things. The authors in [249] proposed a biocyber interface-based privacy scheme. The privacy scheme worked on top of the biocyber interface in the IoBNT model and showed promising results with minimal side effects. Research in autonomous driving is progressing, and driverless buses and taxis are expected on Britain's roads as of 2021 [314]. As explained earlier in this paper, the psychological trust of the population is desirable for the seamless adoption of this technology. Considering Terahertz transmission, spatial modulation [315] has been proposed to minimize the hardware impairments [316]. The development of Wireless Network on Chip (WNoC) enabled by miniaturized transceivers and antenna is also gaining traction [189]. We believe these trends and developments draw us closer to the realization of $6 \mathrm{G}$ wireless communication systems.

\subsection{Future Research Directions}

Pervasive AI is crucial in actualizing intelligent future wireless networks. However, there is a challenge of having energy-efficient hardware at the mobile unit, allowing users to experience high-speed applications such as extended reality, fully autonomous 
systems, and more. Therefore, further research is needed to produce hardware that will be compatible with 6G. These devices are desired to be energy efficient. This keeps in play the vision to have longer battery life. Security and trust of wireless networks is also an issue which 6G is expected to combat. There is a need for more research on quantum communication. As stated earlier in this paper, technologies such as Quantum communication, Internet of Bio-Nano Things might not be mature enough to enable 6G. Still, they will be key future wireless networks. Quantum communication not only improves security but also improves computational efficiency. Space communication has been explored in this paper. If this is incorporated with terrestrial and underwater communication, the vision of a true ubiquitous communication network will be achieved. Saeed et al. [182] envisage the CubeSats to facilitate future wireless communication in space thanks to their low cost and low orbital altitude. However, we have identified challenges in the channel model which need urgent research focus. Future research prospects in software-defined networking, Internet of Space Things, and Machine Learning resource allocation for CubeSats have been identified. Table 19 considers these open research issues on underwater communication, security, channel estimation, and more detail.

Table 19. 6G related open research issues that require further investigation.

\begin{tabular}{|c|c|}
\hline Open Research Issues & Research Directions \\
\hline Channel Estimation & $\begin{array}{l}\text { The use of spatial correlation [317], Low-Complexity Channel Estimation [318], Comprehensive } \\
\text { sensing technique [319], Deep Learning-based technique [320], and more, in the context of 5G, } \\
\text { can be adapted to resolve the Channel Estimation challenges in 6G. }\end{array}$ \\
\hline Security & $\begin{array}{l}\text { Quantum communication has been highlighted to improve the security and privacy of wireless } \\
\text { networks [88]. Access control and authentication challenges in blockchain need to be resolved. } \\
\text { Further research on molecular communication security, which utilizes biochemical signals to } \\
\text { transmit information, is required [321]. }\end{array}$ \\
\hline Underwater Communication & $\begin{array}{l}\text { The underwater optical communication system (UOWC) [322], similar to VLC, application of } \\
\text { acoustic signals requires further research to resolve the limited short-range problem. The need to } \\
\text { integrate aerial, terrestrial and underwater communication is imperative. Further, the need for } \\
\text { cutting-edge networking protocols to accelerate this integration is not negotiable. }\end{array}$ \\
\hline Energy Efficiency & $\begin{array}{l}\text { There are tradeoffs with hardware complexity and energy requirements. However, sustainable } \\
\text { and efficient energy harvesting sources can also be explored [323] to limit carbon emission [324]. } \\
5 \mathrm{G} \text { New radio was designed to aid energy efficiency in 5G. However, the current 5G networks } \\
\text { consume more power than } 4 \mathrm{G} \text { networks [1]. Therefore, research is needed to reduce the } \\
\text { softwarization cost in the existing } 5 \mathrm{G} \text { networks towards 6G. }\end{array}$ \\
\hline Spectral Efficiency & $\begin{array}{l}\text { 6G is expected to leverage on higher spectrums: subTerahertz, Terahertz, optical frequency, and } \\
\text { more. In 5G, Cognitive Radio (CR) improves the SE through dynamic spectrum sharing [325]. } \\
\text { However, there exists a challenge in heterogeneous networks (HetNets) with varying nodes [326]. } \\
\text { A blockchain-based system for network sharing is envisioned [327]. These and other } \\
\text { resource-sharing options such as FlexRAN and LayBack need further research focus [328]. }\end{array}$ \\
\hline Hardware Complexity & $\begin{array}{l}\text { Considering the RIS and THz for } 6 \mathrm{G} \text {, the physical layer is expected to get more complicated, and } \\
\text { this poses severe challenges to hardware design for THz communication. The appropriate } \\
\text { communication systems and networking protocols that aid compatibility need further research. } \\
\text { Further research is required on the scalability of Wireless Network on Chip (WiNoC) models to } \\
\text { sustain transmission at THz over a long distance [329]. }\end{array}$ \\
\hline
\end{tabular}

Saad et al. [47] opined that there would be a shift from smart phones-base station paradigm to smart surface-human embedded implants. They also proposed that performance analysis and optimization will require operating in the $3 \mathrm{D}$ space and that it requires a radio-centric design system that incorporates the 3CLS and AI. It is important to have more research on these technologies to hasten the rate of development. In addition to the future research directions identified in this paper, we have also summarized research trends broached by different researchers in Table 20. Furthermore, future projections were earlier identified in Table 4 of this paper. 
Table 20. Proposed Research Directions in 6G Wireless Communication.

Ref. $\quad$ Future Research Directions

[6] a. VLC is expected to facilitate a higher data rate.

b. Utilizing semantic communication to circumvent the challenges of limits predicted by Shannon's theory.

a. AI to facilitate a fully user-centric network architecture.

[10] b. Research on unsupervised and reinforcement learning, which do not require learning to drive a fully autonomous network.

[40] a. High security, secrecy, and privacy, high intelligent network.

b. Need for better battery life.

a. Need for a new transceiver design that will be compatible with $\mathrm{THz}$ propagation

[45] b. Investigation of health concerns on $\mathrm{THz}$ transmission.

c. Development of 3D frequency.

[80] a. Research on high-speed, low complexity, and low power consumption signal processing technology.

$\begin{array}{ll}\text { [81] } & \text { a. AI-based PHY end to end architecture. } \\ \text { b. Increased spectrum resources through THz, laser, VLC communication, and spectrum sharing techniques. }\end{array}$

c. Secured network facilitated by Quantum communication.

[41] a. A shift from the electronic era in 5G to the optical and photonics era.

b. Actualization of the full potential of the cognitive radio.

a. Further research in quantum computing and communication.

[47] b. The need for scalable AI to facilitate low-latency, and highly reliable networks.

c. New protocols for wireless devices compatibility.

a. A new transceiver architecture for $\mathrm{THz}$ communication.

[48] b. Need for effective spectrum management techniques and spectrum-sharing strategies

c. Beamforming through massive MIMO systems.

a. Leveraging AI for optimized performance.

b. Blockchain for security.

[95] c. Quantum communication for improved speed.

d. Application of meta-learning, light-weight NN, capsule NN for intelligent 6G.

e. Partnership with health and social sciences to develop environmentally friendly devices that will be acceptable.

a. The need for human-centric services as against machine-centric and data-centric services.

b. Vision of a space-air-ground-sea integrated network.
c. Research on the security of wireless networks through quantum-based, blockchain-based, AI-based methods, and more.

[330] $\quad$ a. Need for new network topology.

b. Expansion of network spectrum.

c. Incorporation of the non-terrestrial networks.

\subsection{Lessons Learned}

In this section, we have identified and summarized lessons learned from this research work. We believe these lessons are crucial and will guide researchers on progressing 6G research. 
Lesson 1: Comparing the Key Technologies that will facilitate the actualization of $6 G$.

It has been established that Terahertz communication and VLC will give a higher data rate than the one obtainable in 5G networks. Cell-free massive MIMO presents a new concept that eliminates cells in communication and improves user experience. UAVs and CubeSats, which form the Internet of Space Things introduced in [37], and underwater communication will play a huge role in achieving ubiquitous connectivity. Challenges with each technology have also been identified in this article. It has also been established that quantum communication and blockchain will provide secure future wireless networks. Ambient backscatter communication will also play a huge role in energy and spectral efficiency. Artificial Intelligence will be pervasively adopted to enable intelligent networks, making them self-efficient. Deep Learning has been proposed as an alternative to existing algorithms for modeling channel information. However, despite the high processing power that has expanded AI development in recent times, data are still cumbersome. We propose Big Data to play a crucial role in managing the large amount of data associated with wireless networks.

Lesson 2: $5 G$ is limited, and $6 G$ is proposed to provide requirements that will be compatible with emerging applications and services.

Current 5G systems do not have the bandwidth to support a fully immersive XR experience and high definition holographic communication. Applications such as Tactile Internet, Wireless Brain-Computer Interface also require high reliability and ultra-low latency, which 5G cannot provide. Additionally, needed is a very high data rate in the order of 1 Tbps with a latency $<1 \mathrm{~ms}$, making delay imperceptible to humans. These will be provided by $6 \mathrm{G}$. Achieving this enables new use cases in agriculture, education, media and entertainment, tourism, and logistics. Additionally, it has been established that the sub$6 \mathrm{GHz}$ band is crowded. There are research interests in TeraHertz spectrum communication. This will provide a new spectrum and enable higher data rates, which are desirable in 6G. Optical Wireless Technology such as Visible Light Communication and Free Space Optics also need to be explored.

Lesson 3: Compatibility at the hardware level is still a major challenge as many UE are currently not $6 \mathrm{G}$ compatible.

Artificial Intelligence is proposed to enable wireless networks to be intelligent entities. However, this casts a toll on the energy requirement at the mobile unit, as high processing power is required to process a large amount of data and the AI algorithms. Additionally, there is a need for new chips for TeraHertz communication. Wireless Network on Chip (WNoC) has been introduced in [189], but further research needs to be done to check its practicability. There is a need to have energy-efficient devices that support the driving trends in 6G. There is also a need for new protocols or updates of existing protocols to enable communication in $6 \mathrm{G}$ networks. In all, the hardware and protocols need to be cost-efficient to aid easy commercialization.

Lesson 4: Will there be a complete overhaul of the backhaul of present wireless networks, or will there be new Infrastructure? Not certain.

It is not yet clear if there will be a complete overhaul of existing wireless networks with a new architecture for 6G. However, there will undoubtedly be a need for more infrastructure, especially RIS, UAVs, CubeSats, which are yet to be widely adopted. Massive MIMO previously deployed in $5 \mathrm{G}$ will be further explored to incorporate a cell-free massive communication network. A 3D network architecture that combines satellite, UAV, and terrestrial networks is proposed to facilitate ubiquitous communication. This will bring about space and terrestrial communication. It is also crucial to incorporate underwater communication. It is worthy to note at this juncture that it will be desirable to incorporate the existing architecture, especially those of the recently commercialized 5G. This enables a network that is not just performance efficient but cost-efficient.

Lesson 5: 3CS (Communication, Computing, Control). 
6G has been proposed to be a multi-purpose system that combines communication, computing, control, and localization [47]. The authors in [6,331] went further to include caching. The combination of communication, computing, and control is an aberration from what is obtainable in existing generations where the focus was solely on wireless communication. However, challenges such as enabling intelligent control in stringent applications such as autonomous vehicles, multi-modal fusion for 3D image reconstructing [47], and lack of prior models exist. Quantum communication is proposed to play a key role in improving the speed and performance of computational processes. The actualization of these will facilitate CRAS, XR, and more applications

Lesson 6: Haptics will be more prominent.

Haptics present a form of communication using touch. Haptic devices have a unique bi-directionality feature that allows them to communicate with the brain, i.e., bi-directional communication with the brain. Teletouch facilitated by Haptics technology will remake the internet into allowing users to move distant objects and experiencing instant tactile feedback. Upon the wide adoption of haptics, it has been proposed to be the end of the smartphone era [47], a new era of wearables and haptics will be ushered in. Applications such as multisensory extended reality, BCI will also fuel this transition. However, for these technologies to be widely adopted, the psychological concerns of the users will need to be resolved.

Lesson 7: Industry 4.0 will be facilitated by CRAS, smart logistics, precision agriculture, smart cities.

There will be a pervasive application of AI and automated control systems. This will open up applications such as CRAS that will improve industrial processes and products effectively. Industry 5.0 will be more user-centric with the personalized manufacturing process. Holographic communication, Multisensory XR, Digital Twin, and more will facilitate the actualization of smart cities. This will also bring about an upgrade in the media and entertainment industry. There will be a better user experience in online gaming through extended reality, tactile devices, and more. New use cases in smart logistics, precision agriculture, and more have been introduced in this paper, and these are expected to drive massive industrialization. These applications and use cases make the actualization of $6 \mathrm{G}$ desirable.

Lesson 8: Security, a desirable feature of $6 G$, will be provided by blockchain and quantum communication.

There are research interests in quantum cryptography and quantum machine learning. This is expected to make future wireless networks secured. However, quantum communication research has not received as much attention as other enabling technologies; thus, casting doubts on its maturity in 6G deployment. Therefore, there is a need for more research focus on quantum communication. Blockchain is another technology that will improve the trust and security of future wireless networks. This is a distributed ledger technology with decentralized control. Artificial Intelligence will also play a role in detecting threats in wireless networks, thus creating a secure and self-sustaining network.

Lesson 9: Need for a new networking protocol.

There is also a need for new networking protocols or an upgrade to the existing ones to be compatible with the new technologies such as the $\mathrm{THz}$ frequency spectrum, which are enablers of 6G. As stated earlier in this paper, communicating at a higher frequency spectrum is prone to high path loss. Therefore, there is a need for hardware to improve the transmission range of $\mathrm{THz}$ communication. There is also a need for a robust system and algorithm for handover management in UAV/CubeSat communication. It is as well crucial that these hardware architectures are low-cost and energy-efficient. Additionally, as stated earlier, compatibility with existing infrastructure is desirable. 


\section{Lesson 10: Multiplexing methods.}

Multiplexing techniques such as Orthogonal Frequency Division Multiplexing (OFDM), Generalized Frequency Division Multiplexing (GFDM), Filter Bank Multicarrier (FBMC), Spatial Multiplexing, and more, are proposed in 5G. Further research is needed to ascertain how these multiplexing methods will be crucial in actualizing the desirable 6G networks. Spectrum and infrastructure sharing is also desirable to maximize capabilities, and CR and Blockchain are some of the technologies proposed. Further research is needed to achieve this. Generally, there is a need for new protocols and standards for 6G to enable standardization and compatibility. Additionally, software-defined networking (SDN) needs to be explored to resolve protocol incompatibility.

Lesson 11: Need to provide pragmatic solutions to the vast sustainability problems by adopting innovative and sustainable business models.

Sustainable business is key to knowledge creation to drive human empowerment, technology acquisition and transfer, economic stability, entrepreneurship and innovation, ecological reconstruction, and democratization of government institutions. However, most current business models are not sustainable. There is a need for adaptive and innovative business models to regulate the market forces to achieve global economic stability. Ultimately, such business models will accelerate productivity and rapid economic growth in rural environments towards achieving the UN sustainability goals.

\section{Conclusions}

This paper attempted to discuss how the $6 \mathrm{G}$ wireless network will enable cutting-edge applications, which the existing $5 \mathrm{G}$ has not seamlessly facilitated. The enabling technologies for 6G wireless networks are discussed in detail and contrasted with the existing $5 \mathrm{G}$ technology. The challenges which pose as barriers to the actualization of $6 \mathrm{G}$ wireless communication are emphasized. The accompanying social, psychological, health, and commercialization challenges are discussed. New use cases of $6 \mathrm{G}$ in agriculture, education, media and entertainment, tourism, transport, and logistics, are broached. Channel estimation, security, underwater communication, and more require further research to guarantee the envisioned ubiquitous connectivity in the $6 \mathrm{G}$ era and beyond. The multi-faceted $6 \mathrm{G}$ wireless communication capabilities in accelerating the United Nations Sustainable Development Goals to drastically alleviate poverty, promote an equitable and fair distribution of scarce resources, improve healthcare delivery, and maintain global economic stability are discussed extensively. Finally, we have given a concise but more explicit vision of what $6 \mathrm{G}$ will be, provide an up-to-date review of the emerging trends, assess the potential challenges envisioned in $6 \mathrm{G}$ wireless network deployment, and stimulate research initiatives to tackle these challenges for societal advancement.

Author Contributions: A.L.I. and O.A. were responsible for the conceptualization of the topic; Article gathering and sorting were done by O.A. and A.L.I.; Manuscript writing and original drafting and formal analysis were carried out by O.A. and A.L.I.; Writing of reviews and editing was done by O.A., A.L.I., N.T., and S.S.; the overall research activity was led by A.L.I. All authors have read and agreed to the published version of the manuscript.

Funding: Agbotiname Lucky Imoize is supported by the Nigerian Petroleum Technology Development Fund (PTDF) and the German Academic Exchange Service (DAAD) through the NigerianGerman Postgraduate Program under Grant 57473408.

Data Availability Statement: Data sharing is not applicable to this article.

Acknowledgments: The authors acknowledge the anonymous reviewers for their review comments.

Conflicts of Interest: The authors declare no conflict of interest. 


\section{List of Acronyms}

\begin{tabular}{|c|c|}
\hline Abbreviation & Full Meaning \\
\hline 3CLS & Communications, Computing, Control, Localization and Sensing \\
\hline 3GPP & 3rd Generation Partnership Project \\
\hline $5 G$ & Fifth Generation \\
\hline $6 \mathrm{G}$ & Sixth Generation \\
\hline ABCS & Ambient Backscattering Communication Systems \\
\hline ANN & Artificial Neural Network \\
\hline AI & Artificial Intelligence \\
\hline $\mathrm{AP}$ & Access Points \\
\hline B5G & Beyond 5G \\
\hline BS & Base Stations \\
\hline CRAS & Connected Robotic and Autonomous Systems \\
\hline DL & Deep Learning \\
\hline DLT & Distributed Ledger Technology \\
\hline DNN & Deep Neural Network \\
\hline eMBB & Enhanced Mobile Broadband \\
\hline $\mathrm{EE}$ & Energy Efficiency \\
\hline $\mathrm{EH}$ & Energy Harvesting \\
\hline FSO & Free Space Optical \\
\hline GUE UL & Ground User Uplink \\
\hline IoBNT & Internet of Bio-Nano Things \\
\hline $\mathrm{IoE}$ & Internet of Everything \\
\hline IoT & Internet of Things \\
\hline mBBL & Mobile Broadband Bandwidth Additionally, Low Latency \\
\hline mBBMT & Massive Broadband Bandwidth Machine Type \\
\hline mLLMT & Massive Low Latency Machine Type \\
\hline mURLLC & Massive Ultra-Reliable Low Latency Communication \\
\hline MIMO & Multiple Input Multiple Output \\
\hline ML & Machine Learning \\
\hline MR & Mixed Reality \\
\hline MU & Mobile User \\
\hline NN & Neural Network \\
\hline NOMA & Non-Orthogonal Multiple Access \\
\hline LEO & Low Earth Orbit \\
\hline $\mathrm{Li}-\mathrm{Fi}$ & Light Fidelity \\
\hline LIS & Large Intelligent Surfaces \\
\hline LTCC & Low-Temperature Co-fired Ceramic \\
\hline LTE & Long Term Evolution \\
\hline OAM & Orbital Angular Modulation \\
\hline OWT & Optical Wireless Technology \\
\hline RIS & Reconfigurable Intelligent Surfaces \\
\hline SE & Spectral Efficiency \\
\hline SIWPT & Simultaneous Information and Wireless Transfer \\
\hline TDD & Time-Division Duplexing \\
\hline $\mathrm{U} 2 \mathrm{U}$ & UAV-to-UAV \\
\hline UAV & Unmanned Aerial Vehicles \\
\hline URLLC & Ultra-reliable, Ultra-low Latency Communication \\
\hline VLC & Visible Light Communication \\
\hline VR & Virtual Reality \\
\hline WPT & Wireless Power Transfer \\
\hline QoE & Quality of Experience \\
\hline QoPE & Quality of Physical Experience \\
\hline QoS & Quality of Service \\
\hline $\mathrm{XR}$ & Extended Reality \\
\hline
\end{tabular}




\section{References}

1. You, X.; Wang, C.X.; Huang, J.; Gao, X.; Zhang, Z.; Wang, M.; Huang, Y.; Zhang, C.; Jiang, Y.; Wang, J.; et al. Towards 6G wireless communication networks: Vision, enabling technologies, and new paradigm shifts. Sci. China Inf. Sci. 2021, 64, 110301. [CrossRef]

2. Muñoz-Saavedra, L.; Miró-Amarante, L.; Domínguez-Morales, M. Augmented and virtual reality evolution and future tendency. Appl. Sci. 2020, 10, 322. [CrossRef]

3. Murphy, K.; Darrah, M. Haptics-based apps for middle school students with visual impairments. IEEE Trans. Haptics 2015, 8 , 318-326. [CrossRef]

4. Elliott, D.; Keen, W.; Miao, L. Recent advances in connected and automated vehicles. J. Traffic Transp. Eng. Engl. Ed. 2019, 6, 109-131. [CrossRef]

5. Khan, W.Z.; Rehman, M.H.; Zangoti, H.M.; Afzal, M.K.; Armi, N.; Salah, K. Industrial internet of things: Recent advances, enabling technologies and open challenges. Comput. Electr. Eng. 2020, 81, 106522. [CrossRef]

6. Calvanese Strinati, E.; Barbarossa, S.; Gonzalez-Jimenez, J.L.; Kténas, D.; Cassiau, N.; Maret, L.; Dehos, C. 6G: The Next Frontier: From Holographic Messaging to Artificial Intelligence Using Subterahertz and Visible Light Communication. IEEE Veh. Technol. Mag. 2019, 14, 42-58. [CrossRef]

7. Elmeadawy, S.; Shubair, R.M. 6G Wireless Communications: Future Technologies and Research Challenges. In Proceedings of the 2019 International Conference on Electrical and Computing Technologies and Applications, ICECTA 2019, Ras Al Khaimah, United Arab Emerites, 19-21 November 2019; pp. 2-7.

8. Samsung. The Next Hyper Connected Experience for All. 2020. Available online: https:// research.samsung.com/next-generationcommunications (accessed on 20 January 2021).

9. Yang, P.; Xiao, Y.; Xiao, M.; Li, S. 6G Wireless Communications: Vision and Potential Techniques. IEEE Netw. 2019, 33, 70-75. [CrossRef]

10. Giordani, M.; Polese, M.; Mezzavilla, M.; Rangan, S.; Zorzi, M. Toward 6G Networks: Use Cases and Technologies. IEEE Commun. Mag. 2020, 58, 55-61. [CrossRef]

11. Han, C.; Wu, Y.; Chen, Z.; Wang, X. Terahertz Communications (TeraCom): Challenges and Impact on 6G Wireless Systems. arXiv 2019, arXiv:1912.06040.

12. Rappaport, T.S.; Xing, Y.; Kanhere, O.; Ju, S.; Madanayake, A.; Mandal, S.; Alkhateeb, A.; Trichopoulos, G.C. Wireless communications and applications above $100 \mathrm{GHz}$ : Opportunities and challenges for $6 \mathrm{~g}$ and beyond. IEEE Access 2019, 7, 78729-78757. [CrossRef]

13. Hong, W.; Jiang, Z.H.; Yu, C.; Hou, D.; Wang, H.; Guo, C.; Hu, Y.; Kuai, L.; Yu, Y.; Jiang, Z.; et al. The Role of Millimeter-Wave Technologies in 5G/6G Wireless Communications. IEEE J. Microwav. 2021, 1, 101-122. [CrossRef]

14. Arai, S.; Kinoshita, M.; Yamazato, T. Optical wireless communication: A candidate 6G technology? IEICE Trans. Fundam. Electron. Commun. Comput. Sci. 2021, E104A, 227-234. [CrossRef]

15. Khan, L.U. Visible light communication: Applications, architecture, standardization and research challenges. Digit. Commun. Netw. 2017, 3, 78-88. [CrossRef]

16. Chaudhary, S.; Amphawan, A. The role and challenges of free-space optical systems. J. Opt. Commun. 2014, 35, 327-334. [CrossRef]

17. Zhao, J. A Survey of Intelligent Reflecting Surfaces (IRSs): Towards 6G Wireless Communication Networks. arXiv 2019, arXiv:1907.04789.

18. Basar, E.; Di Renzo, M.; De Rosny, J.; Debbah, M.; Alouini, M.-S.; Zhang, R. Wireless Communications Through Reconfigurable Intelligent Surfaces. IEEE Access 2019, 7, 116753-116773. [CrossRef]

19. Toumi, M.; Aijaz, A. System Performance Insights into Design of RIS-assisted Smart Radio Environments for 6G. arXiv 2021, arXiv:2101.01102.

20. Hu, S.; Rusek, F.; Edfors, O. Beyond Massive MIMO: The Potential of Data Transmission with Large Intelligent Surfaces. IEEE Trans. Signal. Process. 2018, 66, 2746-2758. [CrossRef]

21. Andrews, J.G.; Buzzi, S.; Choi, W.; Hanly, S.V.; Lozano, A.; Soong, A.C.; Zhang, J.C. What will 5G be? IEEE J. Sel. Areas Commun. 2014, 32, 1065-1082. [CrossRef]

22. Interdonato, G.; Björnson, E.; Quoc Ngo, H.; Frenger, P.; Larsson, E.G. Ubiquitous cell-free Massive MIMO communications. Eurasip J. Wirel. Commun. Netw. 2019, 2019, 197. [CrossRef]

23. Chen, M.; Challita, U.; Saad, W.; Yin, C.; Debbah, M. Artificial Neural Networks-Based Machine Learning for Wireless Networks: A Tutorial. IEEE Commun. Surv. Tutor. 2019, 21, 3039-3071. [CrossRef]

24. Ali, S.; Saad, W.; Rajatheva, N.; Chang, K.; Steinbach, D.; Sliwa, B.; Wietfeld, C.; Mei, K.; Shiri, H.; Zepernick, H.-J.; et al. 6G White Paper on Machine Learning in Wireless Communication Networks. arXiv 2020, arXiv:2004.13875.

25. Dai, L.; Jiao, R.; Adachi, F.; Poor, H.V.; Hanzo, L. Deep Learning for Wireless Communications: An Emerging Interdisciplinary Paradigm. IEEE Wirel. Commun. 2020, 27, 133-139. [CrossRef]

26. Manzalini, A. Quantum Communications in Future Networks and Services. Quantum Rep. 2020, 2, 221-232. [CrossRef]

27. Van Huynh, N.; Hoang, D.T.; Lu, X.; Niyato, D.; Wang, P.; Kim, D.I. Ambient backscatter communications: A contemporary survey. IEEE Commun. Surv. Tutor. 2018, 20, 2889-2922. [CrossRef]

28. Gupta, R.; Nair, A.; Tanwar, S.; Kumar, N. Blockchain-assisted secure UAV communication in 6G environment: Architecture, opportunities, and challenges. IET Commun. 2021, 1-16. [CrossRef] 
29. Mahdi Azari, M.; Geraci, G.; Garcia-Rodriguez, A.; Pollin, S. UAV-to-UAV communications in cellular networks. IEEE Trans. Wirel. Commun. 2020, 19, 6130-6144. [CrossRef]

30. Padamvathi, V.; Vardhan, B.V.; Krishna, A.V.N. Quantum Cryptography and Quantum Key Distribution Protocols: A Survey. In Proceedings of the 2016 IEEE 6th International Conference on Advanced Computing (IACC), Bhimavaram, India, 27-28 February 2016; pp. 556-562.

31. Akyildiz, I.F.; Kak, A.; Nie, S. 6G and Beyond: The Future of Wireless Communications Systems. IEEE Access 2020, 8 , 133995-134030. [CrossRef]

32. Chaer, A.; Salah, K.; Lima, C.; Ray, P.P.; Sheltami, T. Blockchain for 5G: Opportunities and challenges. In Proceedings of the 2019 IEEE Globecom Workshops (GC Wkshps), Waikoloa, HI, USA, 9-13 December 2019.

33. David, K.; Berndt, H. 6G Vision and requirements: Is there any need for beyond 5g? IEEE Veh. Technol. Mag. 2018, 13, 72-80. [CrossRef]

34. Fager, C.; Member, S.; Eriksson, T.; Member, S.; Fellow, H.Z.; Dielacher, F.; Member, S.; Studer, C.; Member, S. Implementation Challenges and Opportunities in Beyond-5G and 6G Communication. IEEE J. Microw. 2021, 1, 1-14.

35. Ponnimbaduge Perera, T.D.; Jayakody, D.N.K.; Sharma, S.K.; Chatzinotas, S.; Li, J. Simultaneous Wireless Information and Power Transfer (SWIPT): Recent Advances and Future Challenges. IEEE Commun. Surv. Tutor. 2018, 20, 264-302. [CrossRef]

36. Ebrahimzadeh, A.; Maier, M. Toward 6G: A New Era of Convergence; Wiley-IEEE Press: Hoboken, NJ, USA, 2021.

37. Akyildiz, I.F.; Kak, I.A. The internet of space things/cubesats. IEEE Netw. 2019, 33, 212-218. [CrossRef]

38. Howell, E. CubeSats: Tiny Payloads, Huge Benefits for Space Research ISpace. SPACE. Com. 2018. Available online: https: / / www.space.com/34324-cubesats.html (accessed on 20 January 2021).

39. Nayak, S.; Patgiri, R. 6G Communications: A Vision on the Potential Applications. arXiv 2020, arXiv:2005.07531.

40. Dang, S.; Amin, O.; Shihada, B.; Alouini, M.S. What should 6G be? Nat. Electron. 2020, 3, 20-29. [CrossRef]

41. Tariq, F.; Khandaker, M.R.A.; Wong, K.K.; Imran, M.A.; Bennis, M.; Debbah, M. A Speculative Study on 6G. IEEE Wirel. Commun. 2020, 27, 118-125. [CrossRef]

42. Yang, H.; Alphones, A.; Xiong, Z.; Niyato, D.; Zhao, J.; Wu, K. Artificial intelligence-enabled intelligent 6G networks. IEEE Netw. 2020, 34, 272-280. [CrossRef]

43. Kibria, M.G.; Nguyen, K.; Villardi, G.P.; Zhao, O.; Ishizu, K.; Kojima, F. Big Data Analytics, Machine Learning, and Artificial Intelligence in Next-Generation Wireless Networks. IEEE Access 2018, 6, 32328-32338. [CrossRef]

44. Shafin, R.; Liu, L.; Chandrasekhar, V.; Chen, H.; Reed, J.; Zhang, J.C. Artificial Intelligence-Enabled Cellular Networks: A Critical Path to Beyond-5G and 6G. IEEE Wirel. Commun. 2020, 27, 212-217. [CrossRef]

45. Alsharif, M.H.; Kelechi, A.H.; Albreem, M.A.; Chaudhry, S.A.; Sultan Zia, M.; Kim, S. Sixth generation (6G)wireless networks: Vision, research activities, challenges and potential solutions. Symmetry 2020, 12, 676. [CrossRef]

46. Viswanathan, H.; Mogensen, P.E. Communications in the 6G Era. IEEE Access 2020, 8, 57063-57074. [CrossRef]

47. Saad, W.; Bennis, M.; Chen, M. A Vision of 6G Wireless Systems: Applications, Trends, Technologies, and Open Research Problems. IEEE Netw. 2019, 34, 134-142. [CrossRef]

48. Chowdhury, M.Z.; Shahjalal, M.; Ahmed, S.; Jang, Y.M. 6G Wireless Communication Systems: Applications, Requirements, Technologies, Challenges, and Research Directions. arXiv 2019, arXiv:1909.11315.

49. Yuan, Y.; Zhao, Y.; Zong, B.; Parolari, S. Potential key technologies for 6G mobile communications. Sci. China Inf. Sci. 2020, 63, 183301. [CrossRef]

50. Rahnema, M. Ovewiew of the GSM System and Protocol Architecture. IEEE Commun. Mag. 1993, 31, 92-100. [CrossRef]

51. Gu, G.; Peng, G. The survey of GSM wireless communication system. In Proceedings of the ICCIA $2010-2010$ International Conference on Computer and Information Application, Tianjin, China, 3-5 December 2010; pp. 121-124.

52. Hui, J.Y.; Arthurs, E. A Broadband Packet Switch for Integrated Transport. IEEE J. Sel. Areas Commun. 1987, 5, 1264-1273. [CrossRef]

53. Jung, K. Transition from circuit-switched to packet-switched 3G mobile multimedia telephony. In Proceedings of the 2009 IEEE Int. Symp. a World Wireless, Mob. Multimed. Networks Work. WOWMOM 2009, Kos, Greece, 15-19 June 2009; pp. 1-9.

54. Denton, S.; Brinckerhoff, P. Key Concepts for Evolution Toward Beyond 3G Networks. IEEE Wirel. Commun. 2003, $10,43-48$.

55. Ekström, H.; Furuskär, A.; Karlsson, J.; Meyer, M.; Parkvall, S.; Torsner, J.; Wahlqvist, M. Technical solutions for the 3G long-term evolution. IEEE Commun. Mag. 2006, 44, 38-45. [CrossRef]

56. Imoize, A.L.; Adegbite, O.D. Measurements-Based Performance Analysis of a 4G Lte Network in and Around Shopping Malls and Campus Environments in Lagos Nigeria. Arid Zo. J. Eng. Technol. Environ. 2018, 14, 208-225.

57. Imoize, A.L.; Orolu, K.; Atayero, A.A.-A. Analysis of key performance indicators of a 4G LTE network based on experimental data obtained from a densely populated smart city. Data Br. 2020, 29, 1-17. [CrossRef]

58. Ojo, S.; Imoize, A.; Alienyi, D. Radial basis function neural network path loss prediction model for LTE networks in multitransmitter signal propagation environments. Int. J. Commun. Syst. 2021, 34, 1-26. [CrossRef]

59. Young, W. Advanced Mobile Phone Service: Introduction, Background, and Objectives. Bell Syst. Tech. J. 1979, 58. [CrossRef]

60. Peersman, G.; Cvetkovic, S.; Griffiths, P.; Spear, H. Global system for mobile communications short message service. IEEE Pers. Commun. 2000, 7, 15-23. [CrossRef]

61. Lee, W.C.Y. Overview of cellular CDMA. IEEE Trans. Veh. Technol. 1991, 40, 291-302. [CrossRef] 
62. Kara, N.; Issa, O.; Byette, A. Real 3G WCDMA networks performance analysis. In Proceedings of the Conference on Local Computer Networks, Sydney, NSW, Australia, 17 November 2005; pp. 586-592.

63. Attar, R.; Ghosh, D.; Lott, C.; Fan, M.; Black, P.J.; Rezaiifar, R.; Agashe, P. Evolution of cdma2000 cellular networks: Multicarrier EV-DO. IEEE Commun. Mag. 2006, 44, 46-53. [CrossRef]

64. Garhwal, A.; Bhattacharya, P.P. A review on WiMAX Technology. Int. J. Adv. Comput. Inf. Technol. 2012, 1, 167-173. [CrossRef]

65. Jimaa, S.; Chai, K.K.; Chen, Y.; Alfadhl, Y. LTE-A an overview and future research areas. Int. Conf. Wirel. Mob. Comput. Netw. Commun. 2011, 395-399. [CrossRef]

66. Lamba, M.; Singh, C. Challenges and Future Direction for MIMO Communication System. SOP Trans. Wirel. Commun. 2014, 1, 42-50. [CrossRef]

67. Wu, Q.; Zhang, R. Towards Smart and Reconfigurable Environment: Intelligent Reflecting Surface Aided Wireless Network. IEEE Commun. Mag. 2020, 58, 106-112. [CrossRef]

68. Ngo, H.Q.; Ashikhmin, A.; Yang, H.; Larsson, E.G.; Marzetta, T.L. Cell-Free Massive MIMO Versus Small Cells. IEEE Trans. Wirel. Commun. 2017, 16, 1834-1850. [CrossRef]

69. Akyildiz, I.F.; Jornet, J.M.; Han, C. Terahertz band: Next frontier for wireless communications. Phys. Commun. 2014, 12, 16-32. [CrossRef]

70. Faruque, S. Frequency Division Multiple Access (FDMA). In Radio Frequency Multiple Access Techniques Made Easy; Springer: Cham, Switzerland, 2019; pp. 21-33. [CrossRef]

71. Li, M.; Chen, T.; Yao, X. A critical review of "a practical guide to select quality indicators for assessing pareto-based search algorithms in search-based software engineering": Essay on quality indicator selection for SBSE. In Proceedings of the International Conference on Software Engineering, Casablanca, Morocco, 4-6 January 2018; pp. 17-20.

72. Barreto, A.; Vieira, R. OFDMA Systems and Applications; Taylor and Francis Group: Abingdon, UK, 2010; pp. 563-594; ISBN 9780429074684. [CrossRef]

73. Michailow, N.; Matthe, M.; Gaspar, I.S.; Caldevilla, A.N.; Mendes, L.L.; Festag, A.; Fettweis, G. Generalized frequency division multiplexing for 5th generation cellular networks. IEEE Trans. Commun. 2014, 62, 3045-3061. [CrossRef]

74. Bedoui, A.; Et-Tolba, M. A comparative analysis of filter bank multicarrier (FBMC) as 5G multiplexing technique. In Proceedings of the 2017 International Conference on Wireless Networks and Mobile Communications, WINCOM 2017, Rabat, Morocco, 1-4 November 2017; pp. 1-7.

75. Farhang, M.; Khaleghi Bizaki, H. Adaptive time-frequency multiplexing for 5G applications. AEU Int. J. Electron. Commun. 2020, 117, 153089. [CrossRef]

76. Baghani, M.; Parsaeefard, S.; Derakhshani, M.; Saad, W. Dynamic Non-Orthogonal Multiple Access and Orthogonal Multiple Access in 5G Wireless Networks. IEEE Trans. Commun. 2019, 67, 6360-6373. [CrossRef]

77. Cheng, W.; Zhang, W.; Jing, H.; Gao, S.; Zhang, H. Orbital angular momentum for wireless communications. IEEE Wirel. Commun. 2019, 26, 100-107. [CrossRef]

78. Akay, E.; Sengul, E.; Ayanoglu, E. Achieving full spatial multiplexing and full diversity in wireless communications. IEEE Wirel. Commun. Netw. Conf. WCNC 2006, 4, 2046-2050.

79. Samdanis, K.; Taleb, T. The Road beyond 5G: A Vision and Insight of the Key Technologies. IEEE Netw. 2020, 34, 135-141. [CrossRef]

80. Zhao, Y.; Yu, G.; Xu, H. 6G mobile communication networks: Vision, challenges, and key technologies. Sci. Sin. Inf. 2019, 49, 963-987. [CrossRef]

81. Zhang, Z.; Xiao, Y.; Ma, Z.; Xiao, M.; Ding, Z.; Lei, X.; Karagiannidis, G.K.; Fan, P. 6G Wireless Networks: Vision, Requirements, Architecture, and Key Technologies. IEEE Veh. Technol. Mag. 2019, 14, 28-41. [CrossRef]

82. Chen, S.; Liang, Y.C.; Sun, S.; Kang, S.; Cheng, W.; Peng, M. Vision, Requirements, and Technology Trend of 6G: How to Tackle the Challenges of System Coverage, Capacity, User Data-Rate and Movement Speed. IEEE Wirel. Commun. 2020, 27, 218-228. [CrossRef]

83. Freeman, B.; Nguyen, H. Software-defined networking. Build. Netw. Futur. Get. Smarter Faster More Flex. A Softw. Cent. Approach 2017, 87-102. [CrossRef]

84. Abdelwahab, S.; Hamdaoui, B.; Guizani, M.; Znati, T. Network function virtualization in 5G. IEEE Commun. Mag. 2016, 54, 84-91. [CrossRef]

85. Li, X.; Samaka, M.; Chan, H.A.; Bhamare, D.; Gupta, L.; Guo, C.; Jain, R. Network Slicing for 5G: Challenges and Opportunities. IEEE Internet Comput. 2018. [CrossRef]

86. Mansour, A.; Mesleh, R.; Abaza, M. New challenges in wireless and free space optical communications. Opt. Lasers Eng. 2016, 89, 95-108. [CrossRef]

87. Zhou, S.; Xu, W.; Wang, K.; Di Renzo, M.; Alouini, M.S. Spectral and Energy Efficiency of IRS-Assisted MISO Communication with Hardware Impairments. IEEE Wirel. Commun. Lett. 2020, 9, 1366-1369. [CrossRef]

88. Wang, M.; Zhu, T.; Zhang, T.; Zhang, J.; Yu, S.; Zhou, W. Security and privacy in 6G networks: New areas and new challenges. Digit. Commun. Netw. 2020, 6, 281-291. [CrossRef]

89. Chiaraviglio, L.; Blefari-Melazzi, N.; Liu, W.; Gutierrez, J.A.; Van De Beek, J.; Birke, R.; Chen, L.; Idzikowski, F.; Kilper, D.; Monti, J.P.; et al. 5G in rural and low-income areas: Are we ready? In Proceedings of the 2016 ITU Kaleidoscope Academic Conference ICTs a Sustainable World, ITU WT 2016, Bangkok, Thailand, 14-16 November 2016. [CrossRef] 
90. Rajatheva, N.; Atzeni, I.; Bjornson, E.; Bourdoux, A.; Buzzi, S.; Dore, J.-B.; Erkucuk, S.; Fuentes, M.; Guan, K.; Hu, Y.; et al. White Paper on Broadband Connectivity in 6G. arXiv 2020, arXiv:2004.14247.

91. Huang, T.; Yang, W.; Wu, J.; Ma, J.; Zhang, X.; Zhang, D. A Survey on Green 6G Network: Architecture and Technologies. IEEE Access 2019, 7, 175758-175768. [CrossRef]

92. Han, B.; Jiang, W.; Habibi, M.A.; Schotten, H.D. An Abstracted Survey on 6G: Drivers, Requirements, Efforts, and Enablers. arXiv 2021, arXiv:2101.01062.

93. Conceição, F.; Gomes, M.; Silva, V.; Dinis, R.; Silva, A.; Castanheira, D. A Survey of Candidate Waveforms for beyond 5G Systems. Electronics 2021, 10, 21. [CrossRef]

94. University of Oulu to begin groundbreaking 6G research as part of Academy of Finland's Flagship Programme. Available online: https:/ / www.oulu.fi/university/6genesis (accessed on 20 January 2021).

95. Gui, G.; Liu, M.; Tang, F.; Kato, N.; Adachi, F. 6G: Opening New Horizons for Integration of Comfort, Security and Intelligence. IEEE Wirel. Commun. 2020. [CrossRef]

96. Nie, S.; Jornet, J.M.; Akyildiz, I.F. Deep-learning-based resource allocation for multi-band communications in cubesat networks. In Proceedings of the 2019 IEEE International Conference on Communications Workshops (ICC Workshops), Shanghai, China, 20-24 May 2019.

97. Zhang, C.; Patras, P.; Haddadi, H. Deep Learning in Mobile and Wireless Networking: A Survey. IEEE Commun. Surv. Tutor. 2019, 21, 2224-2287. [CrossRef]

98. Weiss, K.; Khoshgoftaar, T.M.; Wang, D.D. A survey of transfer learning. J. Big Data 2016, 3. [CrossRef]

99. Nikolenko, S.I. Synthetic data for deep learning. arXiv 2019, arXiv:1909.11512.

100. Björnson, E.; Giselsson, P. Two Applications of Deep Learning in the Physical Layer of Communication Systems. IEEE Signal. Process. Mag. 2020, 37, 134-140. [CrossRef]

101. O'Shea, T.; Hoydis, J. An Introduction to Deep Learning for the Physical Layer. IEEE Trans. Cogn. Commun. Netw. 2017, 3, 563-575. [CrossRef]

102. Jiang, C.; Zhang, H.; Ren, Y.; Han, Z.; Chen, K.-C.; Hanzo, L. Machine Learning Paradigms for Next-Generation Wireless Networks. IEEE Wirel. Commun. 2017, 24, 98-105. [CrossRef]

103. Mozaffari, M.; Saad, W.; Bennis, M.; Nam, Y.H.; Debbah, M. A Tutorial on UAVs for Wireless Networks: Applications, Challenges, and Open Problems. IEEE Commun. Surv. Tutor. 2019, 21, 2334-2360. [CrossRef]

104. Rick, T.; Von Kapri, A.; Kuhlen, T. A virtual reality system for the simulation and manipulation of wireless communication networks. In Proceedings of the Proceedings IEEE Virtual Reality, Singapore, 19-23 March 2011; pp. 111-114.

105. Safavat, S.; Sapavath, N.N.; Rawat, D.B. Recent advances in mobile edge computing and content caching. Digit. Commun. Netw. 2020, 6, 189-194. [CrossRef]

106. Ulusar, U.D.; Celik, G.; Al-Turjman, F. Wireless Communication Aspects in the Internet of Things: An Overview. In Proceedings of the Proceedings-2017 IEEE 42nd Conference on Local Computer Networks Workshops, LCN Workshops 2017, Singapore, 9 October 2017; pp. 165-169.

107. Wang, J.; Tang, W.; Han, Y.; Jin, S.; Li, X.; Wen, C.-K.; Cheng, Q.; Cui, T.J. Interplay between RIS and AI in Wireless Communications: Fundamentals, Architectures, Applications, and Open Research Problems. arXiv 2021, arXiv:2101.00250.

108. Letaief, K.B.; Chen, W.; Shi, Y.; Zhang, J.; Zhang, Y.J.A. The Roadmap to 6G: AI Empowered Wireless Networks. IEEE Commun. Mag. 2019, 57, 84-90. [CrossRef]

109. Huang, H.; Guo, S.; Gui, G.; Yang, Z.; Zhang, J.; Sari, H.; Adachi, F. Deep learning for physical-layer 5g wireless techniques: Opportunities, challenges and solutions. IEEE Wirel. Commun. 2020, 27, 214-222. [CrossRef]

110. Mao, B.; Tang, F.; Yuichi, K.; Kato, N. AI based Service Management for 6G Green Communications. arXiv 2021, arXiv:2101.01588.

111. Aceto, G.; Ciuonzo, D.; Montieri, A.; Pescapé, A. Mobile Encrypted Traffic Classification Using Deep Learning: Experimental Evaluation, Lessons Learned, and Challenges. IEEE Trans. Netw. Serv. Manag. 2019, 16, 445-458. [CrossRef]

112. Luo, F.-L. Machine Learning for Future Wireless; John Wiley \& Sons Limited: Hoboken, NJ, USA, 2020.

113. Yuan, J.; Ngo, H.Q.; Matthaiou, M. Machine Learning-Based Channel Estimation in Massive MIMO with Channel Aging In Proceedings of the 2019 IEEE 20th International Workshop on Signal Processing Advances in Wireless Communications (SPAWC), Cannes, France, 2-5 July 2019.

114. Koller, M.; Hellings, C.; Knodlseder, M.; Wiese, T.; Neumann, D.; Utschick, W. Machine Learning for Channel Estimation from Compressed Measurements. In Proceedings of the 2018 15th International Symposium on Wireless Communication Systems (ISWCS), Lisbon, Portugal, 28-31 August 2018.

115. Mei, K.; Liu, J.; Zhang, X.; Wei, J. Machine Learning Based Channel Estimation: A Computational Approach for Universal Channel Conditions. arXiv 2019, arXiv:1911.03886.

116. Arikan, E.; Ul Hassan, N.; Lentmaier, M.; Montorsi, G.; Sayir, J. Challenges and some new directions in channel coding. J. Commun. Netw. 2015, 17, 328-338.

117. Alsheikh, M.A.; Lin, S.; Niyato, D.; Tan, H.P. Machine learning in wireless sensor networks: Algorithms, strategies, and applications. IEEE Commun. Surv. Tutor. 2014, 16, 1996-2018. [CrossRef]

118. Etzlinger, B.; Wymeersch, H. Synchronization and localization in wireless networks. Found. Trends Signal. Process. 2018, 12, 1-106. [CrossRef] 
119. Kumar, S.; Jeon, S.M.; Lee, S.R. Localization Estimation Using Artificial Intelligence Technique in Wireless Sensor Networks. J. Korea Inf. Commun. Soc. 2014, 39C, 820-827.

120. Pandey, S. Localization Adopting Machine Learning Techniques in Wireless Sensor Networks. Int. J. Comput. Sci. Eng. 2018, 6, 366-374. [CrossRef]

121. Luijten, B.; Cohen, R.; De Bruijn, F.J.; Schmeitz, H.A.W.; Mischi, M.; Eldar, Y.C.; Van Sloun, R.J.G. Deep Learning for Fast Adaptive Beamforming. In Proceedings of the ICASSP 2019 IEEE International Conference on Acoustics, Speech and Signal Processing (ICASSP) Brighton, United Kingdom, 12-17 May 2019; pp. 1333-1337.

122. Khan, S.; Huh, J.; Ye, J.C. Adaptive and Compressive Beamforming Using Deep Learning for Medical Ultrasound. IEEE Trans. Ultrason. Ferroelectr. Freq. Control. 2020, 67, 1558-1572. [CrossRef]

123. Sen, J. Mobility and Handoff Management in Wireless Networks. Trends Telecommun. Technol. 2010, 457-484. [CrossRef]

124. Jiang, W.; Strufe, M.; Schotten, H.D. Intelligent network management for 5G systems: The SELFNET approach. In Proceedings of the 2017 European Conference on Networks and Communications (EuCNC), Oulu, Finland, 12-15 June 2017.

125. Shuja, J.; Bilal, K.; Alanazi, E.; Alasmary, W.; Alashaikh, A. Applying machine learning techniques for caching in edge networks: A comprehensive survey. arXiv 2020, arXiv:2006.16864.

126. Bravo, C.; Bäckström, H. Edge Computing and Deployment Strategies for Communication Service Providers. 2020. Available online: https:/ / www.ericsson.com/en/reports-and-papers/white-papers/edge-computing-and-deployment-strategies-forcommunication-service-providers (accessed on 20 January 2021).

127. McClellan, M.; Cervelló-Pastor, C.; Sallent, S. Deep learning at the mobile edge: Opportunities for 5G networks. Appl. Sci. 2020, 10, 4735. [CrossRef]

128. Yu, F.R.; He, Y. Deep Reinforcement Learning for Wireless Networks; Springer: Cham, Switherland, 2019 ; ISBN 9783030105457.

129. Zhang, S.; Zhu, D. Towards artificial intelligence enabled 6G: State of the art, challenges, and opportunities. Comput. Networks 2020, 183, 107556. [CrossRef]

130. Ahmad, I.; Shahabuddin, S.; Kumar, T.; Harjula, E.; Meisel, M.; Juntti, M.; Sauter, T.; Ylianttila, M. Challenges of AI in Wireless Networks for IoT. IEEE Ind. Electron. Mag. 2021, 2-15. [CrossRef]

131. L'Heureux, A.; Grolinger, K.; Elyamany, H.F.; Capretz, M.A.M. Machine Learning with Big Data: Challenges and Approaches. IEEE Access 2017, 5, 7776-7797. [CrossRef]

132. Kato, N.; Mao, B.; Tang, F.; Kawamoto, Y.; Liu, J. Ten challenges in advancing machine learning technologies toward 6G. IEEE Wirel. Commun. 2020, 27, 96-103. [CrossRef]

133. Björnson, E.; Sanguinetti, L.; Wymeersch, H.; Hoydis, J.; Marzetta, T.L. Massive MIMO is a reality-What is next?: Five promising research directions for antenna arrays. Digit. Signal. Process. A Rev. J. 2019, 94, 3-20. [CrossRef]

134. Han, H.; Zhao, J.; Niyato, D.; Di Renzo, M.; Pham, Q.V. Intelligent Reflecting Surface Aided Network: Power Control for Physical-Layer Broadcasting. In Proceedings of the IEEE International Conference on Communications, Dublin, Ireland, 7-11 June 2020. [CrossRef]

135. Wu, Q.; Zhang, R. Intelligent Reflecting Surface Enhanced Wireless Network via Joint Active and Passive Beamforming. IEEE Trans. Wirel. Commun. 2019, 18, 5394-5409. [CrossRef]

136. Jung, M.; Saad, W.; Jang, Y.; Kong, G.; Choi, S. Performance analysis of large intelligent surfaces (LISs): Asymptotic data rate and channel hardening effects. IEEE Trans. Wirel. Commun. 2020, 19, 2052-2065. [CrossRef]

137. Yan, W.; Yuan, X.; Kuai, X. Passive Beamforming and Information Transfer via Large Intelligent Surface. IEEE Wirel. Commun. Lett. 2019, 9, 533-537. [CrossRef]

138. ElMossallamy, M.A.; Zhang, H.; Song, L.; Seddik, K.G.; Han, Z.; Li, G.Y. Reconfigurable intelligent surfaces for wireless communications: Principles, challenges, and opportunities. IEEE Trans. Cogn. Commun. Netw. 2020, 6, 990-1002. [CrossRef]

139. Liaskos, C.; Nie, S.; Tsioliaridou, A.; Pitsillides, A.; Ioannidis, S.; Akyildiz, I. A New Wireless Communication Paradigm through Software-Controlled Metasurfaces. IEEE Commun. Mag. 2018, 56, 162-169. [CrossRef]

140. Hum, S.V.; Perruisseau-Carrier, J. Reconfigurable reflectarrays and array lenses for dynamic antenna beam control: A review. IEEE Trans. Antennas Propag. 2014, 62, 183-198. [CrossRef]

141. Tan, X.; Sun, Z.; Koutsonikolas, D.; Jornet, J.M. Enabling Indoor Mobile Millimeter-wave Networks Based on Smart Reflect-arrays. In Proceedings of the IEEE INFOCOM, Honolulu, HI, USA, 16-19 April 2018; pp. 270-278.

142. Foo, S. Liquid Crystal Reconfigurable Metasurface Reflector Antenna. U.S. Patent 10,490,903, 26 November 2019.

143. Shen, H.; Xu, W.; Gong, S.; He, Z.; Zhao, C. Secrecy Rate Maximization for Intelligent Reflecting Surface Assisted Multi-Antenna Communications. IEEE Commun. Lett. 2019, 23, 1488-1492. [CrossRef]

144. Imoize, A.; Ben-Adeola, B.; Adebisi, J. Development of a Multifactor-Security-Protocol System Using Ambient Noise Synthesis. ICST Trans. Secur. Saf. 2020, 6, 1-12. [CrossRef]

145. Zhang, Z.; Zhang, C.; Jiang, C.; Jia, F.; Ge, J.; Gong, F. Improving Physical Layer Security for Reconfigurable Intelligent Surface aided NOMA 6G Networks. arXiv 2021, arXiv:2101.06948.

146. Wu, Q.; Zhang, R. Weighted Sum Power Maximization for Intelligent Reflecting Surface Aided SWIPT. IEEE Wirel. Commun. Lett. 2020, 9, 586-590. [CrossRef]

147. Hu, S.; Rusek, F.; Edfors, O. The Potential of Using Large Antenna Arrays on Intelligent Surfaces. In Proceedings of the IEEE Veh. Technol. Conference, Sydney, Astrialia, 4-7 June 2017; pp. 4-9. 
148. Yu, X.; Xu, D.; Schober, R. Enabling secure wireless communications via intelligent reflecting surfaces. In Proceedings of the 2019 IEEE Global Communications Conference, GLOBECOM 2019, Waikoloa, HI, USA, 9-13 December 2019.

149. Cui, M.; Zhang, G.; Zhang, R. Secure wireless communication via intelligent reflecting surface. IEEE Wirel. Commun. Lett. 2019, 8, 1410-1414. [CrossRef]

150. Yu, X.; Xu, D.; Sun, Y.; Ng, D.W.K.; Schober, R. Robust and Secure Wireless Communications via Intelligent Reflecting Surfaces. IEEE J. Sel. Areas Commun. 2020, 38, 2637-2652. [CrossRef]

151. Hong, S.; Pan, C.; Ren, H.; Wang, K.; Nallanathan, A. Artificial-Noise-Aided Secure MIMO Wireless Communications via Intelligent Reflecting Surface. IEEE Trans. Commun. 2020, 68, 7851-7866. [CrossRef]

152. Matthaiou, M.; Yurduseven, O.; Ngo, H.Q.; Morales-Jimenez, D.; Cotton, S.L.; Fusco, V.F. The Road to 6G: Ten Physical Layer Challenges for Communications Engineers. IEEE Commun. Mag. 2020, 59, 64-69. [CrossRef]

153. Yang, H.; Cao, X.; Yang, F.; Gao, J.; Xu, S.; Li, M.; Chen, X.; Zhao, Y.; Zheng, Y.; Li, S. A programmable metasurface with dynamic polarization, scattering and focusing control. Sci. Rep. 2016, 6, 35692. [CrossRef]

154. Wang, Z.; Liu, L.; Cui, S. Channel Estimation for Intelligent Reflecting Surface Assisted Multiuser Communications. In Proceedings of the IEEE Wirel. Commun. Netw. Conf. WCNC, Seoul, Korea, 6-9 April 2020.

155. Nadeem, Q.-U.-A.; Kammoun, A.; Chaaban, A.; Debbah, M.; Alouini, M.-S. Intelligent Reflecting Surface Assisted Wireless Communication: Modeling and Channel Estimation. arXiv 2019, arXiv:1906.02360.

156. Mishra, D.; Johansson, H. Channel Estimation and Low-complexity Beamforming Design for Passive Intelligent Surface Assisted MISO Wireless Energy Transfer. In Proceedings of the ICASSP 2019 IEEE International Conference on Acoustics, Speech and Signal Processing (ICASSP), Brighton, UK, 12-17 May 2019; pp. 4659-4663.

157. Myung, S.H.O.N.H. MIMO channel estimation method using ray-tracing propagation model. Electron. Lett. 2005, $41,40-41$.

158. Di Renzo, M.; Song, J. Reflection probability in wireless networks with metasurface-coated environmental objects: An approach based on random spatial processes. Eurasip J. Wirel. Commun. Netw. 2019, 2019, 99. [CrossRef]

159. Taha, A.; Alrabeiah, M.; Alkhateeb, A. Enabling Large Intelligent Surfaces with Compressive Sensing and Deep Learning. arXiv 2019, arXiv:1904.10136.

160. Qin, Z.; Ye, H.; Li, G.Y.; Juang, B.H.F. Deep learning in physical layer communications. IEEE Wirel. Commun. 2019, 26, 93-99. [CrossRef]

161. Yang, Z.; Chen, M.; Wong, K.-K.; Poor, H.V.; Cui, S. Federated Learning for 6G: Applications, Challenges, and Opportunities. arXiv 2021, arXiv:2101.01338.

162. Taha, A.; Zhang, Y.; Mismar, F.B.; Alkhateeb, A. Deep Reinforcement Learning for Intelligent Reflecting Surfaces: Towards Standalone Operation. In Proceedings of the IEEE Workshop on Signal Processing Advances in Wireless Communications, SPAWC, Atlanta, GA, USA, 26-29 May 2020; Volume 2020.

163. Ogbebor, J.O.; Imoize, A.L.; Atayero, A.A.-A. Energy Efficient Design Techniques in Next-Generation Wireless Communication Networks: Emerging Trends and Future Directions. Wirel. Commun. Mob. Comput. 2020, 2020, 19. [CrossRef]

164. Shahraki, A.; Abbasi, M.; Piran, M.J.; Chen, M.; Cui, S. A Comprehensive Survey on 6G Networks:Applications, Core Services, Enabling Technologies, and Future Challenges. arXiv 2021, arXiv:2101.12475.

165. Angjo, J.; Shayea, I.; Ergen, M.; Mohamad, H.; Alhammadi, A.; Daradkeh, Y.I. Handover Management of Drones in Future Mobile Networks: 6G Technologies. IEEE Access 2021, 9, 1. [CrossRef]

166. Demir, K.A.; Cicibas, H.; Arica, N. Unmanned aerial vehicle domain: Areas of research. Def. Sci. J. 2015, 65, 319-329. [CrossRef]

167. Valavanis, K.P.; Vachtsevanos, G.J. Handbook of Unmanned Aerial Vehicles; Springer: Dordrecht, The Netherlands, 2015; ISBN 9789048197071.

168. Kanistras, K.; Martins, G.; Rutherford, M.J.; Valavanis, K.P. A survey of unmanned aerial vehicles (UAVs) for traffic monitoring. In Proceedings of the 2013 International Conference on Unmanned Aircraft Systems (ICUAS), Atlanta, GA, USA, 28-31 May 2013; pp. 221-234.

169. Elloumi, M.; Dhaou, R.; Escrig, B.; Idoudi, H.; Saidane, L.A. Monitoring road traffic with a UAV-based system. In Proceedings of the 2018 IEEE Wireless Communications and Networking Conference (WCNC), Barcelona, Brazil, 15-18 April 2018.

170. Chamoso, P.; González-Briones, A.; De La Prieta, F.; Corchado, J.M. Computer vision system for fire detection and report using UAVs. CEUR Workshop Proc. 2018, 2146, 40-49.

171. Ntalakas, A.; Dimoulas, C.A.; Kalliris, G.; Veglis, A. Drone Journalism: Generating Immersive Experiences. J. Media Crit. 2017, 3, 187-199. [CrossRef]

172. Li, B.; Fei, Z.; Zhang, Y. UAV communications for $5 \mathrm{G}$ and beyond: Recent advances and future trends. IEEE Internet Things J. 2019, 6, 2241-2263. [CrossRef]

173. Noor, F.; Khan, M.A.; Al-Zahrani, A.; Ullah, I.; Al-Dhlan, K.A. A Review on Communications Perspective of Flying Ad-Hoc Networks: Key Enabling Wireless Technologies, Applications, Challenges and Open Research Topics. Drones 2020,4 , 65. [CrossRef]

174. Mahmoud, A.A.; Elazhary, T.T.; Zaki, A. Remote sensing CubeSat. Sens. Syst. Next Gener. Satell. XIV 2010, 7826, $78262 \mathrm{I}$.

175. Peral, E.; Im, E.; Wye, L.; Lee, S.; Tanelli, S.; Rahmat-Samii, Y.; Horst, S.; Hoffman, J.; Yun, S.H.; Imken, T.; et al. Radar Technologies for Earth Remote Sensing from CubeSat Platforms. Proc. IEEE 2018, 106, 404-418. [CrossRef]

176. Wijnen, M.; Aguera-Lopez, N.; Correyero-Plaza, S.; Perez-Grande, D. CubeSat Lunar Positioning System Enabled by Novel On-Board Electric Propulsion. IEEE Trans. Plasma Sci. 2018, 46, 319-329. [CrossRef] 
177. Narayanasamy, A.; Ahmad, Y.A.; Othman, M. Nanosatellites constellation as an IoT communication platform for near equatorial countries. IOP Conf. Ser. Mater. Sci. Eng. 2017, 260, 13. [CrossRef]

178. Camps, A. Nanosatellites and Applications to Commercial and Scientific Missions. Satell. Mission. Technol. Geosci. 2020. [CrossRef]

179. Xiao, Z.; Zhu, L.; Xia, X.G. UAV communications with millimeter-wave beamforming: Potentials, scenarios, and challenges. China Commun. 2020, 17, 147-166. [CrossRef]

180. Goudarzi, S.; Anisi, M.H.; Ciuonzo, D.; Soleymani, S.A.; Pescape, A. Employing Unmanned Aerial Vehicles for Improving Handoff using Cooperative Game Theory. IEEE Trans. Aerosp. Electron. Syst. 2020, 1, 1-17. [CrossRef]

181. Amazon Joins SpaceX, OneWeb and Facebook in the Race to Create Space-Based Internet Services. Available online: https: //servinfo.com.uy/amazon-joins-spacex-oneweb-and-facebook-in-the-race-to-create-space-based-internet-services-media-1/ (accessed on 21 January 2021).

182. Saeed, N.; Elzanaty, A.; Almorad, H.; Dahrouj, H.; Al-Naffouri, T.Y.; Alouini, M.S. CubeSat Communications: Recent Advances and Future Challenges. IEEE Commun. Surv. Tutor. 2020, 22, 1839-1862. [CrossRef]

183. Yao, H.; Wang, L.; Wang, X.; Lu, Z.; Liu, Y. The Space-Terrestrial Integrated Network: An Overview. IEEE Commun. Mag. 2018, 56, 178-185. [CrossRef]

184. Giordani, M.; Zorzi, M. Non-Terrestrial Networks in the 6G Era: Challenges and Opportunities. IEEE Netw. 2020, 12-19. [CrossRef]

185. Gupta, L.; Jain, R.; Vaszkun, G. Survey of Important Issues in UAV Communication Networks. IEEE Commun. Surv. Tutor. 2016, 18, 1123-1152. [CrossRef]

186. Zakeri, A.; Khalili, A.; Javan, M.R.; Mokari, N.; Jorswieck, E.A. Robust Energy-Efficient Resource Management, SIC Ordering, and Beamforming Design for MC MISO-NOMA Enabled 6G. arXiv 2021, arXiv:2101.0679.

187. Imoize, A.L.; Ibhaze, A.E.; Atayero, A.A.; Kavitha, K.V.N. Standard Propagation Channel Models for MIMO Communication Systems. Wirel. Commun. Mob. Comput. 2021, 2021, 36. [CrossRef]

188. Petrov, V.; Pyattaev, A.; Moltchanov, D.; Koucheryavy, Y. Terahertz band communications: Applications, research challenges, and standardization activities. Int. Congr. Ultra Mod. Telecommun. Control. Syst. Work. 2016, 2016, 183-190.

189. Abadal, S.; Han, C.; Jornet, J.M. Wave Propagation and Channel Modeling in Chip-Scale Wireless Communications: A Survey from Millimeter-Wave to Terahertz and Optics. IEEE Access 2020, 8, 278-293. [CrossRef]

190. Ndjiongue, A.R.; Ngatched, T.M.N.; Dobre, O.A.; Armada, A.G. VLC-based networking: Feasibility and challenges. IEEE Netw. 2020, 34, 158-165. [CrossRef]

191. Ariyanti, S.; Suryanegara, M. Visible Light Communication (VLC) for 6G Technology: The Potency and Research Challenges. In Proceedings of the 2020 Fourth World Conference on Smart Trends in Systems, Security and Sustainability (WorldS4), London, UK, 27-28 July 2020; pp. 490-493.

192. Wang, F.; Liu, Y.; Jiang, F. Nan C. High speed underwater visible light communication system based on LED employing maximum ratio combination with multi-PIN reception. Opt. Commun. 2018, 425, 106-112. [CrossRef]

193. Blinowski, G. Security issues in visible light communication systems. IFAC-PapersOnLine 2015, 48, 234-239. [CrossRef]

194. Sadiku, M.N.O.; Musa, S.M.; Nelatury, S.R. Free Space Optical Communications: An Overview. Eur. Sci. J. ESJ 2016, 12, 55. [CrossRef]

195. Malik, A.; Singh, P. Free Space Optics: Current Applications and Future Challenges. Int. J. Opt. 2015, 2015. [CrossRef]

196. Rehman, S.U.; Ullah, S.; Chong, P.H.J.; Yongchareon, S.; Komosny, D. Visible light communication: A system perspectiveOverview and challenges. Sensors 2019, 19, 1153. [CrossRef]

197. Yang, X.; Matthaiou, M.; Yang, J.; Wen, C.K.; Gao, F.; Jin, S. Hardware-Constrained Millimeter-Wave Systems for 5G: Challenges, Opportunities, and Solutions. IEEE Commun. Mag. 2019, 57, 44-50. [CrossRef]

198. Han, C.; Yan, L.; Yuan, J. Hybrid Beamforming for Terahertz Wireless Communications: Challenges, Architectures, and Open Problems. arXiv 2021, arXiv:2101.08469.

199. Ajose, S.O.; Imoize, A.L. Propagation measurements and modelling at $1800 \mathrm{MHz}$ in Lagos Nigeria. Int. J. Wirel. Mob. Comput. 2013, 6, 165-174. [CrossRef]

200. Sebastian, M.T.; Wang, H.; Jantunen, H. Low temperature co-fired ceramics with ultra-low sintering temperature: A review. Curr. Opin. Solid State Mater. Sci. 2016, 20, 151-170. [CrossRef]

201. Zhai, B.; Zhu, Y.; Tang, A.; Wang, X. THzPrism: Frequency-Based Beam Spreading for Terahertz Communication Systems. IEEE Wirel. Commun. Lett. 2020, 9, 897-900. [CrossRef]

202. Tan, J.; Dai, L. THz Precoding for 6G: Applications, Challenges, Solutions, and Opportunities. arXiv 2020, arXiv:2005.10752.

203. Nagatsuma, T. Breakthroughs in Photonics 2013: THz Communications Based on Photonics. IEEE Photonics J. 2014, 6. [CrossRef]

204. Chorti, A.; Barreto, A.N.; Kopsell, S.; Zoli, M.; Chafii, M.; Sehier, P.; Fettweis, G.; Poor, H.V. Context-Aware Security for 6G Wireless The Role of Physical Layer Security. arXiv 2021, arXiv:2101.01536.

205. Manpreet, K. Free Space Optics Communication-Trends and Challenges. Int. J. Eng. Dev. Res. 2017, 5, $2132-2134$.

206. Gampala, G.; Reddy, C.J. Massive MIMO-Beyond 4G and a basis for 5G. In Proceedings of the 2018 International Appl. Comput. Electromagn. Soc. Symp. Denver, ACES-Denver 2018, Denver, CO, USA, 24-29 March 2018; pp. 1-2.

207. Zhang, S.; Staudinger, E.; Jost, T.; Wang, W.; Gentner, C.; Dammann, A.; Wymeersch, H.; Hoeher, P.A. Distributed Direct Localization Suitable for Dense Networks. IEEE Trans. Aerosp. Electron. Syst. 2020, 56, 1209-1227. [CrossRef] 
208. Crowcroft, J.; Kempf, J.; Mendes, P.J.; Sofia, R. User-Centric Networking-10372 Abstracts Collection and Report. In Proceedings of the Dagstuhl Seminar Proceedings 2011, Schloss Dagstuhl-Leibniz-Zentrum fuer Informatik, Wadern, Germany, 14-19 November 2011; pp. 1-17.

209. Alamu, O.; Gbenga-Ilori, A.; Adelabu, M.; Imoize, A.; Ladipo, O. Energy efficiency techniques in ultra-dense wireless heterogeneous networks: An overview and outlook. Eng. Sci. Technol. Int. J. 2020, 23, 1308-1326. [CrossRef]

210. You, L.; Li, K.-X.; Wang, J.; Gao, X.; Xia, X.-G.; Ottersten, B. Massive MIMO Transmission for LEO Satellite Communications. IEEE J. Sel. Areas Commun. 2020, 38, 1851-1865. [CrossRef]

211. Zhang, Q.; Ma, W.; Feng, Z.; Han, Z. Backhaul Capacity Aware Interference Mitigation Framework in 6G Cellular Internet of Things. IEEE Internet Things J. 2021, 4662, 1.

212. Hoang, T.M.; Ngo, H.Q.; Duong, T.Q.; Tuan, H.D.; Marshall, A. Cell-free massive MIMO networks: Optimal power control against active eavesdropping. IEEE Trans. Commun. 2018, 66, 4724-4737. [CrossRef]

213. Dai, H.N.; Zheng, Z.; Zhang, Y. Blockchain for Internet of Things: A Survey. IEEE Internet Things J. 2019, 6, 8076-8094. [CrossRef]

214. Sharma, P.K.; Chen, M.Y.; Park, J.H. A Software Defined Fog Node Based Distributed Blockchain Cloud Architecture for IoT. IEEE Access 2018, 6, 115-124. [CrossRef]

215. Yang, R.; Yu, F.R.; Si, P.; Yang, Z.; Zhang, Y. Integrated Blockchain and Edge Computing Systems: A Survey, Some Research Issues and Challenges. IEEE Commun. Surv. Tutor. 2019, 21, 1508-1532. [CrossRef]

216. Jovović, I.; Husnjak, S.; Forenbacher, I.; Maček, S. Innovative Application of 5G and Blockchain Technology in Industry 4.0 EAI Endorsed Trans. Ind. Networks Intell. Syst. 2019, 6, 157122. [CrossRef]

217. Xie, J.; Tang, H.; Huang, T.; Yu, F.R.; Xie, R.; Liu, J.; Liu, Y. A Survey of Blockchain Technology Applied to Smart Cities: Research Issues and Challenges. IEEE Commun. Surv. Tutor. 2019, 21, 2794-2830. [CrossRef]

218. Memon, M.L.; Saxena, N.; Roy, A.; Shin, D.R. Backscatter Communications: Inception of the Battery-Free Era-A Comprehensive Survey. Electronics 2019, 8, 129. [CrossRef]

219. Long, R.; Guo, H.; Zhang, L.; Liang, Y.C. Full-Duplex Backscatter Communications in Symbiotic Radio Systems. IEEE Access 2019, 7, 21597-21608. [CrossRef]

220. Ciuonzo, D.; Gelli, G.; Pescape, A.; Verde, F. Decision Fusion Rules in Ambient Backscatter Wireless Sensor Networks. In Proceedings of the 2019 IEEE 30th Annual International Symposium on Personal, Indoor and Mobile Radio Communications (PIMRC), Istanbul, Turkey, 8-11 September 2019.

221. Qian, J.; Parks, A.N.; Smith, J.R.; Gao, F.; Jin, S. IoT Communications with M -PSK Modulated Ambient Backscatter: Algorithm, Analysis, and Implementation. IEEE Internet Things J. 2019, 6, 844-855. [CrossRef]

222. Tao, Q.; Zhong, C.; Chen, X.; Lin, H.; Zhang, Z. Optimal Detection for Ambient Backscatter Communication Systems with Multiantenna Reader under Complex Gaussian Illuminator. IEEE Internet Things J. 2020, 7, 11371-11383. [CrossRef]

223. Ajose, S.O.; Bakare, R.A.; Imoize, A.L. BER comparison of different modulation schemes over AWGN and Rayleigh fading channels for MIMO-OFDM system. Int. J. Commun. Netw. Distrib. Syst. 2017, 18, 129-147. [CrossRef]

224. Ajose, S.O.; Imoize, A.L.; Obiukwu, O.M. Bit error rate analysis of different digital modulation schemes in orthogonal frequency division multiplexing systems. Niger. J. Technol. 2018, 37, 727-734. [CrossRef]

225. Liu, V.; Parks, A.; Talla, V.; Gollakota, S.; Wetherall, D.; Smith, J.R. Ambient backscatter. ACM SIGCOMM Comput. Commun. Rev. 2013, 43, 39-50. [CrossRef]

226. Gisin, N.; Thew, R.T. Quantum communication technology. Electron. Lett. 2010, 46, 965-967. [CrossRef]

227. Pirandola, S.; Eisert, J.; Weedbrook, C.; Furusawa, A.; Braunstein, S.L. Advances in quantum teleportation. Nat. Photonics 2015, 9 , 641-652. [CrossRef]

228. Arun, G.; Mishra, V. A review on quantum computing and communication. In Proceedings of the 20142 nd International Conference on "Emerging Technology Trends in Electronics, Communication and Networking", ET2ECN 2014, Surat, India, 26-27 December 2014; Volume 1, pp. 9-13.

229. Nawaz, S.J.; Sharma, S.K.; Wyne, S.; Patwary, M.N.; Asaduzzaman, M. Quantum Machine Learning for 6G Communication Networks: State-of-the-Art and Vision for the Future. IEEE Access 2019, 7, 46317-46350. [CrossRef]

230. Cacciapuoti, A.S.; Caleffi, M.; Tafuri, F.; Cataliotti, F.S.; Gherardini, S.; Bianchi, G. Quantum Internet: Networking Challenges in Distributed Quantum Computing. IEEE Netw. 2020, 34, 137-143. [CrossRef]

231. Lee, Y.L.; Qin, D.; Wang, L.; Sim, G.H. 6G Massive Radio Access Networks: Key Applications, Requirements and Challenges. IEEE Open J. Veh. Technol. 2020, 2, 54-66. [CrossRef]

232. Nokia Nokia, Elisa and Qualcomm Achieve 5G Speed Record in Finland. Available online: https://www.nokia.com/about-us/ news / releases /2020/11/18/nokia-elisa-and-qualcomm-achieve-5g-speed-record-in-finland/\#: \{\}:text=Espoo\%2CFinland-Nokia\%2CElisa,5GmmWavedevicesconnectedsimultaneously (accessed on 8 February 2020).

233. Qualcomm TIM, Ericsson and Qualcomm Set World Record for Long Distance Speed with 5G mmWave Applied to FWA Available online: https:/ / www.qualcomm.com/news/releases/2020/12/04/tim-ericsson-and-qualcomm-set-world-recordlong-distance-speed-5g-mmwave (accessed on 8 December 2020).

234. Padiyar, D.; Hart, S.; Padiyar, J.; Burman, D. Full Color White Light Transmission Hologram by Monochromatic Recording. In Proceedings of the Imaging and Applied Optics 2014, Seattle, WA, USA, 13-17 July 2014.

235. Sung, J.; Lee, G.Y.; Lee, B. Progresses in the practical metasurface for holography and lens. Nanophotonics 2019, 8, 1701-1718. [CrossRef] 
236. Xu, X.; Pan, Y.; Lwin, P.P.M.Y.; Liang, X. 3D holographic display and its data transmission requirement. In Proceedings of the 2011 Int. Conf. Inf. Photonics Opt. Communication IPOC, Jurong West, Singpore, 21-23 October 2011; pp. 1-4.

237. Liu, Y.; Yuan, X.; Xiong, Z.; Kang, J.; Wang, X.; Niyato, D. Federated learning for 6G communications: Challenges, methods, and future directions. China Commun. 2020, 17, 105-118. [CrossRef]

238. Jiang, W.; Han, B.; Habibi, M.A.; Schotten, H.D. The Road Towards 6G: A Comprehensive Survey. IEEE Open J. Commun. Soc. 2021. [CrossRef]

239. Kekkonen, M.; Agyei, E.E.Y.F.; Meschtscherjakov, A.; Oinas-Kukkonen, H. Personalized persuasive holograms: Use case scenario-Running with arnold. CEUR Workshop Proc. 2020, 2629.

240. Yu, H.; Lee, H.; Jeon, H. What is 5G? Emerging 5G mobile services and network requirements. Sustainbility 2017, 9, 1848. [CrossRef]

241. Chen, Y.; Zhu, P.; He, G.; Yan, X.; Baligh, H.; Wu, J. From connected people, connected things, to connected intelligence. In Proceedings of the 2nd 6G Wireless Summit (6G SUMMIT) 2020, Levi, Finland, 17-20 March 2020; pp. 1-7.

242. Burkhardt, F.; Patachia, C.; Mendes, L.; Pirttikangas, S.; Jou, E.; Kuvaja, P.; Heikkilä, M.; Päivärinta, T.; Isomursu, M.; Thakur, A.; et al. 6G White Paper on Validation and Trials for Verticals Towards 2030's. 2020. Available online: https:// www.6gchannel.com/wp-content/uploads/2020/04/6g-white-paper-validation-trials.pdf (accessed on 11 November 2020).

243. Holographic Display Market by Technology (Electro Holographic, Touchable, Laser), Product (Camera, Digital Signage, Medical scanners, Smart TV), Application (Consumer, Commercial, Medical, Industrial), Geography-Global Forecast to $2013-2020$. Available online: https:/ / www.marketsandmarkets.com/Market-Reports/holographic-market-144316799.html (accessed on 11 November 2020).

244. Vulgarakis, A.; Karapantelakis, A.; Fersman, E.; Schrammar, N. 5G Teleoperated Vehicles for Future Public Transport. Available online: https:/ / www.ericsson.com/research-blog/5g-teleoperated-vehicles-future-public-transport/ (accessed on 5 January 2021)

245. Raissi, F.; Yangui, S.; Camps, F. Autonomous Cars, 5G Mobile Networks and Smart Cities: Beyond the Hype. In Proceedings of the 2019 IEEE 28th International Conference on Enabling Technologies: Infrastructure for Collaborative Enterprises, WETICE 2019, Napoli, Italy, 12-14 June 2019; pp. 180-185.

246. ITU-T. The Tactile Internet: ITU-T Technology Watch Report. August 2014, pp. 1-24. Available online: https://www.itu.int/en/ ITU-T/techwatch/Pages/tactile-internet.aspx (accessed on 11 November 2020).

247. Miao, Y.; Jiang, Y.; Peng, L.; Hossain, M.S.; Muhammad, G. Telesurgery Robot Based on 5G Tactile Internet. Mob. Netw. Appl. 2018, 23, 1645-1654. [CrossRef]

248. Akyildiz, I.; Pierobon, M.; Balasubramaniam, S.; Koucheryavy, Y. The Internet of Bio-NanoThings. IEEE Commun. Mag. 2015, 53, 32-40. [CrossRef]

249. El-Fatyany, A.; Wang, H.; Abd El-atty, S.M.; Khan, M. Biocyber Interface-Based Privacy for Internet of Bio-nano Things. Wirel. Pers. Commun. 2020, 114, 1465-1483. [CrossRef]

250. Rajatheva, N.; Atzeni, I.; Bicais, S.; Bjornson, E.; Bourdoux, A.; Buzzi, S.; D’Andrea, C.; Dore, J.-B.; Erkucuk, S.; Fuentes, M.; et al. Scoring the Terabit/s Goal:Broadband Connectivity in 6G. arXiv 2020, arXiv:2008.07220.

251. Özdemir, V.; Hekim, N. Birth of Industry 5.0: Making Sense of Big Data with Artificial Intelligence, "the Internet of Things" and Next-Generation Technology Policy. Omi. A J. Integr. Biol. 2018, 22, 65-76. [CrossRef] [PubMed]

252. Sachsenmeier, P. Industry 5.0-The Relevance and Implications of Bionics and Synthetic Biology. Engineering 2016, 2, 225-229. [CrossRef]

253. Stoynov, V.; Ivanov, A.; Mihaylova, D. Conceptual framework for quality assessment in human-centric 6G XR services Conceptual framework for quality assessment in human- centric 6G XR services. IOP Conf. Ser. Mater. Sci. Eng. 2021, 1032, 1-6. [CrossRef]

254. Elbamby, M.S.; Perfecto, C.; Bennis, M.; Doppler, K. Toward Low-Latency and Ultra-Reliable Virtual Reality. IEEE Netw. 2018, 32, 78-84. [CrossRef]

255. Han, H.; Zhao, J.; Zhai, W.; Xiong, Z.; Lu, W. Smart City Enabled by 5G/6G Networks: An Intelligent Hybrid Random Access Scheme. arXiv 2021, arXiv:2101.06421.

256. Nguyen, D.C.; Pathirana, P.N.; Ding, M.; Seneviratne, A. Blockchain for 5G and beyond networks: A state of the art survey. J. Netw. Comput. Appl. 2020, 166, 102693. [CrossRef]

257. Moioli, R.C.; Nardelli, P.H.J.; Taynnan, M.; Saad, W.; Hekmatmanesh, A.; Gória, P.; de Sena, A.S.; Dzaferagic, M.; Siljak, H.; van Leekwijck, W.; et al. Neurosciences and 6G: Lessons from and needs of communicative brains. arXiv 2020, arXiv:2004.01834.

258. Watanabe, T.; Rees, G. Brain network dynamics in high-functioning individuals with autism. Nat. Commun. 2017, $8,16048$. [CrossRef] [PubMed]

259. Hekmatmanesh, A.; Nardelli, P.H.J.; Handroos, H. Review of the State-of-the-art on Bio-signal-based Brain-controlled Vehicles. arXiv 2020, arXiv:2006.02937.

260. Mahmoud, H.H.H.; Ismail, T. 6G: A comprehensive survey on technologies, applications, challenges, and research problems. Trans. Emerg. Telecommun. Technol. 2021. [CrossRef]

261. Eckhart, M.; Ekelhart, A. A Specification-based State Replication Approach for Digital Twins. In Proceedings of the 2018 Workshop on Cyber-Physical Systems Security and Privacy, Toronto, ON, Canada, 19 October 2018; pp. 36-47.

262. Souza, V.; Cruz, R.; Silva, W.; Lins, S.; Lucena, V. A Digital Twin Architecture Based on the Industrial Internet of Things Technologies. In Proceedings of the 2019 IEEE International Conference on Consumer Electronics, ICCE 2019, Las Vegas, NV, USA, 11-13 January 2019; pp. 1-2. 
263. Fernando, V.; Franques, A. Replica: A Wireless Manycore for Communication-Intensive and Approximate Data. In Proceedings of the Twenty-Fourth International Conference on Architectural Support for Programming Languages and Operating Systems, Providence, RI, USA, 13-17 April 2019; pp. 849-863.

264. Parrott, A.; Warshaw, L. Industry 4.0 and the Digital Twin; Deloitte University Press: Westlake, TX, USA, 2017; pp. 1-17. Available online: https:/ / dupress.deloitte.com/dup-us-en/focus/industry-4-0/digital-twin-technology-smart-factory.html (accessed on 22 October 2020).

265. Del, T.U.; Ding, A.Y.; Janssen, M. Opportunities for Applications Using 5G Networks: Requirements, Challenges, and Outlook. In Proceedings of the Seventh International Conference on Telecommunications and Remote Sensing, Barcelona, Spain, 8-9 October 2018; pp. 27-34.

266. 5GIC Strategy Advisory Board 6G WIRELESS: A New Strategic Vision. Inst. Commun. Syst. James Clerk Maxwell Build. Univ. Surrey. Available online: https://www.surrey.ac.uk/institute-communication-systems/5g-innovation-centre/strategy-advisoryboard (accessed on 15 February 2021).

267. She, C.; Liu, C.; Quek, T.Q.S.; Yang, C.; Li, Y. Ultra-reliable and low-latency communications in unmanned aerial vehicle communication systems. IEEE Trans. Commun. 2019, 67, 3768-3781. [CrossRef]

268. Ding, A.Y.; Janssen, M. 5G applications: Requirements, challenges, and outlook. arXiv 2018. [CrossRef]

269. Varga, P.; Peto, J.; Franko, A.; Balla, D.; Haja, D.; Janky, F.; Soos, G.; Ficzere, D.; Maliosz, M.; Toka, L. 5G Support for Industrial Iot Applications-Challenges, Solutions, and Research Gaps. Sensors 2020, 20, 828. [CrossRef]

270. United States Government Accountability Office. 5G Wireless Capabilities and Challenges for an Evolving Network. Report to Congressional Requesters, GAO-21-26SP. November 2020. Available online: https://www.gao.gov/assets/720/710861.pdf (accessed on 15 February 2021).

271. Guevara, L.; Cheein, F.A. The role of 5G technologies: Challenges in smart cities and intelligent transportation systems. Sustainbility 2020, 12, 6469. [CrossRef]

272. Neumeier, S.; Walelgne, E.A.; Bajpai, V.; Ott, J.; Facchi, C. Measuring the feasibility of teleoperated driving in mobile networks. In Proceedings of the 2019 Network Traffic Measurement and Analysis Conference (TMA), Paris, France, 19-21 June 2019; pp. 113-120.

273. Voigtlander, F.; Ramadan, A.; Eichinger, J.; Grotepass, J.; Ganesan, K.; Canseco, F.D.; Pensky, D.; Knoll, A. 5G for the factory of the future: Wireless communication in an industrial environment. arXiv 2019, arXiv:1904.01476.

274. Jawad, H.M.; Nordin, R.; Gharghan, S.K.; Jawad, A.M.; Ismail, M. Energy-efficient wireless sensor networks for precision agriculture: A review. Sensors 2017, 17, 1781. [CrossRef]

275. Sahota, H.; Kumar, R.; Kamal, A.; Huang, J. An energy-efficient wireless sensor network for precision agriculture. Proc. IEEE Symp. Comput. Commun. 2010,347-350. [CrossRef]

276. Wen, Q.; Chen, Q. The application of internet of things in agricultural means of production supply chain management. WIT Trans. Inf. Commun. Technol. 2014, 61, 617-624.

277. Vasisht, D.; Chandra, R.; Kapoor, A.; Sinha, S.N.; Sudarshan, M.; Stratman, S.; Kapetanovic, Z.; Won, J.; Jin, X. FarmBeats: An IoT Platform for Data-Driven Agriculture FarmBeats: An IoT Platform for Data-Driven Agriculture. In Proceedings of the 14th USENIX Conference on Networked Systems Design and Implementation, Boston, MA, USA, 27-29 March 2017 ; pp. 515-528.

278. Kamilaris, A.; Gao, F.; Prenafeta-Boldu, F.X.; Ali, M.I. Agri-IoT: A semantic framework for Internet of Things-enabled smart farming applications. In Proceedings of the 2016 IEEE 3rd World Forum Internet Things, WF-IoT 2016, Reston, VA, USA, 12-14 December 2016; pp. 442-447.

279. Gupta, M.; Abdelsalam, M.; Khorsandroo, S.; Mittal, S. Security and Privacy in Smart Farming: Challenges and Opportunities. IEEE Access 2020, 8, 34564-34584. [CrossRef]

280. Tzima, S.; Styliaras, G.; Bassounas, A. Augmented reality applications in education: Teachers point of view. Educ. Sci. 2019, 9, 99. [CrossRef]

281. Gallagher, R.; Schoolar, D.; de Renesse, R.; Barton, E. How 5G Will Transform the Business of Media \& Entertainment. 2018. Available online: https:/ / networking.report/whitePapers/how-5g-will-transform-the-business-of-media-and-entertainment/ 6635 (accessed on 15 February 2021).

282. VR Therapy: How Rescape Innovation Is Providing Emotional Support for Covid-19 Frontline Workers. Available online: https: / / www.qualcomm.com/news/onq/2020/08/17/vr-therapy-how-rescape-innovation-providing-emotional-supportcovid-19-frontline? cmpid=oofyus20147\&linkId=97386195 (accessed on 10 November 2020).

283. Cha, S.; Ruiz, M.P.; Wachowicz, M.; Tran, L.H.; Cao, H.; Maduako, I. The role of an IoT platform in the design of real-time recommender systems. In Proceedings of the 2016 IEEE 3rd World Forum on Internet of Things, WF-IoT 2016, Reston, VA, USA, 12-14 December 2016; pp. 448-453.

284. Wang, N. Research on construction of smart tourism perception system and management platform. Appl. Mech. Mater. 2014, 687, 1745-1748. [CrossRef]

285. Guo, Y. The embedding convergence of smart cities and tourism internet of things in China: An advance perspective. Adv. Hosp. Tour. Res. 2014, 2, 54-69.

286. Car, T.; Pilepić Stifanich, L.; Šimunić, M. Internet of Things (IoT) in Tourism and Hospitality: Opportunities and Challenges. In Proceedings of the ToSEE_-Tourism in Southern and Eastern Europe, Opatija, Croatia, 16-18 May 2019; pp. 163-173. 
287. Mulder, N. The impact of the COVID-19 Pandemic on the Tourism Sector in Latin America and the Caribbean, and Options for a Sustainable and Resilient Recovery. 2020, pp. 1-49. Available online: https:/ /www.cepal.org/en/publications/46502-impactcovid-19-pandemic-tourism-sector-latin-america-and-caribbean-and-options (accessed on 12 November 2020).

288. Rogers, S. How Virtual Reality Could Help The Travel \& Tourism Industry in The Aftermath Of The Coronavirus Outbreak. Forbes. 2020, pp. 14-21. Available online: https:/ /www.forbes.com/sites/solrogers/2020/03/18/virtual-reality-and-tourismwhats-already-happening-is-it-the-future/\#329fa05828a6 (accessed on 20 December 2020).

289. Yung, R.; Khoo-Lattimore, C. New realities: A systematic literature review on virtual reality and augmented reality in tourism research Author. Curr. Issues Tour. 2019, 22, 2056-2081. [CrossRef]

290. Demetrescu, E.; D'Annibale, E.; Ferdani, D.; Fanini, B. Digital replica of cultural landscapes: An experimental reality-based workflow to create realistic, interactive open world experiences. J. Cult. Herit. 2020, 41, 125-141. [CrossRef]

291. Tripathy, A.K.; Tripathy, P.K.; Ray, N.K.; Mohanty, S.P. ITour: The Future of Smart Tourism: An IoT Framework for the Independent Mobility of Tourists in Smart Cities. IEEE Consum. Electron. Mag. 2018, 7, 32-37. [CrossRef]

292. Korczak, J.; Kijewska, K. Smart Logistics in the development of Smart Cities. Transp. Res. Procedia 2019, 39, 201-211. [CrossRef]

293. Singh, P.M.; Van Sinderen, M.J.; Wieringa, R.J. Smart logistics: An enterprise architecture perspective. In Proceedings of the CEUR Workshop Proceedings, Como, Italy, 28 August 2017; Volume 1848, pp. 9-16.

294. Witkowski, K. Internet of Things, Big Data, Industry 4.0-Innovative Solutions in Logistics and Supply Chains Management. Procedia Eng. 2017, 182, 763-769. [CrossRef]

295. Xu, T.; Gong, L.; Zhang, W.; Li, X.; Wang, X.; Pan, W. Application of wireless sensor network technology in logistics information system. In Proceedings of the AIP Conference, Busan, Korea, 22-23 April 2017.

296. Becker, M.; Wenning, B.L.; Görg, C.; Jedermann, R.; Timm-Giel, A. Logistic applications with wireless sensor networks. In Proceedings of the 6th Workshop on Hot Topics in Embedded Networked Sensors, HotEmNets 2010, Killarney, Ireland, 28-29 June 2010.

297. Gao, X.; Dai, L.; Han, S.; Chih-Lin, I.; Heath, R.W. Energy-Efficient Hybrid Analog and Digital Precoding for MmWave MIMO Systems with Large Antenna Arrays. IEEE J. Sel. Areas Commun. 2016, 34, 998-1009. [CrossRef]

298. Commission, F.C.; Wheeler, T. The Dangers Of 5G-11 Reasons To Be Concerned. 2018. Available online: https://www. electricsense.com/5g-radiation-dangers/ (accessed on 15 February 2021).

299. Karaboytcheva, M. Effects of $5 \mathrm{G}$ wireless communication on human health. Brief. Eur. Parliam. 2020, 646, 172.

300. Simkó, M.; Mattsson, M.O. 5G wireless communication and health effects-A pragmatic review based on available studies regarding 6 to 100 GHz. Int. J. Environ. Res. Public Health 2019, 16, 3406. [CrossRef] [PubMed]

301. International Commission on Non-Ionizing Radiation Protection (ICNIRP). Principles for Non-Ionizing Radiation Protection. Health Phys. 2020, 118, 477-482. [CrossRef] [PubMed]

302. Katz, M.; Matinmikko-Blue, M.; Latva-Aho, M. 6Genesis Flagship Program: Building the Bridges Towards 6G-Enabled Wireless Smart Society and Ecosystem. In Proceedings of the 2018 10th IEEE Latin-American Conference on Communications, LATINCOM 2018, Guadalajara, Mexico, 14-16 November 2018; pp. 1-6.

303. Bhat, J.R.; AlQahtani, S.A. 6G Ecosystem: Current Status and Future Perspective. IEEE Access 2021. [CrossRef]

304. Yrjola, S.; Ahokangas, P.; Matinmikko-Blue, M. Novel Context and Platform Driven Business Models via 5G Networks. In Proceedings of the 2018 IEEE 29th Annual International Symposium on Personal, Indoor and Mobile Radio Communications (PIMRC), Bologna, Italy, 9-12 September 2018.

305. Ahokangas, P.; Matinmikko-Blue, M.; Yrjola, S.; Seppanen, V.; Hammainen, H.; Jurva, R.; Latva-aho, M. Business Models for Local 5G Micro Operators. IEEE Trans. Cogn. Commun. Netw. 2019, 5, 730-740. [CrossRef]

306. Cruz, C.O.; Sarmento, J.M. “Mobility as a service” platforms: A critical path towards increasing the sustainability of transportation systems. Sustainability 2020, 12, 6368. [CrossRef]

307. Yrjölä, S.; Ahokangas, P.; Matinmikko-Blue, M. Sustainability as a challenge and driver for novel ecosystemic 6G business scenarios. Sustainability 2020, 12, 8951. [CrossRef]

308. Kuhlman, T.; Farrington, J. What is sustainability? Sustainability 2010, 2, 3436-3448. [CrossRef]

309. Schaltegger, S.; Hansen, E.G.; Lüdeke-Freund, F. Business Models for Sustainability: Origins, Present Research, and Future Avenues. Organ. Environ. 2016, 29, 3-10. [CrossRef]

310. Evans, S.; Vladimirova, D.; Holgado, M.; Van Fossen, K.; Yang, M.; Silva, E.A.; Barlow, C.Y. Business Model Innovation for Sustainability: Towards a Unified Perspective for Creation of Sustainable Business Models. Bus. Strateg. Environ. 2017, 26, 597-608. [CrossRef]

311. Ziegler, V.; Yrjola, S. 6G indicators of value and performance. In Proceedings of the 2nd 6G Wirel. Summit 2020 Gain Edge 6G Era, 6G SUMMIT 2020, Levi, Lapland, 17-20 March 2020; pp. 1-5.

312. Yrjölä, S. Decentralized 6G Business Models. In Proceedings of the 6G Wirel. Summit, Levi, Finland, April 2019; pp. 5-7.

313. Hayes, B.J. 6G and the reinvention of mobile. Eng. Technol. Netw. Commun. 2020, 15, 26-29.

314. Independent. Driverless Buses and Taxis to Be Launched in Britain by 2021. 2018. Available online: https://www.independent. co.uk/travel/news-and-advice/self-driving-buses-driverless-cars-edinburgh-fife-forth-bridge-london-greenwich-a8647926 .html (accessed on 11 November 2020).

315. Alafia, A.; Ajose, S.; Imoize, A. A study on low-complexity transmit antenna selection for generalized spatial modulation. IIUM Eng. J. 2018, 19, 105-117. [CrossRef] 
316. Mao, T.; Wang, Q.; Wang, Z. Spatial Modulation for Terahertz Communication Systems with Hardware Impairments. IEEE Trans. Veh. Technol. 2020, 69, 4553-4557. [CrossRef]

317. Khan, I.; Rodrigues, J.J.P.C.; Al-Muhtadi, J.; Khattak, M.I.; Khan, Y.; Altaf, F.; Mirjavadi, S.S.; Choi, B.J. A Robust Channel Estimation Scheme for 5 G Massive MIMO Systems. Wirel. Commun. Mob. Comput. 2019, 2019. [CrossRef]

318. Saraereh, O.A.; Khan, I.; Alsafasfeh, Q.; Alemaishat, S.; Kim, S. Low-complexity channel estimation in 5G massive MIMO-OFDM systems. Symmetry 2019, 11, 713. [CrossRef]

319. Khan, I.; Singh, D. Efficient compressive sensing based sparse channel estimation for $5 \mathrm{G}$ massive MIMO systems. AEU Int. J. Electron. Commun. 2018, 89, 181-190. [CrossRef]

320. Moon, S.; Kim, H.; Hwang, I. Deep learning-based channel estimation and tracking for millimeter-wave vehicular communications. J. Commun. Netw. 2020, 22, 177-184. [CrossRef]

321. Bi, D.; Almpanis, A.; Noel, A.; Deng, Y.; Schober, R. A survey of molecular communication in cell biology: Establishing a new hierarchy for interdisciplinary applications. arXiv 2020, arXiv:2009.00090.

322. Spagnolo, G.S.; Cozzella, L.; Leccese, F. Underwater optical wireless communications: Overview. Sensors 2020, 20, 2261. [CrossRef]

323. Alcaraz López, O.L.; Alves, H.; Souza, R.D.; Montejo-Sánchez, S.; García Fernández, E.M.; Latva-aho, M. Massive wireless energy transfer: Enabling sustainable IoT towards 6G era. arXiv 2019, arXiv:1912.05322.

324. Malmodin, J.; Lundén, D. The electricity consumption and operational carbon emissions of ICT network operators $2010-2015$. Sustain. Commun. 2018, 1, 1-13.

325. Bhandari, S.; Joshi, S. Cognitive radio technology in 5G wireless communications. In Proceedings of the 2018 2nd IEEE International Conference on Power Electronics, Intelligent Control and Energy Systems, ICPEICES 2018, Delhi, India, 22-24 October 2018; pp. 1115-1120.

326. Zhang, H.; Chu, X.; Guo, W.; Wang, S. Coexistence of Wi-Fi and heterogeneous small cell networks sharing unlicensed spectrum. IEEE Commun. Mag. 2015, 53, 158-164. [CrossRef]

327. Weiss, M.B.H.; Werbach, K.; Sicker, D.C.; Bastidas, C.E.C. On the application of blockchains to spectrum management. IEEE Trans. Cogn. Commun. Netw. 2019, 5, 193-205. [CrossRef]

328. Slamnik-Kriještorac, N.; Kremo, H.; Ruffini, M.; Marquez-Barja, J.M. Sharing Distributed and Heterogeneous Resources toward End-to-End 5G Networks: A Comprehensive Survey and a Taxonomy. IEEE Commun. Surv. Tutor. 2020, 22, 1592-1628. [CrossRef]

329. Shamim, M.S.; Mansoor, N.; Samaiyar, A.; Ganguly, A.; Deb, S.; Sunndar Ram, S. Energy-efficient wireless network-on-chip architecture with log-periodic on-chip antennas. In Proceedings of the ACM Great Lakes Symposium on VLSI, GLSVLSI, Houston, TX, USA, 21-23 May 2014; pp. 85-86.

330. Nakamura, T. 5G Evolution and 6G. In Proceedings of the 2020 IEEE Symposium on VLSI Technology, Honolulu, HI, USA, 16-19 June 2020; p. 1. [CrossRef]

331. Ndikumana, A.; Tran, N.H.; Ho, T.M.; Han, Z.; Saad, W.; Niyato, D.; Hong, C.S. Joint Communication, Computation, Caching, and Control in Big Data Multi-Access Edge Computing. IEEE Trans. Mob. Comput. 2020, 19, 1359-1374. [CrossRef] 